\title{
BIODIVERSIDADE DE MOSCAS-DAS-FRUTAS DO GÊNERO ANASTREPHA (DIPTERA, TEPHRITIDAE) NO CAMPUS LUIZ DE QUEIROZ, PIRACICABA, SÃo PAUlo
}

\section{KEIKO URAMOTO}

\author{
Dissertação apresentada à Escola Superior de \\ Agricultura "Luiz de Queiroz", Universidade de São \\ Paulo, para obtenção do título de Mestre em Ciências, \\ Área de Concentração: Entomologia.
}

PIR ACIC AB A

Estado de São Paulo - Brasil

Maio - 2002 


\title{
BIODIVERSIDADE DE MOSCAS-DAS-FRUTAS DO GÊNERO ANASTREPHA (DIP., TEPHRITIDAE) NO CAMPUS LUIZ DE QUEIROZ, PIRACICABA, SÃO PAULO
}

\author{
KEIKO URAMOTO \\ Bióloga
}

Orientador: Prof. Dr. ROBERTO ANTONIO ZUCCHI

\author{
Dissertação apresentada à Escola Superior de \\ Agricultura "Luiz de Queiroz", Universidade de São \\ Paulo, para obtenção do título de Mestre em Ciências, \\ Área de Concentração: Entomologia.
}

PIR A CICAB A

Estado de São Paulo - Brasil

Maio - 2002 


\section{Dados Internacionais de Catalogação na Publicação (CIP) DIVISÃO DE BIBLIOTECA E DOCUMENTAÇÃO - ESALQ/USP}

\section{Uramoto, Keiko}

Biodiversidade de moscas-das-frutas do gênero Anastrepha (Dip., Tephritidae) no Campus Luiz de Queiroz, Piracicaba, São Paulo / Keiko Uramoto. - - Piracicaba, 2002.

$85 \mathrm{p}$.

Dissertação (mestrado) - - Escola Superior de Agricultura Luiz de Queiroz, 2002. Bibliografia.

1. Análise quantitativa 2. Biodiversidade 3. Flutuação populacional 4. Mosca-dasfrutas 5. Planta hospedeira I. Título

CDD 632.774

\section{"Permitida a cópia total ou parcial deste documento, desde que citada a fonte - $\mathrm{O}$ autor"}


À minha família,

Agradeço e ofereço.

A minha mãe, Shizue, que é um símbolo de perseverança e de luta e ao meu pai, Yoshito (in memorian), que me ensinou o caminho da honestidade e responsabilidade,

Dedico.

"Pouca ciência torna os homens orgulhosos; muita ciência torna-os humildes. Assim, as espigas vazias elevam a cabeça soberba, enquanto as cheias inclinam-se humildemente para a terra."

Anônimo 


\section{AGRADECIMENTOS}

Ao Prof. Dr. Roberto Antonio Zucchi pela amizade, confiança e pela orientação, não apenas neste trabalho, mas também ao longo do meu aprendizado em identificação de moscas-das-frutas.

Ao Prof. Dr. Julio Marcos Melges Walder, responsável pelo projeto de controle de populações de moscas-das-frutas no campus Luiz de Queiroz, por permitir a utilização do material coletado na área.

Ao Prof. Dr. Aldo Malavasi pela amizade, pelo incentivo constante e apoio logístico durante a execução deste trabalho no laboratório de Moscas-das-Frutas, IBUSP, e pela revisão da dissertação.

Ao Instituto de Biociências, Universidade de São Paulo, (IBUSP) por me conceder a oportunidade de realizar o curso de pós-graduação.

A Dra. Regina Lúcia Sugayama pela amizade sincera, sugestões na análise dos dados e editoração da dissertação. Fico devendo os famosos "pinguinos".

Ao Prof. Dr. Edison José de Paula pela revisão criteriosa deste trabalho e por me mostrar a via de Chuang Tsu.

Ao Prof. Dr. José Rubens Pirani pela identificação do material botânico. 
A Dra. Janisete Gomes Silva pela amizade, revisão minuciosa da dissertação e tradução do resumo.

Ao Luís Anselmo Lopes pelo envio do material biológico e dos dados coletados durante o trabalho de campo.

A Profa. Dra. Denise Selivon Sheepmaker por permitir o uso do CCD.

Ao Marcio Valentim Cruz pela elaboração das fotografias dos acúleos no microscópio eletrônico de varredura.

Ao Miguel Francisco de Souza Filho pelo envio das inúmeras cópias de artigos de referências.

Aos amigos e colegas do Departamento de Entomologia da Esalq pela convivência agradável durante o período em que freqüentei as disciplinas do curso, em especial, a Geni, Elizabeth e Ranyse pelo inestimável auxílio em resolver meus problemas em Piracicaba.

Aos amigos e colegas do laboratório de Moscas-das-Frutas do IBUSP pela colaboração durante a execução deste trabalho. 


\section{SUMÁRIO}

Página

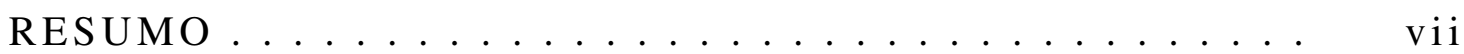

SUMMARY ......................

1 INTRODUÇÃO . . . . . . . . . . . . . . . . . 1

2 REVISÃO DE LITERATURA . . . . . . . . . . . 3

2.1 Moscas-das-frutas .................. 3

2.2 Análise faunística. . . . . . . . . . . . . . 8

2.3 Flutuação populacional de moscas-das-frutas ....... 10

2.4 Plantas hospedeiras . . . . . . . . . . . . . . . 13

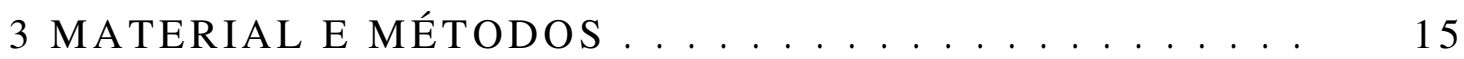

3.1 Área experimental: localização e caracterização . . . . 15

3.2 Levantamento com armadilhas e diretamente dos frutos 16

3.3 Ilustrações . . . . . . . . . . . . . . . 22

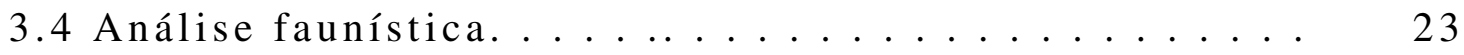

3.5 Flutuação populacional. . . . . . . . . . . 25

4 RESULTADOS E DISCUSSÃO. . . . . . . . . . . 26

4.1 Levantamento das espécies de Anastrepha e chave de

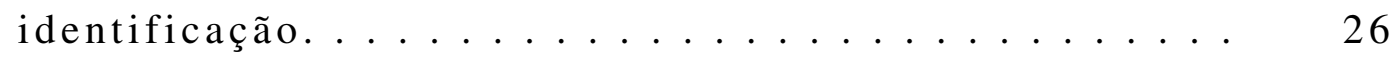

4.2 Análise quantitativa e distribuição da população de Anastrepha no campus............... 36

4.3 Flutuação das espécies mais abundantes. . . . . . . . 47

4.4 Coleta e relações com plantas hospedeiras. . . . . . . 56

5 CONCLUSÕES . . . . . . . . . . . . . . . . 63

REFERÊNCIAS BIBLIOGRÁFICAS ............ 65 


\section{BIODIVERSIDADE DE MOSCAS-DAS-FRUTAS DO GÊNERO ANASTREPHA (DIP., TEPHRITIDAE) NO CAMPUS LUIZ DE QUEIROZ, PIRACICABA, SÃo PAUlo}

Autora: KEIKO URAMOTO

Orientador: Prof. Dr. ROBERTO ANTONIO ZUCCHI

\section{RESUMO}

Este trabalho foi conduzido na área abrangida pelo campus Luiz de Queiroz/Universidade de São Paulo, no município de Piracicaba, Estado de São Paulo. Teve como objetivos, determinar a composição do gênero Anastrepha Schiner, sua distribuição e a análise quantitativa da população. Além disso, verificou-se a relação da flutuação populacional com variáveis bióticas e abióticas e a associação das espécies de plantas hospedeiras, estabelecidas na área, com as espécies de Anastrepha. Foram examinadas 23.263 fêmeas de Anastrepha coletadas em armadilhas McPhail e 18 espécies pertencentes a 9 grupos infragenéricos foram assinaladas. A distribuição das fêmeas por armadilha foi fortemente agregada, com 5 armadilhas (6\%) capturando 50\% do total de fêmeas. Apenas A. fraterculus (Wiedemann) e A. obliqua (Macquart) foram dominantes. A. fraterculus foi a espécie mais freqüente, representando $80,2 \%$ do total de fêmeas capturadas no campus e a mais constante ocorrendo em $98,04 \%$ das amostras. Em ordem decrescente de freqüência, seguiram-se A. obliqua $(12,6 \%), A$. pseudoparallela (Loew) (3,1\%) e A. bistrigata Bezzi (2,1\%). As demais 
espécies apresentaram frequiência menor que $1 \%$. O valor elevado do índice de Simpson $(0,66)$ e os valores baixos do índice de Shannon $(0,7521)$ e de equiitatividade $(0,459)$ resultaram da alta frequiência de $A$. fraterculus. Um aumento no nível populacional das espécies de Anastrepha ocorreu de agosto a novembro com um pico máximo em setembro. A disponibilidade de frutos hospedeiros foi mais determinante na variação do tamanho da população das espécies mais abundantes de Anastrepha que as variáveis climáticas.

Um total de 565 amostras de frutos pertencentes a 11 famílias e, pelo menos, 25 espécies botânicas foi coletado em 47 estações de capturas. Foram identificadas 10.290 fêmeas e das 18 espécies de Anastrepha capturadas em armadilhas somente 6 emergiram das amostras de frutos: A. bistrigata Bezzi, A. fraterculus (Wiedemann), A. obliqua (Macquart), A. pseudoparallela (Loew), A. serpentina (Wiedemann) e A. sororcula Zucchi. A. fraterculus foi a espécie que infestou maior diversidade de frutos. Os hospedeiros preferidos de A. obliqua foram as espécies da família Anacardiaceae. A. pseudoparallela e A. serpentina infestaram exclusivamente Passifloraceae e Sapotaceae, respectivamente. Uma nova associação de mosca-das-frutas com planta hospedeira foi constatada: A. fraterculus em Syagrus romanzoffiana (Cham.) Glassman (coquinho). Foi reportado o primeiro registro da associação de A. fraterculus em Manilkara zapota L. (sapoti) no Brasil. 


\title{
BIODIVERSITY OF ANASTREPHA FRUIT FLIES (DIP., TEPHRITIDAE) ON THE LUIZ DE QUEIROZ CAMPUS, PIRACICABA, SÃO PAULO
}

\author{
Author: KEIKO URAMOTO \\ Adviser: Prof. Dr. ROBERTO ANTONIO ZUCCHI
}

\section{SUMMARY}

This study was conducted in the Luiz de Queiroz campus of the Universidade de São Paulo, in Piracicaba, state of São Paulo. The aim of this study was to determine the number of species in the genus Anastrepha Schiner on campus, their distribution and the quantitative analysis of the population. Moreover, this study correlated populational fluctuations with biotic and abiotic factors as well as the association between host plant species and the Anastrepha species in that area. A total of 23,263 females of Anastrepha collected in MacPhail traps was examined, and 18 species belonging to nine infrageneric groups were registered. The distribution of females per trap was strongly clustered, with 5 traps $(6 \%)$ capturing $50 \%$ of the total of females. Only A. fraterculus (Wiedemann) and A. obliqua (Macquart) were considered dominant species. A. fraterculus was by far the most frequent species, representing $80.2 \%$ of the total of females captured on campus, and the most constant, occurring in $98.04 \%$ of the analyzed samples. In decreasing order of frequency, A. obliqua (12.6\%), A. pseudoparallela (Loew) (3.1\%), and A. bistrigata Bezzi (2.1\%) comprised the other major species. The remaining species showed frequency lower than $1 \%$. The high value of the Simpson's index (0.66) as wel 
as the low values of Shannon's index (0.7521) and the equitability index (0.459) resulted from the high frequency of $A$. fraterculus. The populational level of Anastrepha increased from August to November with the highest peak in September. The availability of host fruit, more than climatic parameters determined most of the variation of population size in the most abundant species of Anastrepha.

A total of 565 fruit samples representing at least 25 plant species from 11 families was collected in 47 capture sites. 10,290 females were identified. Of the 18 Anastrepha species captured in traps, only 6 also emerged from fruit samples: $A$. bistrigata Bezzi, A. fraterculus (Wiedemann), A. obliqua (Macquart), A. pseudoparallela (Loew), A. serpentina (Wiedemann) e A. sororcula Zucchi. A. fraterculus infested the greatest diversity of hosts. The preferred hosts of A. obliqua were plant species in the family Anacardiaceae. A. pseudoparallela and A. serpentina infested only species in the families Passifloraceae and Sapotaceae, respectively. A new fruit fly and host plant association was registered: A. fraterculus with Syagrus romanzoffiana (Cham.) Glassman (queen palm). The association of A. fraterculus with Manilkara zapota L. (sapodilla) was reported here for the first time in Brazil. 


\section{INTRODUÇÃO}

O Brasil é o terceiro maior produtor de frutas frescas do mundo, produzindo aproximadamente 35 milhões de toneladas anuais, gerando 4 milhões de empregos diretos e um PIB (Produto Interno Bruto) agrícola de US\$11 bilhões, segundo o Instituto Brasileiro de Frutas (Ibraf) (2001a). Embora o volume de exportações de frutas tenha aumentado nos últimos anos, em 2000 o país exportou menos de 430 mil toneladas (cerca de 1\%), o equivalente a US\$169,8 milhões (Ibraf, 2001b). Uma das principais causas para esta baixa taxa de exportação é a presença de pragas nas áreas cultivadas, entre elas as moscas-das-frutas.

As moscas-das-frutas são sérias pragas da fruticultura mundial, acarretando perdas significativas à produção e limitando o livre trânsito de frutas frescas devido às restrições impostas pelas medidas quarentenárias dos países importadores (Malavasi, 2000). Os danos diretos decorrem do fato das fêmeas realizarem a postura dos ovos no epi ou mesocarpo do fruto em amadurecimento e as larvas alimentarem-se da polpa. Os prejuízos à exportação decorrem da presença de determinadas espécies na área de cultivo. Segundo a FAO (Organização das Nações Unidas para a Alimentação e a Agricultura), estes insetos causam prejuízo de US $\$ 1,7$ bilhão por ano no mundo, dos quais $10 \%$ no Brasil (Ibraf, 2001a).

A maioria das espécies de tefritídeos consideradas pragas da fruticultura pertence aos gêneros Anastrepha Schiner, Bactrocera Macquart, Ceratitis Macleay, Dacus Fabricius e Rhagoletis Loew. Apenas algumas espécies dos gêneros Carpomya Costa, Euphranta Loew, Monacrostichus Bezzi, Neoceratitis Hendel, Toxotrypana Gerstaecker e Zonosemata Benjamin são consideradas pragas de frutos (Norrbom et al., 1998). 
As espécies de moscas-das-frutas de importância econômica no Brasil pertencem a quatro gêneros: Anastrepha, Bactrocera, Ceratitis e Rhagoletis. Atualmente, no Brasil estão registradas 95 espécies do gênero Anastrepha e 4 do gênero Rhagoletis (Zucchi, 2000a; Ronchi-Teles, 2000). Os gêneros Bactrocera e Ceratitis estão representados por B. carambolae Drew \& Hancock e C. capitata (Wiedemann). Entretanto, apenas $C$. capitata e sete espécies de Anastrepha são economicamente importantes no Brasil, uma vez que $B$. carambolae está restrita ao Oiapoque, AP, na fronteira com a Guiana Francesa, onde estão sendo realizados programas de erradicação. As espécies de Rhagoletis são consideradas pragas esporadicamente apenas no sul do Brasil (Zucchi, 2000a).

Um projeto institucional, financiado pelo convênio entre o Ministério da Agricultura e o CENA (Centro de Energia Nuclear na Agricultura) e pelo Research Contract da FAO/IAEA (Food and Agriculture Organization of the United Nations / International Atomic Energy Agency), encontra-se atualmente em andamento. O objetivo é controlar ou suprimir as populações de moscas-das-frutas da área abrangida pelo campus Luiz de Queiroz/Universidade de São Paulo, no município de Piracicaba, Estado de São Paulo, utilizando a técnica do inseto estéril e liberação inundativa de parasitóides. Estas técnicas oferecem potencial quase ilimitado para o manejo populacional das moscas-das-frutas de modo seguro para o ambiente e a um custo relativamente baixo (Walder, 2000).

O conhecimento prévio das espécies e seus hospedeiros na área é fundamental para o estabelecimento de um programa de controle de moscas-das-frutas.

Este estudo teve por objetivo fornecer subsídios para o programa de controle de moscas-das-frutas na área que abrange o campus Luiz de Queiroz/Universidade de São Paulo. Assim, foram estudados: a composição específica do gênero Anastrepha; a distribuição e a análise quantitativa das populações das espécies de Anastrepha no campus; as flutuações populacionais das espécies mais freqüentes e as variáveis que poderiam influir no tamanho destas populações; a associação entre as espécies de plantas hospedeiras estabelecidas na área e as espécies de Anastrepha. 


\section{REVISÃO DE LITERATURA}

\subsection{Moscas-das-frutas}

As moscas-das-frutas pertencem à ordem Diptera, subordem Brachycera, infraordem Muscomorpha, seção Schizophora, superfamília Tephritoidea, família Tephritidae (McAlpine, 1989).

A família Tephritidae, com 481 gêneros e 4.352 espécies, apresenta grande

diversidade taxonômica e distribui-se em todas as regiões temperada e tropical do mundo (Thompson, 1998; Norrbom, 2001a). Os gêneros representados por espécies economicamente importantes são classificados na subfamília Trypetinae, tribo Toxotrypanini (Anastrepha e Toxotrypana) e tribo Carpomyini (Rhagoletis), na subfamília Dacinae, tribos Ceratitidini (Ceratitis) e Dacini (Bactrocera e Dacus) (Norrbom, 2001b).

O gênero Ceratitis é constituído por 70 espécies, cuja distribuição está restrita ao continente africano, com exceção de $C$. capitata, a mosca-do-mediterrâneo (Norrbom, 1998). O provável centro de origem desta espécie é a África Equatorial, mas um processo global de invasão tem ocorrido ao longo deste século (Silva, 2000). No Brasil, esta espécie foi detectada no início do século (Ihering, 1901), sendo considerada uma das pragas de maior importância quarentenária, infestando preferencialmente espécies de frutos introduzidos (Malavasi \& Morgante, 1980). Até a década de 80, C. capitata estava aparentemente restrita às regiões Sul e Sudeste do Brasil, sendo o Estado da Bahia o seu limite de distribuição ao norte (Malavasi et al., 1980; Nascimento \& Zucchi, 1981). No entanto, recentemente sua ocorrência foi registrada no Rio Grande do Norte (Costa et al., 1993), Rondônia (Ronchi-Teles \& Silva 1996), Maranhão (Ronchi-Teles et al., 1997), 
Pará (Silva et al., 1998), Ceará (Sales \& Gonçalves, 2000) e Pernambuco (Haji \& Miranda, 2000), ampliando sua área de distribuição por quase todos os Estados das regiões Norte e Nordeste. Além desta espécie, há um registro de C. malgassa Munro no continente americano em Chapingo, México, entretanto, atualmente não tem sido detectada no Novo Mundo (Zucchi, 2001).

Até recentemente, Bactrocera era considerado subgênero de Dacus. Drew (1989) propôs uma nova combinação, elevando Bactrocera à categoria de gênero, que passou a reunir as espécies mais importantes economicamente do antigo gênero Dacus. O gênero Bactrocera está distribuído principalmente na Ásia tropical, Austrália e ilhas do Pacífico, com ocorrência secundária na Ásia temperada, África tropical, sul da Europa e norte da América do Sul. As espécies deste gênero são altamente invasoras, principalmente B. dorsalis (Malavasi et al., 2000). B. carambolae, a mosca-dacarambola, foi introduzida no Suriname provavelmente por turistas e comerciantes da Indonésia (Sauers-Muller, 1991). É a única espécie do gênero introduzida na América do Sul e no Brasil foi detectada recentemente no Amapá (Zucchi, 2000a).

O gênero Rhagoletis compreende 62 espécies, distribuídas no Novo Mundo, Europa e áreas temperadas da Ásia (Norrbom et al., 1998), das quais apenas 4 ocorrem no Brasil, $R$. adusta Foote, $R$. blanchardi Aczél, $R$. ferruginea Hendel e $R$. macquarti (Loew) e, de modo geral não são consideradas pragas de importância econômica (Zucchi, 2000a).

O gênero Anastrepha foi proposto por Schiner em 1868, que designou Dacus serpentinus Wiedemann como espécie-tipo. Os gêneros Acrotoxa Loew, 1873 e Leptoxys Macquart, 1843 foram considerados sinônimos de Anastrepha por Bezzi (1909). Stone (1939) propôs o gênero Lucumaphila para agrupar as espécies com acúleo de no máximo $0,05 \mathrm{~mm}$ de largura e elevou o subgênero Pseudodacus à categoria de gênero. Posteriormente, aqueles gêneros (Lucumaphila Stone, 1939 e Pseudodacus Hendel, 1914) e Phobema Aldrich, 1925 foram considerados sinonímias de Anastrepha por Steyskal (1977).

Norrbom et al. (1999) revisaram os estudos sobre análises filogenética e imunológica, que indicam que os gêneros Anastrepha e Toxotrypana formam um grupo 
monofilético. Assim, foram reunidos, juntamente com o gênero Hexachaeta, na tribo Toxotrypanini.

Atualmente, Anastrepha inclui 197 espécies válidas e, com base principalmente em estudos de morfologia dos adultos, são separadas em 17 grupos infragenéricos. Entretanto, várias espécies não se enquadram em nenhum dos 17 grupos (Norrbom et al., 1999). As 95 espécies assinaladas no Brasil são distribuídas em, pelo menos, 13 grupos. O grupo fraterculus ocorre em todos os estados brasileiros amostrados. Subseqüentemente, os grupos serpentina e pseudoparallela são os mais constantes nas diferentes regiões do Brasil, enquanto o grupo punctata restringe-se apenas aos Estados de Mato Grosso do Sul, São Paulo e Rio Grande do Sul. Os Estados de São Paulo e da Bahia são os que apresentam maior diversidade de espécies, onde ocorrem 13 e 12 grupos, respectivamente, seguidos por Amazonas, Mato Grosso do Sul e Minas Gerais com 11 grupos em cada Estado.

Algumas espécies de ampla distribuição como A. fraterculus e A. hamata formam complexos de espécies crípticas (Norrbom, 1985; Steck, 1991, 1998; Morgante et al., 1980). Selivon (1996) estudou populações de A. fraterculus de várias regiões do Brasil e caracterizou duas espécies crípticas do complexo fraterculus.

As espécies deste gênero são originárias do continente americano e nenhuma espécie é considerada invasora, uma vez que estão estabelecidas dentro de sua provável área de origem (Malavasi et al., 2000). A maioria das espécies de Anastrepha distribuise pela Região Neotropical e algumas espécies ocorrem no sul da região Neártica. $\mathrm{O}$ gênero está estabelecido no sul dos EUA, no México, na América Central e em toda a América do Sul, exceto no Chile, onde ocorre esporadicamente ao norte do deserto de Atacama na fronteira com o Peru (Malavasi et al., 2000). No Brasil, o gênero Anastrepha foi observado em todos os Estados, embora não haja registros publicados para alguns deles (Malavasi et al., 2000).

Há uma extensa literatura sobre levantamentos das espécies de Anastrepha, os quais contribuíram para os estudos de diversidade e distribuição geográfica: México (Aluja et al., 1987; Malo et al., 1987; Hernandez-Ortiz, 1992), Costa Rica (Jiron et al., 1988; Gónzalez et al., 1988), Guatemala (Eskafi \& Cunnigham, 1987), Belize 
(O'Doherty \& Link, 1993), Argentina (Blanchard, 1961), Cuba (Fernandez et al., 1997), Colombia (Bueno, 1981 e 1994), Peru (Korytkowski \& Ojeda, 1968 e 1969; Cuculiza e Torres, 1975), Venezuela (Caraballo, 1981). Novas descrições, ocorrências e revisões de espécies também têm sido elaboradas: México (Leyva \& Reyes, 1989; Miranda-Salcedo \& Leyva, 1996; Hernandez-Ortiz, 1998), Bolívia (Norrbom \& Kim, 1988a), Peru (Norrbom \& Kim, 1988a e 1993), Panamá (Norrbom \& Kim, 1988a; Norrbom, 1997), Colômbia (Norrbom, 1991 e 1997; Carrejo \& Gonzalez, 1993; Yepes, 1999), Venezuela (Norrbom, 1991, 1993, 1997 e 1998), Porto Rico e República Dominicana (Norrbom, 1998), Costa Rica (Norrbom, 1998), Argentina (Norrbom, 1998), Ilhas Virgens e Ilha Mona (Norrbom, 1998), Jamaica (Norrbom, 1998).

No Brasil, foram realizados levantamentos em quase todos os Estados: Amapá, Amazonas, Pará, Rondônia e Roraima (Zucchi, 1989; Couturier et al., 1993; Silva, 1993; Zucchi et al., 1996; Silva \& Ronchi-Teles, 2000; Ronchi-Teles, 2000), Maranhão (Oliveira et al., 2000), Piauí (Menezes et al., 2000); Ceará (Sales \& Gonçalves, 2000), Rio Grande do Norte (Nascimento et al. 1993; Araujo et al., 2000), Paraíba (Araujo et al., 2000), Pernambuco (Haji \& Miranda, 2000), Bahia (Nascimento \& Carvalho, 2000), Alagoas (Malavasi et al. 1980), Sergipe (Malavasi et al. 1980), Mato Grosso e Mato Grosso do Sul (Uchôa \& Zucchi, 2000), Goiás (Veloso et al., 2000), Espírito Santo (Martins et al., 2000), Rio de Janeiro (Aguiar-Menezes \& Menezes, 2000), Minas Gerais (Alvarenga et al., 2000), Paraná (Fehn, 1981), Santa Catarina (Nora et al., 2000), São Paulo (Souza Filho et al., 2000) e Rio Grande do Sul (Canal et al., 1993; Kovaleski et al., 1999; Kovaleski et al., 2000). Hernández-Ortiz \& Aluja (1993) verificaram que apenas 3,3\% das espécies de Anastrepha apresentam distribuição geográfica ampla e que o Brasil é um dos países de maior diversidade. A. fraterculus, A. obliqua e A. sororcula são as espécies mais distribuídas no país (Zucchi, 1988).

Aluja (1994) considerou sete espécies como sendo economicamente importantes: A. fraterculus (Wiedemann), A. obliqua (Macquart), A. ludens (Loew), A. suspensa (Loew), A. grandis (Macquart), A. serpentina (Wiedemann) e A. striata Schiner.

Dentre as espécies registradas no Brasil, sete são as de maior importância econômica (Zucchi, 2000a): A. fraterculus (Wiedemann), A. grandis (Macquart), A. 
obliqua (Macquart), A. pseudoparalella (Loew), A. sororcula Zucchi, A. striata Schiner e A. zenildae Zucchi. Entretanto, dependendo da área considerada, outras espécies podem vir a ser importantes em função dos frutos que atacam e de suas abundâncias relativas (Zucchi, 2000a).

No Estado de São Paulo foram assinaladas 35 espécies de Anastrepha até o momento (Souza Filho et al., 2000). Referências dos registros destas espécies são apresentadas a seguir.

Em nota sobre a mosca-das-frutas, Hempel (1901) não esclareceu se os exemplares identificados como A. fraterculus (Wiedemann) eram provenientes de São Paulo, entretanto, consta de outra referência (Hempel, 1906) que exemplares desta espécie foram obtidos de frutos coletados em Campinas, SP, considerando-se a primeira ocorrência neste Estado.

Bezzi (1909) elaborou um catálogo e chave de identificação das espécies conhecidas e descreveu A. daciformis Bezzi de material procedente de São Paulo. Este autor, em um trabalho posterior (1919), apresentou uma chave de identificação das espécies brasileiras e registrou para o Estado de São Paulo as espécies A. grandis (Macquart), A. psedoparallela (Loew), A. obliqua (Macquart) e descreveu A. bistrigata Bezzi de material proveniente de Bauru, SP.

A. serpentina (Wiedemann) foi citada pela primeira vez por Tavares (1915) e A. punctata Hendel por Fischer (1933), no trabalho em que apresentou uma redescrição da espécie.

Costa Lima (1934) estudou 62 espécies de Anastrepha e incluiu o Estado de São Paulo na área de distribuição de A. connexa Stone, A. distincta Greene e A. luederwaldti Lima.

A. consobrina (Loew) foi obtida de frutos de maracujá em levantamento de pragas nas plantas cultivadas em São Paulo (Fonseca, 1934).

A. costalimai Autuori foi descrita a partir de exemplares coletados na capital de São Paulo (Autuori, 1936). A. barbiellinii Lima foi descrita de material coletado em SP (1938) e Stone (1942), em revisão das espécies de Anastrepha, citou A. caudata Stone e A. elegans Blanchard como espécies que ocorrem em São Paulo. 
Zucchi (1978) revisando as espécies brasileiras de Anastrepha, assinalou a presença de A. barnesi Aldrich, A. barrettoi Zucchi, A. dissimilis Stone, A. rheediae Stone, A. simulans Zucchi, A. sororcula Zucchi, A. xanthochaeta Hendel, A. zenildae Zucchi e A. zernyi Lima.

Malavasi et al. (1980) realizaram levantamento de moscas-das-frutas em amostras de plantas hospedeiras coletadas em várias localidades brasileiras e registraram a ocorrência de A. pickeli Lima e o redescobrimento de A. punctata em São Paulo.

Arrigoni (1984), em levantamento realizado nos municípios de Limeira, Jundiaí e Piracicaba, SP, registrou, dentre as 14 espécies encontradas, a primeira ocorrência de A. bahiensis Lima e A. kuhlmani Lima.

Em estudo conduzido em pomar cítrico em Jaboticabal, SP, foram detectadas pela primeira vez A. leptozona Hendel e A. montei Lima (Fernandes et al., 1984). A. quiinae Lima foi encontrada em pomar de citros em Ribeirão Preto, SP (Fernandes, 1987).

Em levantamento de 3 anos em 12 municípios de São Paulo, Calza et al. (1988) obtiveram 11 espécies de Anastrepha, dentre as quais o primeiro registro de A. manihoti Lima.

Recentemente, Souza Filho (1999) realizou extenso trabalho de coletas de plantas hospedeiras em 94 municípios paulistas, acrescentando A. amita Zucchi, A. striata Schiner e A. turpiniae Stone à lista de espécies registradas neste Estado.

\subsection{Análise faunística}

O número total de indivíduos amostrados em uma determinada área e a análise quantitativa da diversidade têm sido bastante empregados em estudos faunísticos.

Estudos conduzidos em pomares comerciais mostraram que embora várias espécies de moscas-das-frutas estejam presentes, apenas uma ou duas foram consideradas dominantes, e que a dominância das espécies foi influenciada principalmente por fatores ecológicos, como a abundância e a riqueza de espécies de 
plantas hospedeiras, a complexidade dos pomares e o agroecossistema adjacente e altitude (Malo et al., 1987; Soto-Manitiu \& Jirón, 1989; Aluja, 1994).

No Brasil, existem poucos estudos sobre análise faunística, entretanto todos apresentam resultados semelhantes aos trabalhos realizados em outros países. Nascimento et al. (1983) apresentaram análise faunística das espécies de Anastrepha de 5 municípios no Recôncavo Baiano e dentre as 20 espécies encontradas, apenas 3 foram dominantes, A. fraterculus, A. obliqua e A. sororcula. Arrigoni (1984) levantou as espécies de moscas-das-frutas de três municípios do Estado de São Paulo e concluiu que A. fraterculus e C. capitata foram as espécies dominantes e constantes dentre as 14 obtidas.

Em estudo conduzido em Vacaria, RS, Kovaleski (1997) obteve um valor igual a 16 para a riqueza de espécies de Anastrepha, sendo que apenas duas foram consideradas dominantes. A. fraterculus foi predominante, contribuindo com mais de $80 \%$ do total de indivíduos capturados e resultando em valores altos do índice de Simpson. A espécie também apresentou os maiores valores de constância.

Nascimento et al. (1993) caracterizaram duas comunidades estimando a frequiência, a constância e a dominância para as espécies de Anastrepha em duas áreas de produção de melão no Estado do Rio Grande do Norte. Verificaram que, embora a diversidade de espécies fosse similar, as freqüências das espécies foram diferentes nos dois locais.

Aluja et al. (1996) estimaram os índices de diversidade, Shannon-Weaver e Simpson-Yule em cinco pomares comerciais de manga no sudeste do México. Observaram que, embora os pomares fossem próximos, houve diferenças significativas no número de adultos capturados e na diversidade de espécies de Anastrepha em cada pomar.

Martins et al. (1996) estimaram a frequiência, a riqueza de espécies e a dominância, para as espécies de moscas-das-frutas coletadas em três pomares de papaia no norte do Espírito Santo, concluindo que houve diferença nos valores dos índices entre os pomares estudados. 
Canal et al. (1998) e Canal (1997) realizaram estudos em quatro municípios de Minas Gerais ao longo de dois anos e detectaram 20 espécies de Anastrepha. Os valores do índice de Margalef para as quatro comunidades estudadas foram similares entre si. Apenas A. obliqua e A. zenildae foram as espécies predominantes.

\subsection{Flutuação populacional de moscas-das-frutas}

A flutuação populacional de adultos de Anastrepha tem sido estudada por toda a área de distribuição geográfica das espécies do gênero. Segundo Aluja (1994), as flutuações populacionais de adultos em pomares comerciais estão relacionadas a duas variáveis: disponibilidade de frutos de plantas hospedeiras e condições climáticas. Em monoculturas, ocorre um pico populacional logo após o período de amadurecimento dos frutos e um declínio quando não há frutos disponíveis. Nos pomares diversificados, as flutuações são provavelmente minimizadas pela presença de plantas hospedeiras alternativas (Aluja, 1994).

Em algumas áreas tem-se observado que a flutuação temporal da população de adultos está relacionada principalmente à disponibilidade de plantas hospedeiras e não às variáveis climáticas. Celedonio-Hurtado et al. (1995) observaram os picos populacionais logo após o período de máxima disponibilidade de frutos hospedeiros e consideraram que esse fator é determinante na flutuação populacional. Estes autores mostraram que a precipitação pluviométrica não influenciou na flutuação populacional. Aluja et al. (1996) também reforçam a idéia de que a disponibilidade de hospedeiros influencia a população de Anastrepha. Soto-Manitiu \& Jirón (1989), em estudo das espécies de Anastrepha associadas à manga na Costa Rica, constataram que os picos populacionais de três espécies coincidiram com a maior produção de frutos. Tan \& Serit (1994) concluíram que a disponibilidade de hospedeiros adequados é a variável que mais influencia o tamanho da população de adultos de Bactrocera dorsalis Hendel nos trópicos.

Em estudos similares conduzidos no Brasil os resultados foram condizentes com aqueles obtidos nos trabalhos citados anteriormente. Segundo Puzzi \& Orlando (1965), a presença de plantas hospedeiras e o estágio de maturação dos frutos são os fatores 
principais na flutuação populacional das moscas-das-frutas. Em estudo conduzido em um pomar não-comercial em Itaquera, SP, Malavasi \& Morgante (1981) verificaram que, em geral, o pico populacional de A fraterculus ocorreu próximo ao final do período de frutificação das plantas hospedeiras e que a população de adultos não desapareceu completamente, permanecendo populações residuais entre as épocas de frutificação. As flutuações populacionais de C. capitata e Anastrepha spp. em Itaguaí, RJ, foram relacionadas às épocas de disponibilidade de frutos nativos (Aguiar-Menezes \& Menezes, 1996). Fehn (1982) observou que a relação entre o número de indivíduos capturados e as variáveis climáticas não é constante e que a presença de hospedeiros alternativos é o principal fator que influencia a flutuação de Anastrepha spp. em Pelotas, Canguçu e Piratini, municípios do Rio Grande do Sul. Zahler (1991) estudou a flutuação populacional de moscas-das-frutas em dois pomares de manga no Distrito Federal e observou que a população mais abundante coincidiu com a época de frutificação e que não houve correlação entre as variáveis climáticas e o tamanho da população. Aquele autor verificou que em pomar diversificado, onde ocorreu frutificação o ano inteiro, houve correlação positiva do tamanho populacional de moscas-das-frutas com o período chuvoso e negativa com o período seco (Zahler, 1990). Em seis municípios de Minas Gerais, Canal (1997) concluiu que a disponibilidade de frutos hospedeiros foi o principal fator relacionado com a flutuação populacional dos tefritídeos.

A abundância de C. capitata em Kauai, Havaí, parece estar relacionada negativamente com pluviosidade, ou seja, em áreas mais secas o número de indivíduos coletados em armadilhas foi maior (Vargas et al., 1983).

Nascimento et al. (1982) estudaram as flutuações populacionais de cinco espécies de Anastrepha no Recôncavo Baiano e verificaram correlações entre temperaturas máxima e média e as coletas de moscas-das-frutas, no entanto, não observaram correlação com a precipitação pluviométrica e a temperatura mínima.

O tamanho da população de $C$. capitata em cafeeiros de Pindorama e Campinas, municípios de São Paulo, foi influenciado pela disponibilidade de frutos maduros. Em Campinas, a temperatura também teve influência sobre a população desta espécie, 
enquanto em Pindorama nenhuma das variáveis climáticas analisadas teve influência (Parra et al., 1982)

Em Piracicaba, SP, Arrigoni (1984) analisou a influência das variáveis meteorológicas na flutuação populacional de moscas-das-frutas (Anastrepha e Ceratitis), verificando correlação positiva com a velocidade dos ventos e a umidade relativa do ar. Observou que a precipitação pluviométrica e a temperatura não influenciaram o tamanho populacional dos tefritídeos. Ao relacionar a época de frutificação dos frutos hospedeiros com o aumento da população, verificou que esta variável teve influência muito mais determinante que as variáveis climáticas.

Raga et al. (1996) conduziram estudos sobre dinâmica populacional de moscasdas-frutas em pomar de citros em Presidente Prudente, SP, verificando que os dados sobre flutuação populacional de $C$. capitata estavam negativamente correlacionados com a umidade relativa e a flutuação de espécies de Anastrepha com a precipitação pluviométrica e as temperaturas média e mínima.

A temperatura máxima e a umidade relativa no período da manhã foram os fatores climáticos favoráveis de causa-efeito na captura de adultos de A. striata na Venezuela (Rodriguez et al., 1999).

Em áreas tropicais observa-se que a abundância de moscas-das-frutas é influenciada, em geral, pela disponibilidade de frutos hospedeiros e, em alguns casos, pelas variáveis climáticas como precipitação pluviométrica, umidade relativa e temperatura máxima. Entretanto, em áreas de clima temperado, o principal fator que regula as populações é a temperatura relativamente baixa durante o inverno (Papadopoulos et al., 2001). Em estudos realizados em Vacaria, RS, onde o clima é subtropical, Kovaleski (1997) observou que o tamanho da população de A. fraterculus pode ser regulado pela oferta de hospedeiros e pelo rigor das temperaturas do inverno.

Nas áreas onde ocorre sucessão de hospedeiros, as populações das espécies polífagas podem se manter em níveis altos em todas as estações do ano. Segundo Malavasi \& Morgante (1981), quando há um intervalo sem produção de frutos, as populações podem se manter no estágio adulto e pode ocorrer diminuição no seu 
tamanho, mas um pequeno número de sobreviventes pode restabelecer a população, já que as fêmeas de tefritídeos polífagos apresentam alta fecundidade.

\subsection{Plantas hospedeiras}

Segundo Norrbom (1985), o gênero Anastrepha não é suficientemente antigo para ter coevoluído com as suas plantas hospedeiras. Entretanto, sugeriu que as associações com plantas hospedeiras estão parcialmente relacionadas filogeneticamente dentro do gênero. A especificidade entre certas espécies e plantas hospedeiras é uma característica interessante de Anastrepha, como o grupo pseudoparallela associado quase exclusivamente ao gênero Passiflora (Passifloraceae) e as espécies dos grupos serpentina, daciformis, dentata, robusta e leptozona à família Sapotaceae (Norrbom 1985). Outras espécies são consideradas polífagas e atacam plantas de diferentes espécies e famílias, como A. fraterculus, A. suspensa e A. ludens (Malavasi et al., 1980; Norrbom \& Kim, 1988b; Zucchi, 1988).

Os dados sobre a associação de espécies de Anastrepha e as plantas hospedeiras são escassas na literatura. Segundo Norrbom \& Kim (1988b), há registros de plantas hospedeiras para apenas $39 \%$ das espécies de Anastrepha. Além disso, aproximadamente $70 \%$ dos registros de hospedeiros correspondem as sete espécies importantes economicamente (Norrbom, 1985). Um dos catálogos mais completos sobre os hospedeiros das espécies de Anastrepha foi publicado por Norrbom \& Kim (1988b).

Uma determinada espécie de tefritídeo capturada em uma armadilha instalada em uma árvore não permite associar esta planta como sua hospedeira (Aluja et al. (1987), Malo et al. (1987), Norrbom \& Kim (1988b) e Zucchi (2000b). Para 56\% das espécies assinaladas no Brasil, não há registros da relação com plantas hospedeiras, uma vez que a maioria dos levantamentos de espécies foi realizada com armadilhas contendo atrativo alimentar (Zucchi, 2000b).

Os levantamentos baseados em coleta de frutos no Brasil foram intensificados nas últimas décadas, sobretudo devido à importância de se conhecer a associação com os frutos hospedeiros, tanto para estudos de biologia e ecologia de moscas-das-frutas, como 
para programas de manejo destas pragas. Malavasi et al. (1980) realizaram amplo levantamento a partir de frutos coletados em diversas regiões do Brasil. Outros levantamentos foram conduzidos em vários Estados: Amazonas (Couturier et al., 1993; Silva, 1993; Silva et al., 1996; Zucchi et al., 1996, Ronchi-Teles, 2000), Roraima (Ronchi-Teles et al., 1995), Pará (Ohashi, 1997), Piauí (Zucchi et al., 1995), Rio Grande do Norte (Araujo et al., 1996), Mato Grosso do Sul (Uchôa, 1999), Goiás (Veloso, 1997), Minas Gerais (Canal, 1997), Rio de Janeiro (Aguiar-Menezes \& Menezes, 1996), São Paulo (Arrigoni, 1984; Raga et al., 1996a, 1996b, 1977; Souza Filho, 1999) e Rio Grande do Sul (Kovaleski, 1997).

Uma lista de hospedeiros das espécies de Anastrepha assinaladas no Brasil, com as respectivas referências, foi elaborada por Zucchi (2000b). 


\section{MATERIAL E MÉTODOS}

\section{1 Área experimental: localização e caracterização}

Os estudos foram conduzidos no campus Luiz de Queiroz/USP no município de

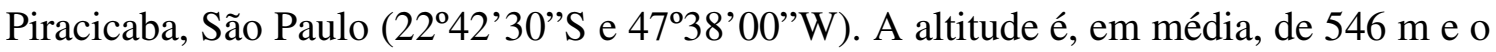
clima, segundo a classificação de Koppen, do tipo Cwa, tropical de altitude, com inverno seco e temperatura do mês mais quente maior que $22^{\circ} \mathrm{C}$ (Sentelhas, 2001). A Figura 1 representa o climograma da região com dados de 1917 a 1997.

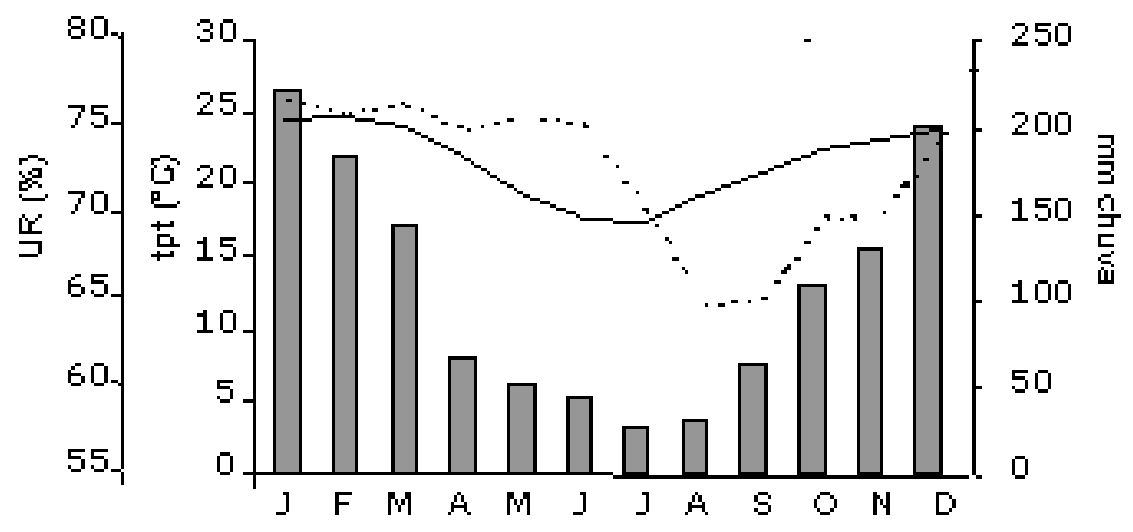

Figura 1 - Climograma de Piracicaba, 1917-1997: temperatura média (linha sólida), umidade relativa do ar (linha tracejada) e precipitação pluviométrica (colunas). (Fonte: Departamento de Ciências Exatas, ESALQ/ USP)

O campus é uma área contínua de aproximadamente 800 ha, com cultivo de inúmeros hospedeiros primários de moscas-das-frutas, tais como, laranja, café, pêssego, uvaia, carambola, goiaba, manga, jabuticaba, abacate, acerola, serigüela, nêspera, 
pitanga, além dos hospedeiros silvestres. É um local praticamente isolado dos demais focos de moscas-das-frutas, por ser circundado na sua grande parte pela cultura da canade-açúcar e, em menor proporção, por pastagens, reflorestamento e área urbana (J. M. M. Walder, comunicação pessoal).

\subsection{Levantamento das espécies com armadilhas e diretamente dos frutos}

As coletas de moscas-das-frutas foram realizadas através de armadilhas plásticas tipo McPhail, contendo, como atrativo alimentar, proteína hidrolisada de milho estabilizada com bórax ( $\mathrm{pH}$ entre 8,5 e 9,0) e diluída a $5 \%$, instaladas nas copas de árvores (hospedeiras ou não) no período de julho de 1998 a junho de 1999. Um total de 84 armadilhas foi distribuído por toda a área de estudo (Figura 2).

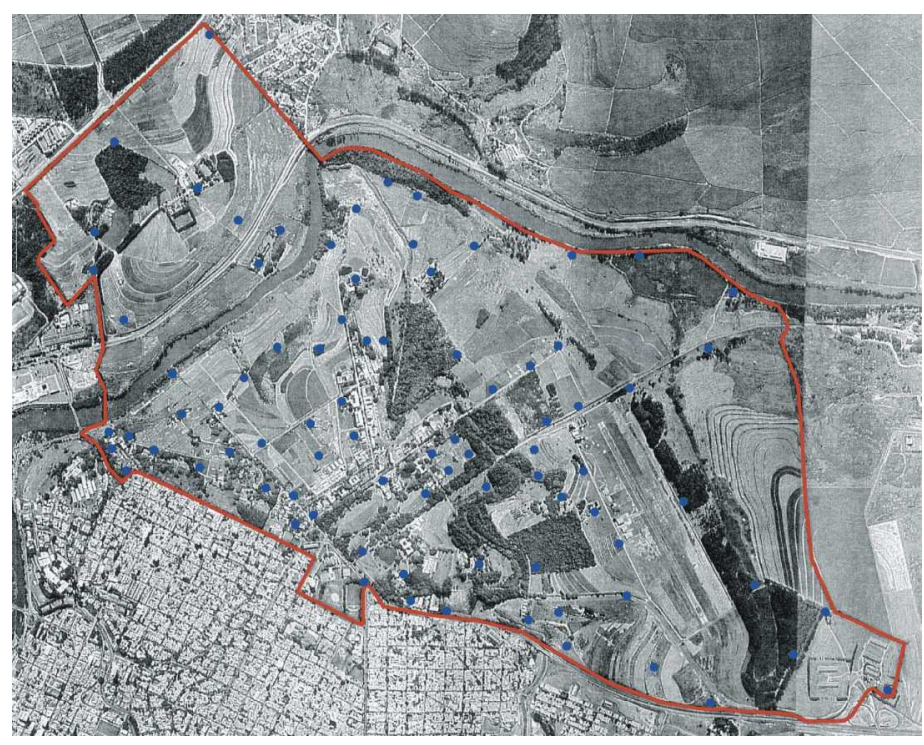

Figura 2 - Vista aérea do Campus Universitário Luiz de Queiroz, USP, Piracicaba, SP. 
As coordenadas, a localização e as espécies de plantas presentes em cada ponto de coleta, além das distâncias entre as armadilhas instaladas estão na tabela 1. As armadilhas permaneceram instaladas durante todo o período de estudo. Apenas o atrativo alimentar era reposto uma vez por semana, quando o material capturado era recolhido. Todas as armadilhas foram verificadas semanalmente nas 84 estações de coleta. Os exemplares de Anastrepha capturados foram sexados. Os machos não foram considerados neste estudo, uma vez que apenas as fêmeas apresentam os principais caracteres diagnósticos para a identificação específica. As fêmeas foram separadas por coletas semanais e armazenadas em frascos de vidro contendo etanol $70 \%$ para identificação posterior.

Para se determinar a associação entre a planta hospedeira e a espécie de Anastrepha foram efetuadas coletas sistemáticas de frutos de janeiro a dezembro de 1999. As amostras foram constituídas de frutos maduros ou em amadurecimento coletados diretamente das árvores ou recém-caídos. Os locais de coleta dos frutos corresponderam aqueles estabelecidos pela instalação das armadilhas. Com relação às espécies de frutos, as amostras variaram ao longo do ano, de acordo com a época de frutificação de cada espécie de planta.

Tabela 1. Localização e caracterização dos pontos de coleta estabelecidos no campus Luiz de Queiroz, Piracicaba, SP.

\begin{tabular}{|c|c|c|c|c|}
\hline$N^{o}$ & $\begin{array}{l}\text { Latitude }(S) \text {, longitude } \\
(W) \text { e altitude }(\mathrm{m})\end{array}$ & Distância (m) & Local & Vegetação* \\
\hline 1 & $\begin{array}{l}22^{\circ} 43^{\prime} 07.0^{\prime \prime S} \\
47^{\circ} 36^{\prime} 25.3^{\prime \prime}, 656\end{array}$ & $1-58: 560$ & Granja doméstica & $\begin{array}{l}\text { Caju, caqui, pitanga, jabuticaba, } \\
\text { jatobá, goiaba, citros, abacate, } \\
\text { acerola, limão siciliano, banana }\end{array}$ \\
\hline 2 & $\begin{array}{l}22^{\circ} 42^{\prime} 23.4^{\prime \prime S} \\
47^{\circ} 37^{\prime} 06.0^{\prime \prime} \mathrm{W}, 611\end{array}$ & $2-6: 460$ & Aeroporto & Mata ciliar, eucalipto \\
\hline 3 & $\begin{array}{l}2243^{\prime} 11.5^{\prime \prime} \mathrm{S} \\
47^{\circ} 36^{\prime} 57.5^{\prime \prime}, 501\end{array}$ & 3- 53: 640 & $\begin{array}{l}\text { Parte alta da antiga estrada } \\
\text { para São Paulo }\end{array}$ & $\begin{array}{l}\text { Manga, limão tahiti, abacate, limão } \\
\text { siciliano, laranja ponkan }\end{array}$ \\
\hline 4 & $\begin{array}{l}22^{\circ} 42^{\prime} 57.0^{\prime \prime S}, \\
47^{\circ} 37^{\prime} 25.2^{\prime \prime} \mathrm{W}, 391\end{array}$ & $4-59: 220$ & $\begin{array}{l}\text { Colônia na estrada para São } \\
\text { Paulo }\end{array}$ & $\begin{array}{l}\text { Várias frutíferas, entre as quais, } \\
\text { abacate }\end{array}$ \\
\hline 5 & $\begin{array}{l}22^{\circ} 42^{\prime} 54.4^{\prime \prime S}, \\
47^{\circ} 37^{\prime} 18.4^{\prime \prime}, 479\end{array}$ & $5-55: 440$ & $\begin{array}{l}\text { Pomar de jabuticaba na } \\
\text { antiga estrada para São } \\
\text { Paulo }\end{array}$ & Jabuticaba \\
\hline
\end{tabular}


Tabela 1. Localização e caracterização dos pontos de coleta estabelecidos no campus Luiz de Queiroz, Piracicaba, SP.

\begin{tabular}{|c|c|c|c|c|}
\hline$N^{o}$ & $\begin{array}{l}\text { Latitude }(S) \text {, longitude } \\
(W) \text { e altitude }(m)\end{array}$ & Distância (m) & Local & Vegetação* \\
\hline 6 & $\begin{array}{l}22^{\circ} 42^{\prime} 44.3^{\prime \prime S} \\
47^{\circ} 37^{\prime} 09.9^{\prime \prime}, 427\end{array}$ & $6-62: 580$ & $\begin{array}{l}\text { Pomar próximo ao } \\
\text { aeroporto }\end{array}$ & Laranja Valência, laranja Natal \\
\hline 7 & $\begin{array}{l}22^{\circ} 42^{\prime} 28.5^{\prime \prime S} \\
47^{\circ} 37^{\prime} 16.1^{\prime \prime W}, 588\end{array}$ & $7-8: 120$ & $\begin{array}{l}\text { Pomar próximo ao } \\
\text { aeroporto }\end{array}$ & Jaca \\
\hline 8 & $\begin{array}{l}22^{\circ} 42^{\prime} 34.9^{\prime \prime S} \\
47^{\circ} 37^{\prime} 21.7^{\prime \prime W}, 588\end{array}$ & $8-9: 100$ & Dep. Horticultura & Manga \\
\hline 9 & $\begin{array}{l}22 \mathrm{o} 42^{\prime} 43.9^{\prime \prime} \mathrm{S} \\
47^{\circ} 37^{\prime} 26.3^{\prime \prime W}, 588\end{array}$ & $9-10: 60$ & Dep. Horticultura & Pêssego, macadâmia \\
\hline 10 & $\begin{array}{l}22^{\circ} 42^{\prime} 33.3^{\prime \prime S}, \\
47^{\circ} 37^{\prime} 34.9^{\prime \prime} \mathrm{W}, 465\end{array}$ & $10-11: 320$ & Dep. Horticultura & $\begin{array}{l}\text { Manga, jaca nêspera, acerola, goiaba, } \\
\text { maracujá, pêssego }\end{array}$ \\
\hline 11 & $\begin{array}{l}22 \mathrm{o} 42^{\prime} 43.2^{\prime \prime S} \\
47^{\circ} 37^{\prime} 40.2^{\prime \prime} \mathrm{W}, 601\end{array}$ & $11-12: 340$ & $\begin{array}{l}\text { Cafezal do Dep. Ent., Fit., } \\
\text { Z. Agr. }\end{array}$ & Café e plantas nativas \\
\hline 12 & $\begin{array}{l}22^{\circ} 42^{\prime} 46.6^{\prime \prime S}, \\
47^{\circ} 37^{\prime} 29.1 " \mathrm{~W}, 503\end{array}$ & 12-72: 1460 & Dep. Ent., Fit., Z. Agr. & $\begin{array}{l}\text { Várias frutíferas, entre os quais, } \\
\text { azeitona-do-Ceilão, citros }\end{array}$ \\
\hline 13 & $\begin{array}{l}22^{\circ} 42^{\prime} 24.6^{\prime \prime S} \\
47^{\circ} 37^{\prime} 40.5^{\prime \prime}, 496\end{array}$ & $13-82: 100$ & Dep. Horticultura & $\begin{array}{l}\text { Jabuticaba, acerola, uvaia, abiu, } \\
\text { serigüela, carambola, abricó-de- } \\
\text { macaco }\end{array}$ \\
\hline 14 & $\begin{array}{l}22^{\circ} 41^{\prime} 52.4^{\prime \prime S} \\
47^{\circ} 37^{\prime} 16.1^{\prime \prime W}, 554\end{array}$ & $14-15: 400$ & $\begin{array}{l}\text { Captação de água na Lagoa } \\
\text { Presídio }\end{array}$ & $\begin{array}{l}\text { Citros, manga, abacate, caju, } \\
\text { maracujá, pitanga }\end{array}$ \\
\hline 15 & $\begin{array}{l}22^{\circ} 42^{\prime} 11.2^{\prime \prime S} \\
47^{\circ} 37^{\prime} 19.4^{\prime \prime}, 594\end{array}$ & $15-51: 140$ & Posto meteorológico & $\frac{\text { Abacate, manga,café, citros, planta }}{\text { nativa }}$ \\
\hline 16 & $\begin{array}{l}22^{\circ} 42^{\prime} 30.9^{\prime \prime S} \\
47^{\circ} 37^{\prime} 48.9^{\prime \prime}, 584\end{array}$ & $16-33: 240$ & $\begin{array}{l}\text { Área de convivência, próx. } \\
\text { restaurante central }\end{array}$ & Café e plantas nativas, chapéu-de-sol \\
\hline 17 & $\begin{array}{l}22^{\circ} 42^{\prime} 33.1^{\prime \prime S}, \\
47^{\circ} 37^{\prime} 42.3^{\prime \prime W}, 584\end{array}$ & $17-16: 220$ & Posto Odontológico & Goiaba, manga, jabuticaba \\
\hline 18 & $\begin{array}{l}22^{\circ} 42^{\prime} 30.1^{\prime \prime S} \\
47^{\circ} 38^{\prime} 05.8^{\prime \prime} \mathrm{W}, 659\end{array}$ & $18-69: 360$ & Dep. Genética & $\begin{array}{l}\text { Banana, manga, goiaba, citros, } \\
\text { jabuticaba, mamão, ameixa-amarela, } \\
\text { maracujá-doce, } \underline{\text { jambolão }}\end{array}$ \\
\hline 19 & $\begin{array}{l}22^{\circ} 42^{\prime} 31.6^{\prime \prime S} \\
47^{\circ} 38^{\prime} 08.0^{\prime \prime W}, 694\end{array}$ & $19-56: 320$ & $\begin{array}{l}\text { Área de produção de mudas } \\
\text { (Ciagri) }\end{array}$ & $\begin{array}{l}\text { Pitanga, citros, jabuticaba, serigüela, } \\
\text { pêra, acerola, cuietê, limão tahiti, } \\
\text { goiaba, banana, nêspera, mamão, } \\
\text { caqui, lima-da-pérsia, manga, } \\
\text { tamarindo, uvaia, falso mangostão }\end{array}$ \\
\hline 20 & $\begin{array}{l}22^{\circ} 42^{\prime} 37.8^{\prime \prime S}, \\
47^{\circ} 38^{\prime} 11.4^{\prime \prime} \mathrm{W}, 478\end{array}$ & $20-19: 40$ & $\begin{array}{l}\text { Pomar doméstico, próximo } \\
\text { ao CEBITEC }\end{array}$ & Manga, goiaba, citros, jabuticaba \\
\hline 21 & $\begin{array}{l}22^{\circ} 42^{\prime} 23.5^{\prime \prime S}, \\
47^{\circ} 38^{\prime} 19.4^{\prime \prime W}, 501\end{array}$ & $21-23: 220$ & Lab. Biotecnologia Animal & $\begin{array}{l}\text { Jabuticaba, nêspera, mamão goiaba, } \\
\text { acerola, uvaia, jaca, manga, pitanga, } \\
\text { macadâmia, citros, abacate }\end{array}$ \\
\hline 22 & $\begin{array}{l}22^{\circ} 42^{\prime} 18.4^{\prime \prime S}, \\
47^{\circ} 38^{\prime} 22.6^{\prime \prime W}, 568\end{array}$ & $22-78: 160$ & Pomar no Dep. Genética & Jabuticaba, citros, manga, abacate \\
\hline 23 & $\begin{array}{l}22^{\circ} 42^{\prime} 30.9^{\prime \prime S}, \\
47^{\circ} 38^{\prime \prime} 17.8^{\prime \prime W}, 581\end{array}$ & $23-65: 100$ & Pomar no Dep. Zootecnia & Manga \\
\hline
\end{tabular}


Tabela 1. Localização e caracterização dos pontos de coleta estabelecidos no campus Luiz de Queiroz, Piracicaba, SP.

\begin{tabular}{|c|c|c|c|c|}
\hline$N^{o}$ & $\begin{array}{l}\text { Latitude (S), longitude } \\
(W) \text { e altitude }(\mathrm{m})\end{array}$ & Distância $(m)$ & Local & Vegetação* \\
\hline 24 & $\begin{array}{l}22^{\circ} 42^{\prime} 20.4^{\prime \prime S}, \\
47^{\circ} 38^{\prime} 32.3^{\prime \prime} \mathrm{W}, 594\end{array}$ & $24-31: 140$ & Suinocultura & $\begin{array}{l}\text { Goiaba, abacate, nêspera, fruta-do- } \\
\text { conde, manga,citros, figo-da-índia }\end{array}$ \\
\hline 25 & $\begin{array}{l}22^{\circ} 42^{\prime} 03.1^{\prime \prime S}, \\
47^{\circ} 37^{\prime} 59.7^{\prime \prime W}, 571\end{array}$ & $25-29: 140$ & $\begin{array}{l}\text { Pomar no restaurante dos } \\
\text { professores }\end{array}$ & Café \\
\hline 26 & $\begin{array}{l}22^{\circ} 41^{\prime} 49.1^{\prime \prime S}, \\
47^{\circ} 38^{\prime} 01.0^{\prime \prime}, 581\end{array}$ & $26-74: 180$ & $\begin{array}{l}\text { Casa de bombas no Dep. } \\
\text { Agricultura }\end{array}$ & Mata ciliar, jambolão, manga \\
\hline 27 & $\begin{array}{l}22^{\circ} 41^{\prime} 57.5^{\prime \prime S}, \\
47^{\circ} 37^{\prime} 43.2^{\prime \prime W}, 575\end{array}$ & $27-45: 420$ & Arrozal na colônia & $\begin{array}{l}\text { Abacate, manga, jabuticaba, serigüela, } \\
\text { banana, planta nativa }\end{array}$ \\
\hline 28 & $\begin{array}{l}22^{\circ} 42^{\prime} 11.9^{\prime \prime S}, \\
47^{\circ} 37^{\prime} 56.0^{\prime \prime}, 583\end{array}$ & $28-37: 880$ & Dep. Agricultura & $\begin{array}{l}\text { Manga, mamão, citros, sapoti, } \\
\text { jabuticaba, planta nativa }\end{array}$ \\
\hline 29 & $\begin{array}{l}22^{\circ} 41^{\prime} 59.9^{\prime \prime S} \\
47^{\circ} 37^{\prime} 57.3^{\prime \prime W}, 681\end{array}$ & $29-26: 180$ & Restaurante dos professores & Café, limão, jabuticaba e carcina \\
\hline 30 & $\begin{array}{l}22^{\circ} 42^{\prime} 16.8^{\prime \prime S}, \\
47^{\circ} 38^{\prime} 08.7^{\prime \prime W}, 648\end{array}$ & $30-18: 100$ & Biblioteca central & Bambuzal, mata ciliar, planta nativa \\
\hline 31 & $\begin{array}{l}22^{\circ} 42^{\prime} 12.0^{\prime \prime S}, \\
47^{\circ} 38^{\prime} 30.6^{\prime \prime W}, 548\end{array}$ & $31-22: 300$ & Dep. Genética & Bambuzal, mata ciliar, planta nativa \\
\hline 32 & $\begin{array}{l}22^{\circ} 42^{\prime} 07.0^{\prime \prime S}, \\
47^{\circ} 38^{\prime} 10.9^{\prime \prime}, 500\end{array}$ & $32-80: 240$ & Seringal & $\underline{\text { Seringueira }}$ \\
\hline 33 & $\begin{array}{l}22^{\circ} 42^{\prime} 22.3^{\prime \prime S} \\
47^{\circ} 37^{\prime} 56.5^{\prime \prime} \mathrm{W}, 627\end{array}$ & $33-70: 100$ & Banco Banespa & Café, mamão, goiaba, planta nativa \\
\hline 34 & $\begin{array}{l}22^{\circ} 41^{\prime} 51.6^{\prime \prime} \mathrm{S} \\
47^{\circ} 37^{\prime} 47^{\circ} .3^{\prime \prime W}, 616\end{array}$ & $34-35: 300$ & Colônia & Banana, arrozal, planta nativa \\
\hline 35 & $\begin{array}{l}22^{\circ} 41^{\prime} 43.7^{\prime \prime S}, \\
47^{\circ} 37^{\prime} 52.0^{\prime \prime W}, 537\end{array}$ & $35-36: 120$ & Observatório & Mata ciliar \\
\hline 36 & $\begin{array}{l}22^{\circ} 41^{\prime} 46.5^{\prime \prime S}, \\
47^{\circ} 37^{\prime} 39.8^{\prime \prime W}, 501\end{array}$ & $36-44: 440$ & Colônia & Mata ciliar \\
\hline 37 & $\begin{array}{l}22^{\circ} 41^{\prime} 54.2^{\prime \prime S}, \\
47^{\circ} 38^{\prime} 15.0^{\prime \prime}, 557\end{array}$ & $37-38: 160$ & Engenho da Esalq & $\begin{array}{l}\text { Citros, jabuticaba, abacate, amora, } \\
\text { goiaba, banana, jambolão, pêssego, } \\
\text { abóbora, serigüela, mamão, manga, } \\
\text { cabeça-de-negro, nêspera }\end{array}$ \\
\hline 38 & $\begin{array}{l}22^{\circ} 41^{\prime} 48.6^{\prime \prime S}, \\
47^{\circ} 38^{\prime} 10.8^{\prime \prime W}, 555\end{array}$ & $38-40: 620$ & Engenho da Esalq & $\begin{array}{l}\text { Citros, jabuticaba, abacate, amora, } \\
\text { goiaba, banana, jambolão, pêssego, } \\
\text { abóbora, serigüela, mamão, manga, } \\
\text { cabeça-de-negro, nêspera }\end{array}$ \\
\hline 39 & $\begin{array}{l}22^{\circ} 42^{\prime} 02.1^{\prime \prime S}, \\
47^{\circ} 38^{\prime} 41.9^{\prime \prime}, 549\end{array}$ & $39-79: 280$ & Faz. Areão & Manga \\
\hline 40 & $\begin{array}{l}22^{\circ} 41^{\prime} 47.6^{\prime \prime S}, \\
47^{\circ} 38^{\prime} 19.9^{\prime \prime W}, 543\end{array}$ & $40-41: 160$ & Faz. Areão & $\underline{\text { Citros }}$ \\
\hline 41 & $\begin{array}{l}22^{\circ} 41^{\prime} 40.7^{\prime \prime S}, \\
47^{\circ} 38^{\prime} 27.3^{\prime \prime W}, 544\end{array}$ & $41-42: 940$ & Sede da Faz. Areão & $\begin{array}{l}\text { Maracujá, café africano, castanha-da- } \\
\text { índia, manga, nêspera }\end{array}$ \\
\hline
\end{tabular}


Tabela 1. Localização e caracterização dos pontos de coleta estabelecidos no campus Luiz de Queiroz, Piracicaba, SP.

\begin{tabular}{|c|c|c|c|c|}
\hline$N^{o}$ & $\begin{array}{l}\text { Latitude (S), longitude } \\
(W) \text { e altitude (m) }\end{array}$ & Distância (m) & Local & Vegetação* \\
\hline 42 & $\begin{array}{l}22^{\circ} 41^{\prime} 14.1 " \mathrm{~S}, \\
47^{\circ} 38^{\prime} 19.3^{\prime \prime W}, 574\end{array}$ & $42-43: 880$ & Faz. Areão & $\begin{array}{l}\text { Abacate, manga, citros, goiaba, planta } \\
\text { nativa }\end{array}$ \\
\hline 43 & $\begin{array}{l}22^{\circ} 41^{\prime} 31.1^{\prime \prime S}, \\
47^{\circ} 38^{\prime} 38.2^{\prime \prime W}, 694\end{array}$ & $43-57: 400$ & Faz. Areão & Mata ciliar \\
\hline 44 & $\begin{array}{l}22^{\circ} 41^{\prime} 50.8^{\prime \prime S} \\
47^{\circ} 37^{\prime} 33.3^{\prime \prime W}, 577\end{array}$ & $44-27: 360$ & Colônia & Pasto, mata ciliar, goiaba \\
\hline 45 & $\begin{array}{l}22^{\circ} 42^{\prime \prime} 09.2^{\prime \prime S} \\
47^{\circ} 37^{\prime} 38.7^{\prime \prime W}, 596\end{array}$ & $45-73: 480$ & Confinamento do gado & Pasto, mata ciliar \\
\hline 46 & $\begin{array}{l}22^{\circ} 42^{\prime} 11.4^{\prime \prime S} \\
47^{\circ} 37^{\prime} 52.6^{\prime W}, 739\end{array}$ & $46-50: 360$ & Estrada para Monte Alegre & Manga \\
\hline 47 & $\begin{array}{l}22^{\circ} 42^{\prime} 25.5^{\prime \prime S}, \\
47^{\circ} 37^{\prime} 27.2^{\prime \prime}, 592\end{array}$ & $47-52: 340$ & $\begin{array}{l}\text { Seringal próximo ao } \\
\text { aeroporto }\end{array}$ & $\underline{\text { Seringueira, }}$ mata ciliar \\
\hline 48 & $\begin{array}{l}22^{\circ} 42^{\prime} 21.3^{\prime \prime S}, \\
47^{\circ} 37^{\prime} 19.3^{\prime \prime W}, 704\end{array}$ & $48-47: 140$ & Aeroporto & $\begin{array}{l}\text { Cultura anual, feijão, café, planta } \\
\underline{\text { nativa }}\end{array}$ \\
\hline 49 & $\begin{array}{l}22^{\circ} 42^{\prime} 55.7^{\prime \prime S} \\
47^{\circ} 37^{\prime} 02.9^{\prime \prime} \mathrm{W}, 615\end{array}$ & 49 - 14: 420 & Ponte da lagoa Presídio & Mata ciliar, eucalipto. \\
\hline 50 & $\begin{array}{l}22^{\circ} 42^{\prime} 02.3^{\prime \prime S} \\
47^{\circ} 37^{\prime} 45.1^{\prime \prime W}, 522\end{array}$ & $50-49: 360$ & $\begin{array}{l}\text { Captação de água na lagoa } \\
\text { Presídio }\end{array}$ & Mata ciliar \\
\hline 51 & $\begin{array}{l}22^{\circ} 42^{\prime} 12.8^{\prime \prime S} \\
47^{\circ} 37^{\prime} 24.7^{\prime \prime W}, 591\end{array}$ & $51-48: 340$ & Posto de tratamento de água & $\underline{\text { Abacate, }}$ amora, citros, goiaba \\
\hline 52 & $\begin{array}{l}22^{\circ} 42^{\prime} 19.3^{\prime \prime S} \\
47^{\circ} 37^{\prime} 38.1^{\prime \prime W}, 630\end{array}$ & $52-13: 500$ & $\begin{array}{l}\text { Ponte do rio Pisca (fornos } \\
\text { de carvão) }\end{array}$ & Mata ciliar, planta nativa \\
\hline 53 & $\begin{array}{l}22^{\circ} 42^{\prime} 06.2^{\prime \prime S}, \\
47^{\circ} 36^{\prime} 42.5^{\prime \prime W}, 525\end{array}$ & $53-1: 680$ & Represa & Goiaba, pitanga, amora, mata ciliar \\
\hline 54 & $\begin{array}{l}22^{\circ} 43^{\prime} 04.1^{\prime \prime S} \\
47^{\circ} 37^{\prime} 05.8^{\prime \prime W}, 572\end{array}$ & $54-3: 380$ & $\begin{array}{l}\text { Estrada antiga para São } \\
\text { Paulo }\end{array}$ & $\underline{\text { Citros }}$ \\
\hline 55 & $\begin{array}{l}22^{\circ} 42^{\prime} 53.2^{\prime \prime S} \\
47^{\circ} 37^{\prime} 06.2^{\prime \prime} \mathrm{W}, 526\end{array}$ & $55-54: 340$ & $\begin{array}{l}\text { Pomar de laranja próximo } \\
\text { ao aeroporto }\end{array}$ & Planta nativa \\
\hline 56 & $\begin{array}{l}22^{\circ} 42^{\prime} 41.5^{\prime \prime S} \\
47^{\circ} 37^{\prime} 58.8^{\prime \prime W}, 641\end{array}$ & $56-71: 60$ & Ginásio de esportes da Esalq & Mata ciliar, planta nativa \\
\hline 57 & $\begin{array}{l}22^{\circ} 41^{\prime} 46.3^{\prime \prime S}, \\
47^{\circ} 38^{\prime} 44.4^{\prime \prime W}, 539\end{array}$ & $57-39: 440$ & Lagoa na Faz. Areião & Mata ciliar, eucalipto e pinus. \\
\hline 58 & $\begin{array}{l}22^{\circ} 42^{\prime} 56.5^{\prime \prime S}, \\
47^{\circ} 36^{\prime} 34.4^{\prime \prime W}, 699\end{array}$ & $58-61: 480$ & Entre Esalq e Caterpillar & Eucalipto, sorgo, cana-de-açúcar. \\
\hline 59 & $\begin{array}{l}22^{\circ} 43^{\prime} 01.9^{\prime \prime S} \\
47^{\circ} 37^{\prime} 19.5^{\prime \prime W}, 534\end{array}$ & $59-5: 100$ & $\begin{array}{l}\text { Estação de tratamento de } \\
\text { água }\end{array}$ & Jambolão, planta nativa \\
\hline 60 & $\begin{array}{l}22^{\circ} 42^{\prime} 54.2^{\prime \prime S}, \\
47^{\circ} 37^{\prime} 43.5^{\prime \prime W}, 566\end{array}$ & $60-4: 530$ & DER & $\underline{\text { Planta nativa }}$ \\
\hline 61 & $\begin{array}{l}22^{\circ} 42^{\prime} 53.1^{\prime \prime S}, \\
47^{\circ} 36^{\prime} 43.7^{\prime \prime W}, 586\end{array}$ & $61-2: 620$ & Ponte da represa Perá & $\begin{array}{l}\text { Mata ciliar, pinus, eucalipto, } \\
\text { bambuzal, planta nativa }\end{array}$ \\
\hline 62 & $\begin{array}{l}22^{\circ} 42^{\prime} 48.0^{\prime \prime S}, \\
47^{\circ} 37^{\prime} 27.4^{\prime \prime} \mathrm{W}, 510\end{array}$ & $62-63: 480$ & Mata no aeroporto & Mata ciliar, planta nativa \\
\hline
\end{tabular}


Tabela 1. Localização e caracterização dos pontos de coleta estabelecidos no campus Luiz de Queiroz, Piracicaba, SP.

\begin{tabular}{|c|c|c|c|c|}
\hline$N^{o}$ & $\begin{array}{l}\text { Latitude }(S) \text {, longitude } \\
(W) \text { e altitude }(m)\end{array}$ & Distância $(m)$ & Local & $V_{\text {egetação* }}^{*}$ \\
\hline 63 & $\begin{array}{l}22^{\circ} 42^{\prime} 35.6^{\prime \prime S}, \\
47^{\circ} 37^{\prime} 15.9^{\prime \prime} \mathrm{W}, 588\end{array}$ & $63-7=140$ & Dep. Horticultura & Manga, banana, abacaxi \\
\hline 64 & $\begin{array}{l}22^{\circ} 42^{\prime} 51.4^{\prime \prime S} \\
47^{\circ} 37^{\prime} 50.1^{\prime \prime W}, 547\end{array}$ & $64-81: 60$ & Prefeitura nova & $\begin{array}{l}\text { Pitanga,citros, manga, } \\
\text { goiaba,jabuticaba, manga }\end{array}$ \\
\hline 65 & $\begin{array}{l}22^{\circ} 42^{\prime} 32.5^{\prime \prime S} \\
47^{\circ} 38^{\prime} 10.4^{\prime \prime W}, 651\end{array}$ & $65-20: 60$ & Dep. Genética & $\begin{array}{l}\text { Manga, mamão, citros, jabuticaba, } \\
\text { jambolão, abricó-de-macaco, ata, } \\
\text { banana, acerola. }\end{array}$ \\
\hline 66 & $\begin{array}{l}22^{\circ} 42^{\prime} 30.1^{\prime \prime S}, \\
47^{\circ} 38^{\prime} 21.3^{\prime \prime W}, 501\end{array}$ & $66-21: 120$ & Criadouro de jacaré & $\begin{array}{l}\text { Mamão, manga, goiaba, citros, } \\
\text { jambolão, pitanga, planta nativa }\end{array}$ \\
\hline 67 & $\begin{array}{l}22^{\circ} 42^{\prime} 26.0^{\prime \prime S}, \\
47^{\circ} 38^{\prime} 32.6^{\prime \prime}, 602\end{array}$ & $67-66: 240$ & Confinamento de capivaras & $\begin{array}{l}\text { Goiaba, jambolão, pitanga, amêndoa, } \\
\text { mamão, planta nativa }\end{array}$ \\
\hline 68 & $\begin{array}{l}22^{\circ} 42^{\prime} 20.3^{\prime \prime S}, \\
47^{\circ} 38^{\prime} 37.6^{\prime \prime W}, 525\end{array}$ & $68-24: 320$ & Colônia do CENA & Manga, abacate, mamão, citros \\
\hline 69 & $\begin{array}{l}22^{\circ} 42^{\prime} 23.1^{\prime \prime S}, \\
47^{\circ} 38^{\prime} 17.4^{\prime \prime}, 533\end{array}$ & 69-75: 1000 & $\begin{array}{l}\text { Entre a biblioteca central e } \\
\text { Dep. Genética }\end{array}$ & Manga, goiaba \\
\hline 70 & $\begin{array}{l}22^{\circ} 42^{\prime} 19.1^{\prime \prime S} \\
47^{\circ} 38^{\prime} 00.4^{\prime \prime W}, 668\end{array}$ & $70-30: 180$ & $\begin{array}{l}\text { Pomar do Lab. Tecnologia } \\
\text { do Açúcar e Álcool }\end{array}$ & Manga, várias frutíferas \\
\hline 71 & $\begin{array}{l}22^{\circ} 42^{\prime} 46.6^{\prime \prime S} \\
47^{\circ} 37^{\prime} 57.5^{\prime \prime}, 486\end{array}$ & $71-64: 280$ & Quadra de tênis da Esalq & $\underline{\text { Planta nativa }}$ \\
\hline 72 & $\begin{array}{l}22^{\circ} 42^{\prime} 17.6^{\prime \prime S} \\
47^{\circ} 37^{\prime} 08.0^{\prime \prime} \mathrm{W}, 332\end{array}$ & $72-46: 560$ & Estrada para Monte Alegre & $\underline{\text { Planta nativa }}$ \\
\hline 73 & $\begin{array}{l}22^{\circ} 42^{\prime} 09.1^{\prime \prime S} \\
47^{\circ} 37^{\prime} 53.4^{\prime \prime W}, 581\end{array}$ & 73 - 28: 10 & $\begin{array}{l}\text { Alameda de eucaliptos (rio } \\
\text { Pisca) }\end{array}$ & $\underline{\text { Eucaliptos, mata ciliar }}$ \\
\hline 74 & $\begin{array}{l}22^{\circ} 41^{\prime} 44.0^{\prime \prime S}, \\
47^{\circ} 37^{\prime} 59.9^{\prime \prime}, 599\end{array}$ & $74-34: 380$ & $\begin{array}{l}\text { Bambuzal próximo ao } \\
\text { confinamento do gado }\end{array}$ & Mata ciliar, jambolão \\
\hline 75 & $\begin{array}{l}22^{\circ} 42^{\prime} 26.5^{\prime \prime S}, \\
47^{\circ} 38^{\prime} 39.8^{\prime \prime} \mathrm{W}, 584\end{array}$ & $75-76: 60$ & Pátio do CENA & Abacate, citros, nêspera \\
\hline 76 & $\begin{array}{l}22^{\circ} 42^{\prime} 21.8^{\prime \prime S}, \\
47^{\circ} 38^{\prime} 44.5^{\prime \prime}, 513\end{array}$ & $76-68: 40$ & Oficina do CENA & $\underline{\text { Serigüela }}$ \\
\hline 77 & $\begin{array}{l}22^{\circ} 42^{\prime} 29.7^{\prime \prime} \mathrm{S} \\
47^{\circ} 38^{\prime} 35.8^{\prime \prime} \mathrm{W}, 525\end{array}$ & $77-67: 240$ & Entrada do CENA & $\underline{\text { Nêspera, plantas nativas }}$ \\
\hline 78 & $\begin{array}{l}22^{\circ} 42^{\prime} 12.0^{\prime \prime S}, \\
47^{\circ} 38^{\prime} 18.1^{\prime \prime W}, 573\end{array}$ & $78-32: 200$ & Dep. Genética & Mata ciliar \\
\hline 79 & $\begin{array}{l}22^{\circ} 42^{\prime} 02.6^{\prime \prime S} \\
47^{\circ} 38^{\prime} 47^{\circ} .1^{\prime \prime W}, 743\end{array}$ & 79 - 76: 900 & Faz. Areão & Manga, plantas nativas \\
\hline 80 & $\begin{array}{l}22^{\circ} 42^{\prime} 08.3^{\prime \prime S}, \\
47^{\circ} 38^{\prime} 06.6^{\prime \prime W}, 721\end{array}$ & $80-25: 120$ & $\begin{array}{l}\text { Cultura de café, cacau e } \\
\text { seringueira }\end{array}$ & Café, cacau \\
\hline 81 & $\begin{array}{l}22^{\circ} 42^{\prime} 50.6^{\prime \prime S}, \\
47^{\circ} 37^{\prime} 50.2^{\prime \prime W}, 563\end{array}$ & $81-60: 280$ & Museu & $\begin{array}{l}\text { Goiaba, acerola, jabuticaba, uva, } \\
\text { mamão, lima, tangerina, café, planta } \\
\text { nativa }\end{array}$ \\
\hline 82 & $\begin{array}{l}22^{\circ} 42^{\prime} 24.2^{\prime \prime S}, \\
47^{\circ} 37^{\prime} 45.2^{\prime \prime} \mathrm{W}, 376\end{array}$ & $82-83: 40$ & Horta do Dep. Horticultura & Várias frutíferas, uvaia \\
\hline
\end{tabular}


Tabela 1. Localização e caracterização dos pontos de coleta estabelecidos no campus Luiz de Queiroz, Piracicaba, SP.

\begin{tabular}{lllll}
\hline$N^{o}$ & $\begin{array}{l}\text { Latitude }(\mathrm{S}), \text { longitude } \\
\text { (W) e altitude }(\mathrm{m})\end{array}$ & Distância $(\mathrm{m})$ & Local & Vegetação* $^{*}$ \\
\hline 83 & $\begin{array}{l}22^{\circ} 42^{\prime} 26.7^{\prime \prime} \mathrm{S}, \\
47^{\circ} 37^{\prime} 39.0^{\prime \prime} \mathrm{W}, 651\end{array}$ & $83-84: 60$ & Horta do Dep. Horticultura & Várias frutíferas, planta nativa \\
84 & $22^{\circ} 42^{\prime} 27.0^{\prime \prime} \mathrm{S}$, & $84-17: 120$ & Horta do Dep. Horticultura & Planta nativa, várias frutíferas \\
& $47^{\circ} 37^{\prime} 44.3^{\prime \prime} \mathrm{W}, 420$ & & & \\
\hline
\end{tabular}

*As plantas sublinhadas correspondem às árvores nas quais foram instaladas as armadilhas.

O material coletado foi levado ao laboratório da Seção de Entomologia do CENA, onde os frutos de cada amostra foram separados, colocados em bandejas com vermiculita para servir de substrato para empupação e cobertas com tecido de algodão para evitar reinfestação. O substrato foi peneirado e os pupários separados e mantidos em gaiolas até a emergência dos adultos. Os espécimens obtidos foram quantificados e as fêmeas isoladas e preservadas em frascos de vidro contendo etanol $70 \%$ para posterior identificação das espécies. Nesse estudo analisou-se apenas o aspecto qualitativo da relação fruto e espécie de Anastrepha, de modo que os índices de infestação dos frutos não foram estabelecidos.

A identificação específica de Anastrepha foi feita através das fêmeas, baseada principalmente no ápice do acúleo utilizando-se chaves de identificação (Lima, 1934; Stone, 1942; Steyskal, 1977; Zucchi, 1978, 2000a; Norrbom, 1985).

Os espécimes voucher foram depositados na coleção do Departamento de Entomologia, Fitopatologia e Zoologia Agrícola da ESALQ/USP, Piracicaba, SP.

\subsection{Ilustrações}

Uma chave para identificação das espécies de Anastrepha registradas no campus foi elaborada e os caracteres diagnósticos mais importantes foram ilustrados. As asas dos espécimens analisados foram montadas em Permount ${ }^{\circledR}$ entre lâmina e lamínula de vidro, 
após serem desidratadas e limpas em xilol. Asas, mesoescutos, mediotergitos e abdome foram observados em estereomicroscópio e as imagens captadas por uma câmera digital Leica ${ }^{\circledR}$ mod. DC 100 acoplada a um computador. Os acúleos foram extrovertidos, mantidos em etanol puro e desidratados no ponto crítico Balzers ${ }^{\circledR}$ mod. CPD 030. Logo após esta operação, foram montados sobre fita adesiva de dupla face colada em stubs, de modo que o eixo mais longo dos acúleos ficasse perpendicular em relação à superfície do stub. Subseqüentemente foram metalizados no sputtering Balzers ${ }^{\circledR}$ mod. SCD 050 e fotografados em microscópio eletrônico de varredura Zeiss ${ }^{\circledR}$ mod. DSM 940.

\subsection{Análise faunística}

A análise faunística das espécies de Anastrepha foi elaborada baseando-se em Silveira Neto et al. (1976), Krebs (1978) e Ludwig \& Reynolds (1988). Foram estimados os seguintes parâmetros:

- Frequiência: $p_{i}=\frac{n_{i}}{N}$, onde $n_{i}$ : número de indivíduos da espécie i e $N$ : total de indivíduos da amostra. É a proporção de indivíduos de uma espécie em relação ao total de indivíduos da amostra.

- Constância: Porcentagem de amostras em que uma determinada espécie esteve presente. $C=\frac{p \cdot 100}{N}$, onde p: número de amostras com a espécie e N: número total de amostras tomadas. Classificação das espécies quanto à constância:

- Espécie constante: presente em mais de 50\% das amostras

○ Espécie acessória: presente em 25-50\% das amostras

- Espécie acidental: presente em menos de $25 \%$ das amostras

- Riqueza (S): Número total de espécies observadas na comunidade. 
- Número de espécies dominantes: Uma espécie é considerada dominante quando apresenta frequiência superior a $1 / \mathrm{S}$, onde $\mathrm{S}$ é o número total de espécies na comunidade.

- Índice de Simpson: É um índice de dominância e reflete a probabilidade de que dois indivíduos escolhidos ao acaso na comunidade pertençam à mesma espécie. Este índice varia de 0 a 1 e quanto mais alto o valor do índice de Simpson, maior a probabilidade de ambos serem da mesma espécie, ou seja, maior a dominância e menor a diversidade. É calculado como: $\lambda=\sum_{1}^{S} p_{i}^{2}$, onde $p_{i}$ : proporção de cada espécie, para i variando de 1 a $S$ (Riqueza); e $p_{i}$ : frequiência da espécie $i$.

- Índice de Shannon: Mede o grau de incerteza em prever a que espécie pertencerá um indivíduo escolhido, ao acaso, de uma amostra com $\mathrm{S}$ espécies e $\mathrm{N}$ indivíduos. Quanto menor o valor do índice de Shannon, menor o grau de incerteza e portanto, diversidade da amostra baixa. A diversidade tende a ser mais alta quanto maior o valor do índice. É calculado por meio da fórmula $H^{\prime}=-\sum_{1}^{S}\left(p_{i} \cdot \ln p_{i}\right)$, onde pi: freqüência de cada espécie, para i variando de 1 a S (Riqueza).

- Índice de Hill modificado: É um índice de eqüitatividade, que refere à distribuição da abundância das espécies, ou seja, a maneira pela qual a abundância (por exemplo, número de indivíduos) está distribuída entre as espécies de uma comunidade. Quando todas as espécies numa amostra são igualmente abundantes, o índice de eqüitatividade deve assumir o valor máximo e decresce tendendo a zero à medida em que as abundâncias relativas das espécies divergirem desta igualdade. Ele tem como parâmetros os índices de Simpson e Shannon: $E=\left\lfloor\frac{1}{\lambda}-1\right\rfloor / e^{H^{\prime}}-1$, onde $\lambda$ : Índice de Simpson e H' = Índice de Shannon 


\subsection{Flutuação populacional}

Foram analisadas as flutuações populacionais do total de fêmeas de Anastrepha e das espécies mais abundantes capturadas nas 84 armadilhas tipo McPhail distribuídas no campus. A variação sazonal das populações foi elaborada considerando-se o número total de fêmeas capturadas mensalmente. Esse valor foi obtido somando-se os números de fêmeas (valores absolutos) capturadas em todas as armadilhas nas quatro semanas de cada mês.

A flutuação populacional foi analisada em relação às variáveis climáticas (temperatura máxima, mínima e média; precipitação pluviométrica; umidade relativa e velocidade média do vento) e ao período de frutificação dos hospedeiros primários das espécies mais abundantes. Os dados meteorológicos foram obtidos do Departamento de Ciências Exatas/Esalq (2001) e as informações sobre a fenologia dos hospedeiros foram baseadas em Lorenzi (1992), Souza Filho (1999) e Rodrigues (1996). 


\section{RESULTADOS E DISCUSSÃO}

\subsection{Levantamento das espécies de Anastrepha e chave de identificação}

Foram examinadas 23.263 fêmeas de Anastrepha coletadas em armadilhas tipo McPhail no período de 12 meses. Foram identificadas 18 espécies em 9 grupos infragenéricos, segundo a classificação de Norrbom et al. (1999). Os grupos daciformis, punctata, leptozona, grandis, serpentina e striata foram representados por apenas uma espécie, o grupo pseudoparallela por duas, o grupo spatulata por três e fraterculus foi o grupo mais representado com oito espécies (Tabela 2).

Tabela 2. Espécies de Anastrepha capturadas em armadilhas McPhail no campus Luiz de Queiroz, Piracicaba, SP, julho/1998 - junho/99.

\begin{tabular}{ll}
\hline Grupo & Espécies \\
\hline daciformis & A. daciformis Bezzi \\
fraterculus & A. amita Zucchi \\
& A. barbielinii Lima \\
& A. distincta Greene \\
A. fraterculus (Wiedemann) & A. obliqua (Macquart) \\
A. sororcula Zucchi \\
grandis & A. zenildae Zucchi \\
leptozona & A. grandis (Macquart) \\
pseudoparallela & A. leptozona Hendel \\
& A. dissimilis Stone \\
punctata & A. pseudoparallela (Loew) \\
serpentina & A. punctata Hendel \\
spatulata & A. serpentina (Wiedemann) \\
& A. manihoti Lima \\
striata & A. montei Lima \\
& A. pickeli Lima \\
& A.bistrigata Bezzi
\end{tabular}


Dentre as 35 espécies de Anastrepha registradas no Estado de São Paulo (Souza Filho et al., 2000) aproximadamente 50\% foram detectadas neste estudo, elevando para 18 o número de espécies registradas no município de Piracicaba.

A partir dos dados de coletas em armadilhas e de amostras de frutos ao longo de um ano no município de Piracicaba, SP, Arrigoni (1984) identificou 9 espécies: $A$. barbiellinii Lima, A. bistrigata Bezzi, A. daciformis Bezzi, A. distincta Greene, A. fraterculus (Wiedemann), A. montei Lima, A. pseudoparallela (Loew), A. serpentina (Wiedemann) e A. sororcula Zucchi. Em levantamento de 3 anos, realizado em 12 municípios de São Paulo, Calza et al. (1988) obtiveram 11 espécies de Anastrepha. Raga et al. (1996) detectaram 9 espécies de Anastrepha em pomar de citros em Presidente Prudente, SP, em coletas com armadilhas efetuadas durante 2 anos. A ocorrência de maior riqueza específica de Anastrepha no campus Luiz de Queiroz pode ser atribuída à grande diversidade de espécies de plantas cultivadas na área (observadas, pelo menos, 53), muitas das quais consideradas hospedeiros primários de moscas-dasfrutas, além de plantas nativas.

Zucchi (2000a) apresentou os principais caracteres taxonômicos para identificação das espécies de Anastrepha, salientando que o aspecto geral do ápice do acúleo é o mais importante para a identificação específica e que alguns caracteres podem apresentar variações intraespecíficas. Os exemplares obtidos neste trabalho, em geral, eram monomórficos, obedecendo o padrão apresentado nas descrições das espécies, com exceção de $A$. fraterculus, que apresentou variações na asa (coloração geral, as faixas e o tamanho) e no ápice do acúleo (ver a chave ilustrada), como observado por vários autores (Bezzi, 1909; Stone, 1942; Araujo, 1997). 
Chave ilustrada para a identificação das espécies de Anastrepha registradas no campus Luiz de Queiroz/USP

1) Asa com faixa costal estendendo-se por toda margem anterior, sem área hialina distinta no ápice da nervura $\mathrm{R}_{1}$ 2

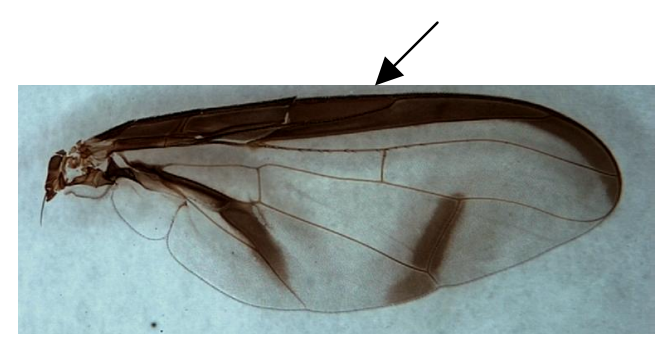

Asa com faixa costal interrompida próximo ao ápice da nervura $\mathrm{R}_{1}$ 3

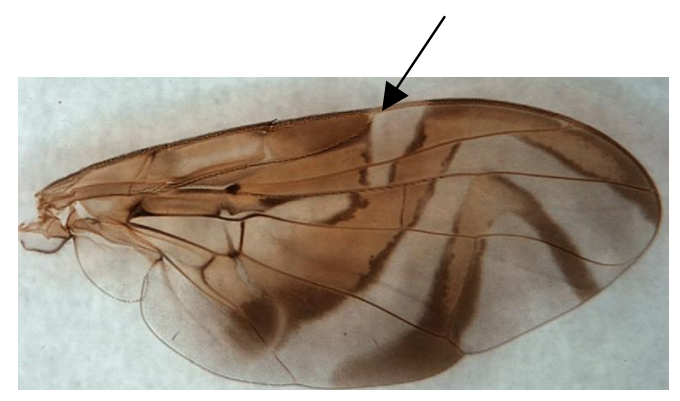

2) Faixa $S$ ausente; coloração geral escura; mesonoto com faixas claras presuturais dorsocentrais isoladas; ápice do acúleo com pequenos dentes

A. daciformis Bezzi
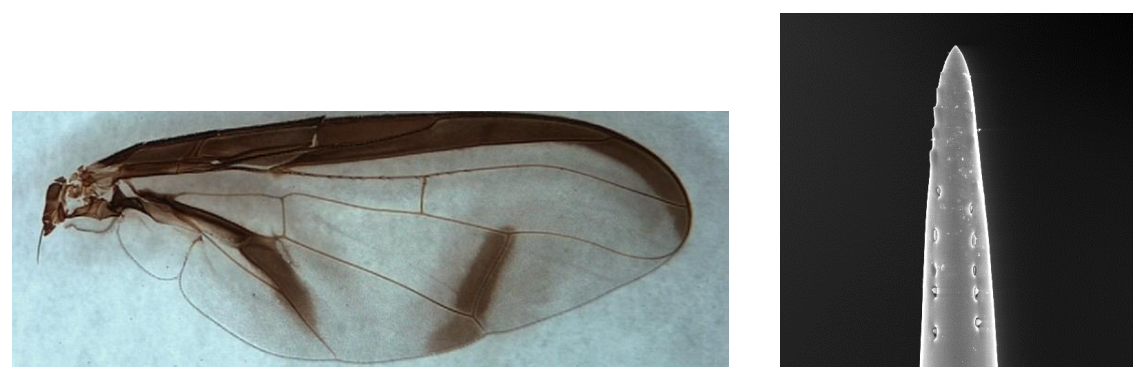
Faixa S da asa presente; coloração geral amarelada; mesonoto com faixas negras sublaterais interrompidas na sutura transversa; ápice do acúleo sem dentes A. grandis (Macquart)
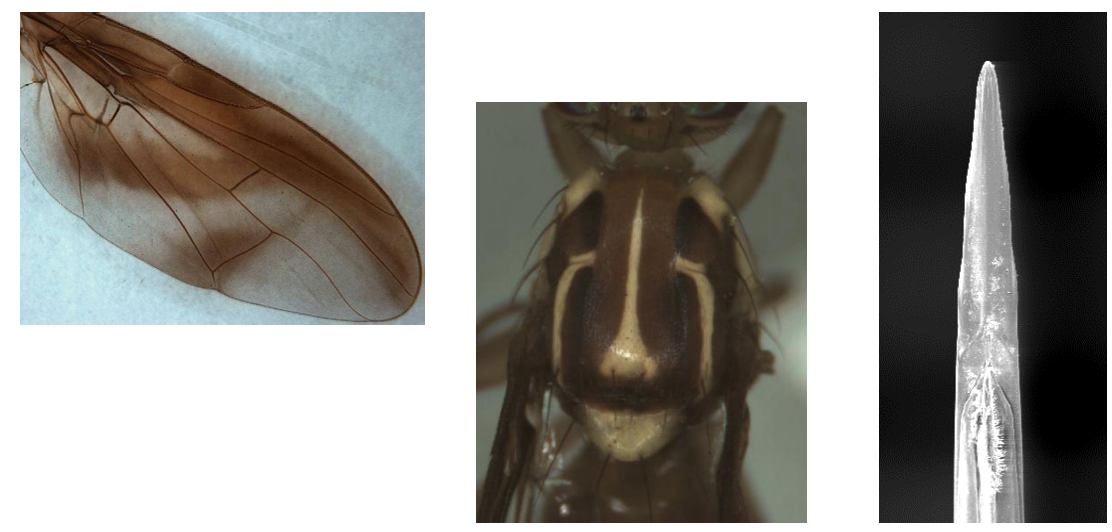

3) Mesonoto com duas manchas circulares escuras na margem posterior; sintergosternito 7 com menos de 2,0 mm de comprimento

A. punctata Hendel

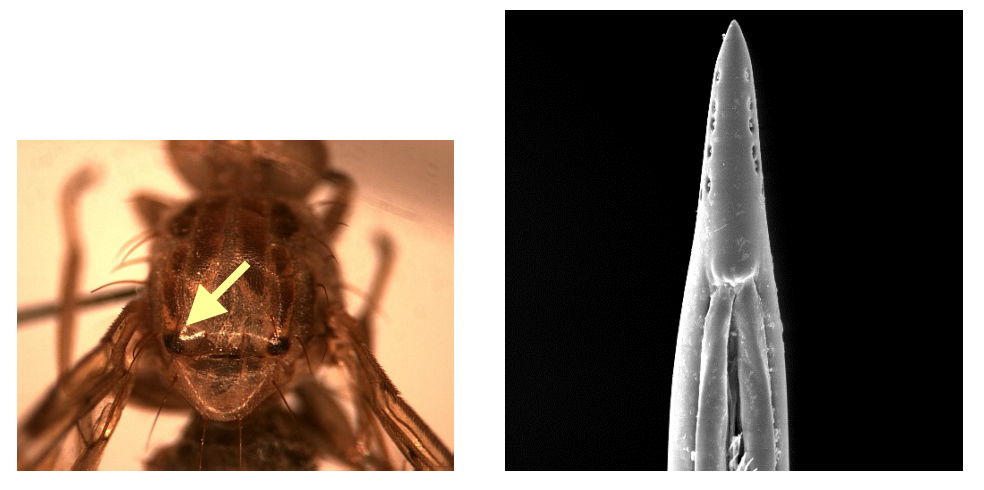

Mesonoto sem manchas circulares na margem posterior 4

4) Acúleo com menos de $0,07 \mathrm{~mm}$ de largura; ápice do acúleo sem dentes A. montei Lima
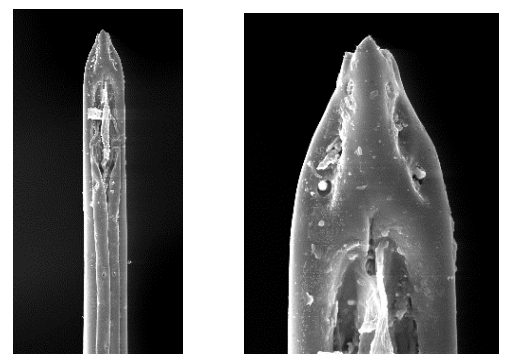
Acúleo com mais de 0,07 mm de largura 5

5) Mesonoto e abdome escuros; mesonoto com faixas mediana e sublaterais amareladas; abdome com uma faixa dorsal amarela; asa com a faixa $\mathrm{V}$ apenas com o ramo proximal; ápice do acúleo com dentes pequenos em mais da metade apical A. serpentina (Wiedemann)
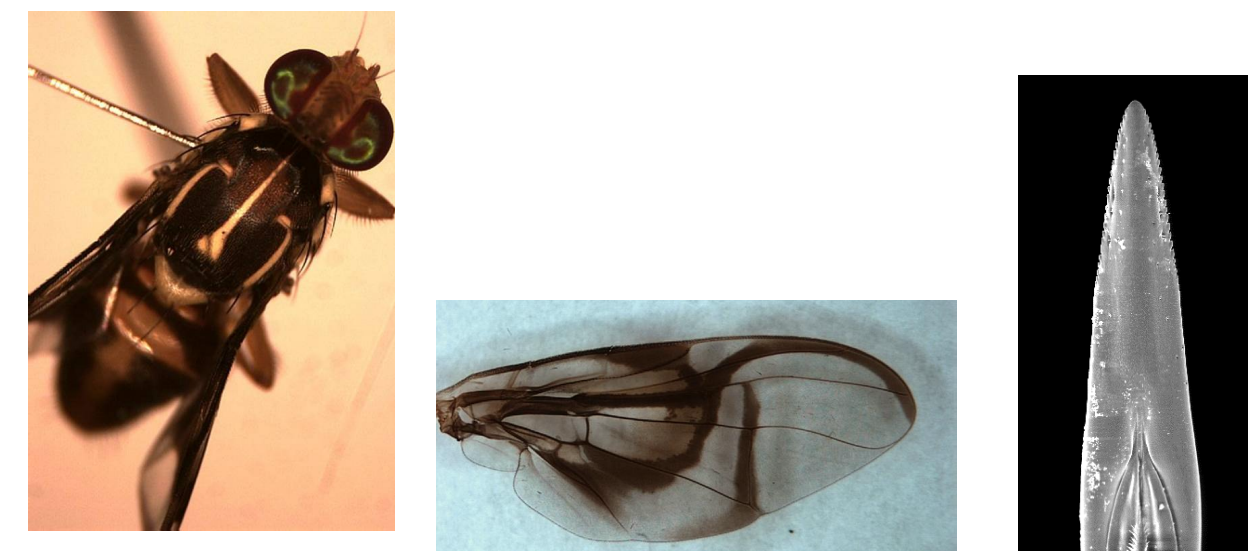

Mesonoto e abdome predominantemente amarelados 6

6) Mesonoto com faixas negras longitudinais sublaterais; acúleo com mais de 3,0 mm de comprimento e com o ápice arredondado e sem dentes

A. bistrigata Bezzi
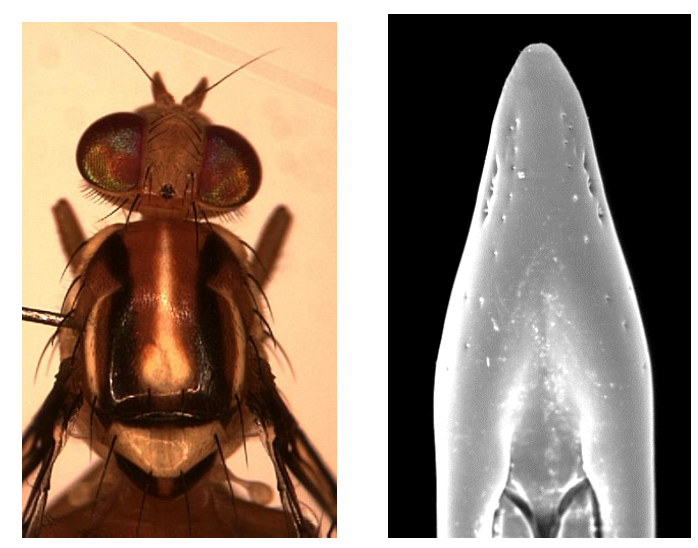
Mesonoto sem faixas negras longitudinais

7) Mediotergito e subescutelo sem faixas escuras laterais ........................................ 8

Mediotergito e/ou subescutelo com faixas escuras laterais ..................................14

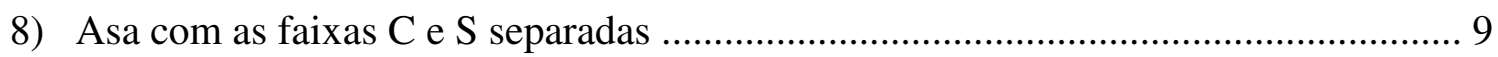

Asa com as faixas C e S unidas ...................................................................... 10

9) Asa com a nervura $M$ acentuadamente curvada atingindo a faixa $S$; faixa $V$ incompleta, às vezes apenas com o ramo proximal

A. leptozona Hendel
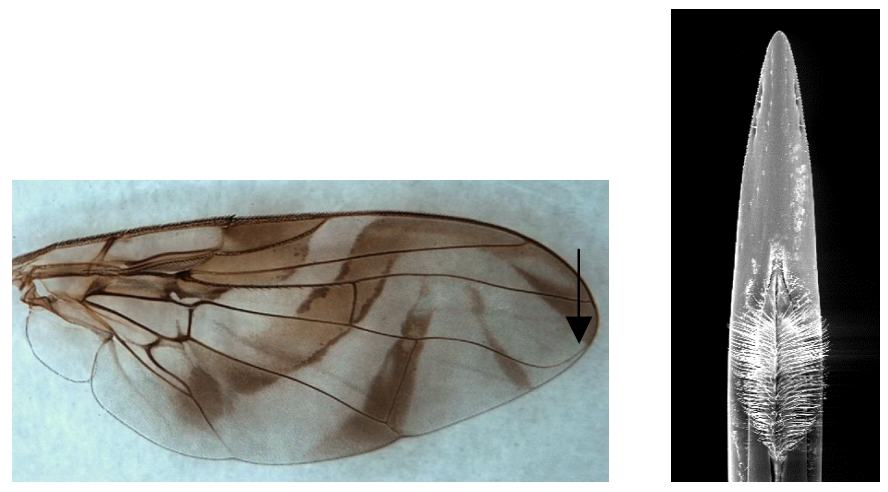

Asa com a nervura $\mathrm{M}$ não atingindo a faixa $\mathrm{S}$; faixa $\mathrm{V}$ completa

A. dissimilis Stone
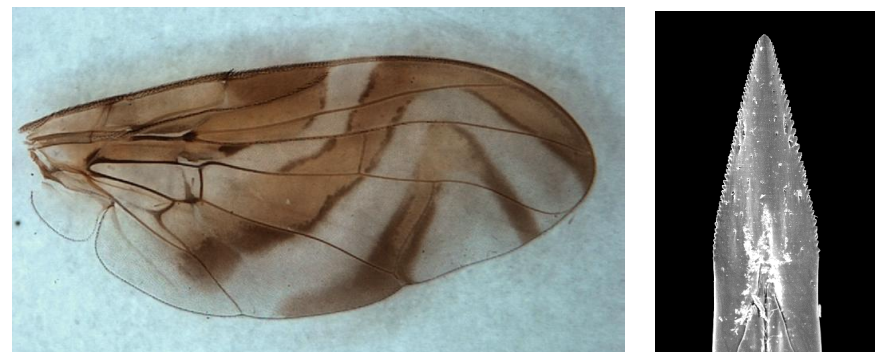

10) Ápice do acúleo com dentes estendendo-se além do nível da abertura cloacal 
Ápice do acúleo com dentes que não se estendem além do nível da abertura cloacal .12

11) Ápice do acúleo com constrição evidente antes da serra A. manihoti Lima
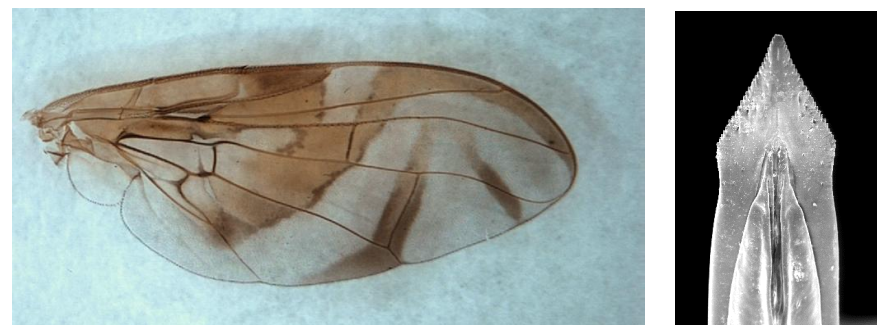

Ápice do acúleo sem constrição antes da serra

A. pickeli Lima
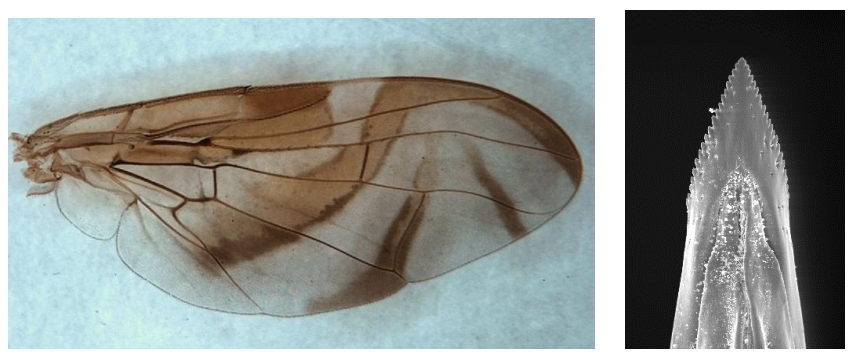

12) Ápice do acúleo com dentes sobre quase toda a sua extensão; alguns dentes mais internos A. pseudoparallela (Loew)
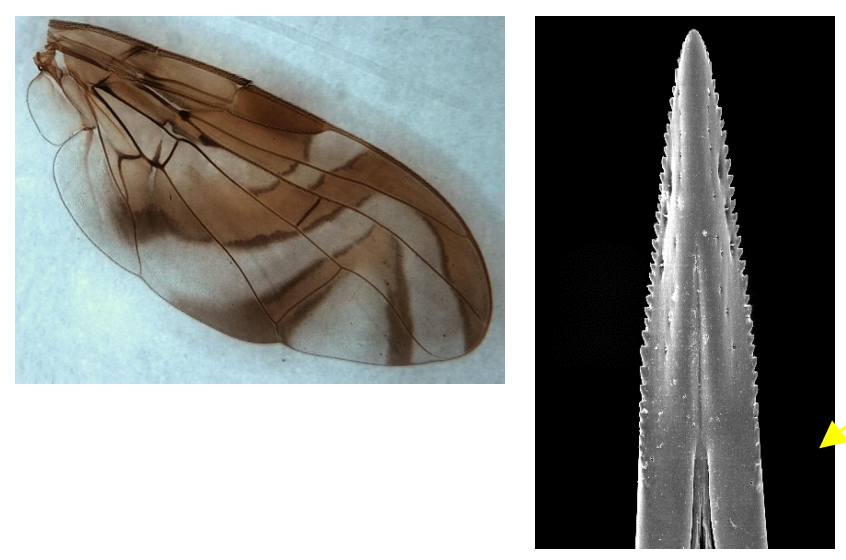

Ápice do acúleo com dentes sobre menos da metade apical 13 
13) Ápice do acúleo afilando gradativamente até a extremidade e com dentes sobre $1 / 5$ apical

A. barbiellinii Lima
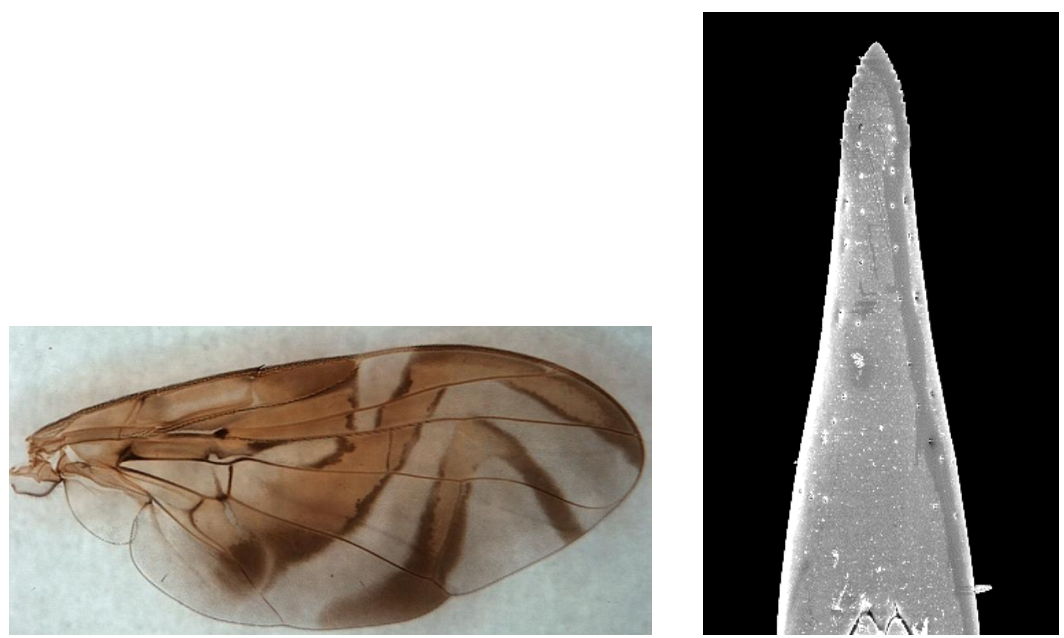

Ápice do acúleo aproximadamente com a mesma largura em toda sua extensão com dentes arredondados e pouco salientes sobre $2 / 5$ apical A. amita Zucchi
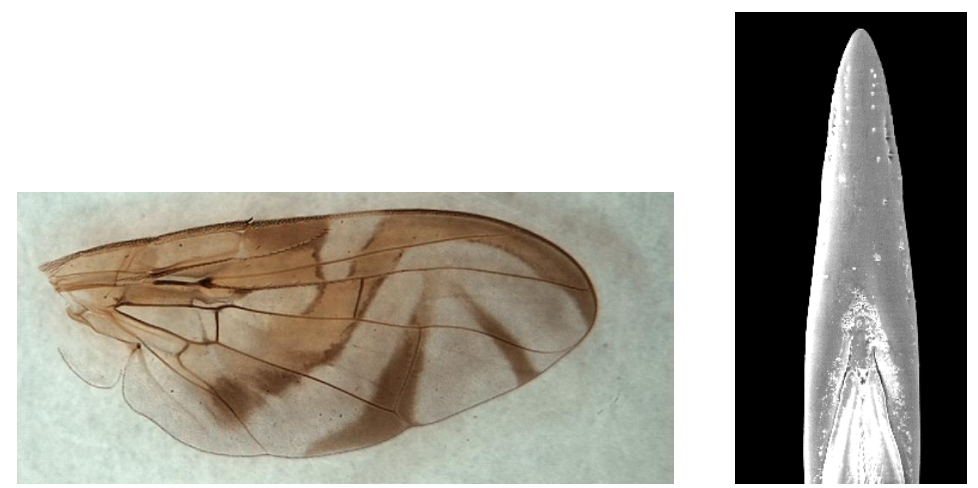

14) Ápice do acúleo com dentes sobre menos da metade apical 15 Ápice do acúleo com dentes sobre pelo menos a metade apical 16

15) Ápice do acúleo afilando gradativamente até a extremidade e com mais de $2,0 \mathrm{~mm}$ de comprimento A. distincta (Greene) 


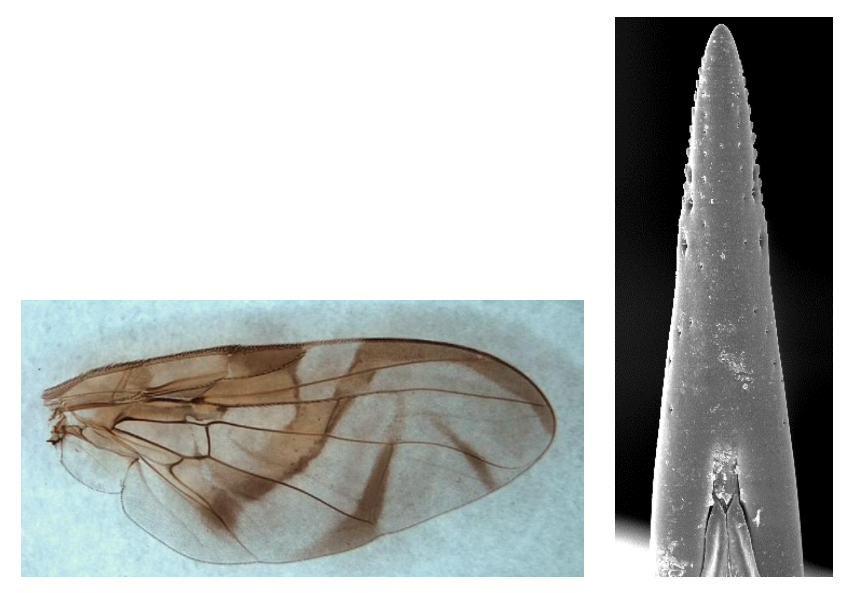

Ápice do acúleo com a extremidade não afilada e com 1,8 mm de comprimento; dentes do ápice pouco salientes e arredondados A. amita Zucchi

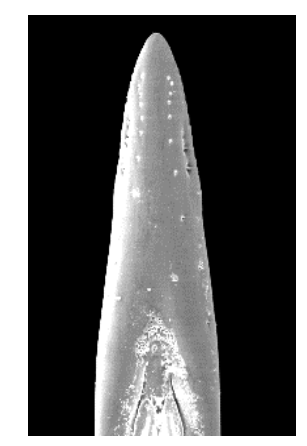

16) Subescutelo sem manchas laterais; faixa $V$ da asa, em geral, pouco nítida no vértice; ápice do acúleo com dentes agudos sobre mais da metade apical
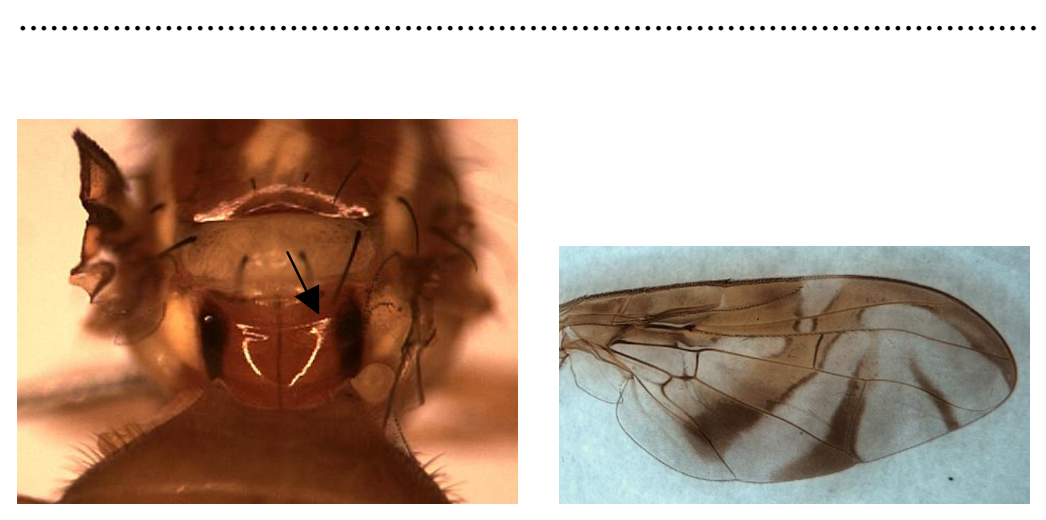

A. obliqua (Macquart)

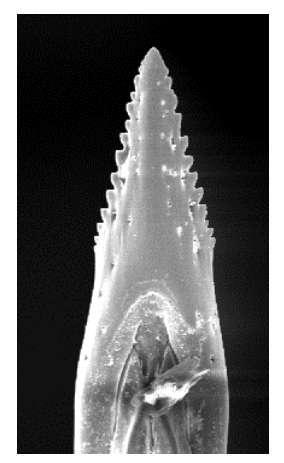


Subescutelo com manchas laterais

17) Ápice do acúleo com discreta constrição antes da serra, com $0,30-0,34 \mathrm{~mm}$ de comprimento e com mais de 12 dentes sobre $2 / 3$ apical A. zenildae Zucchi
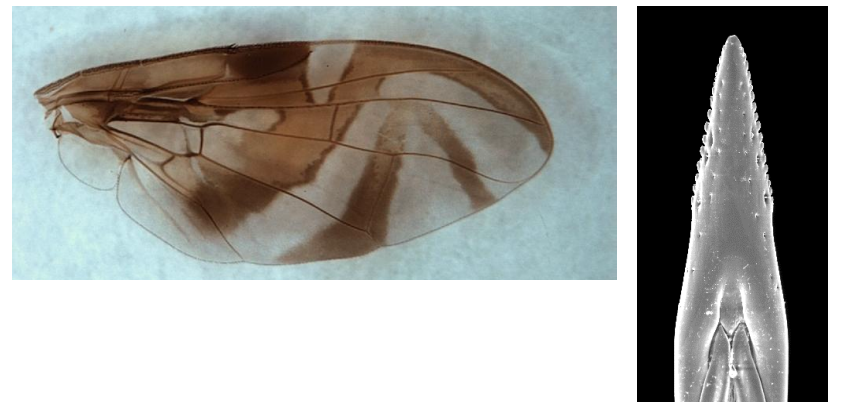

Ápice do acúleo com nítida constrição antes da serra, com no máximo $0,30 \mathrm{~mm}$ de comprimento e com 12 ou menos dentes na serra

18) Faixa V, em geral, completa; ápice do acúleo afilado, com $0,21-0,30 \mathrm{~mm}$ de comprimento e com dentes sobre a metade apical. A. fraterculus (Wiedemann)
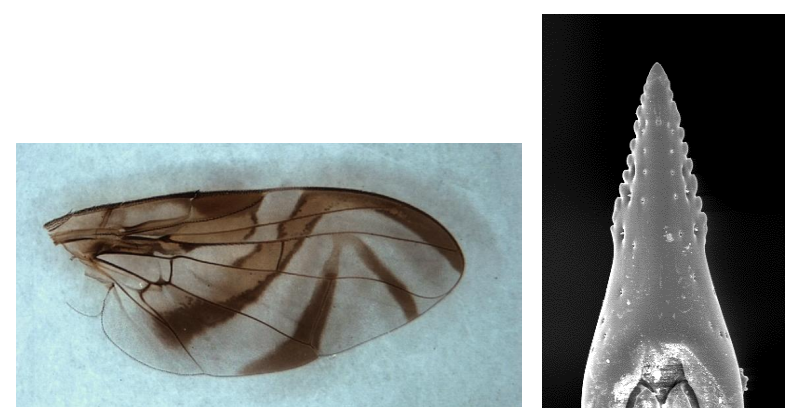

Faixa $\mathrm{V}$, em geral, incompleta (pouco nítida no vértice); ápice do acúleo curto e largo com 0,18- 0,22 mm de comprimento e com dentes arredondados sobre mais da metade apical A. sororcula Zucchi
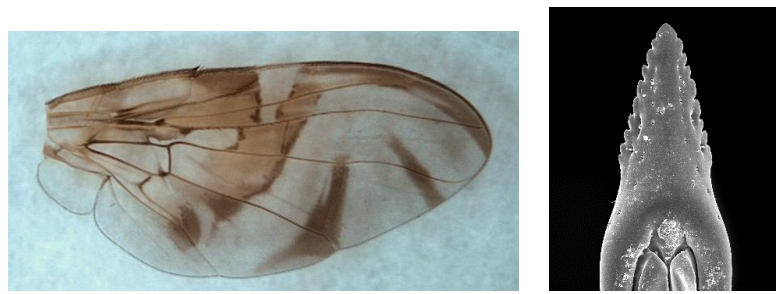


\subsection{Análise quantitativa e distribuição da população de Anastrepha}

A análise das coletas obtidas do conjunto das armadilhas demonstrou que a distribuição das fêmeas por armadilha foi fortemente agregada, com 5 armadilhas (6\%) capturando $50 \%$ do total de fêmeas. Um total de 34 armadilhas (40,5\%) capturou 90\% das fêmeas e as 50 remanescentes $(49,5 \%)$ coletaram apenas $10 \%$ do total das fêmeas. A figura 3 mostra o agrupamento das armadilhas de acordo com o número de fêmeas capturadas. As armadilhas foram separadas segundo os critérios descritos abaixo. O número entre parênteses representa o total de armadilhas em cada condição: grupo 1 (vermelho) armadilhas que capturaram mais de 800 fêmeas (3); grupo 2 (laranja) armadilhas que capturaram entre 401 e 800 fêmeas (9); grupo 3 (verde) armadilhas que capturaram entre 201 e 400 fêmeas (14); grupo 4 (azul) armadilhas que capturaram entre 101 e 200 fêmeas (11); grupo 5 (preto) armadilhas que capturaram menos de 100 fêmeas (47).

As estações de coleta do grupo 1 (5, 27 e 82) foram estabelecidas em áreas de grande oferta de frutos de um hospedeiro adequado para A. fraterculus, possivelmente jabuticabeira, uma vez que este hospedeiro ocorria naqueles locais de coleta. Sobretudo a armadilha 5, que foi instalada em um pomar de jabuticabeiras, determinando capturas

elevadas de A. fraterculus e contribuindo significativamente para o aumento no total geral dos exemplares coletados. 


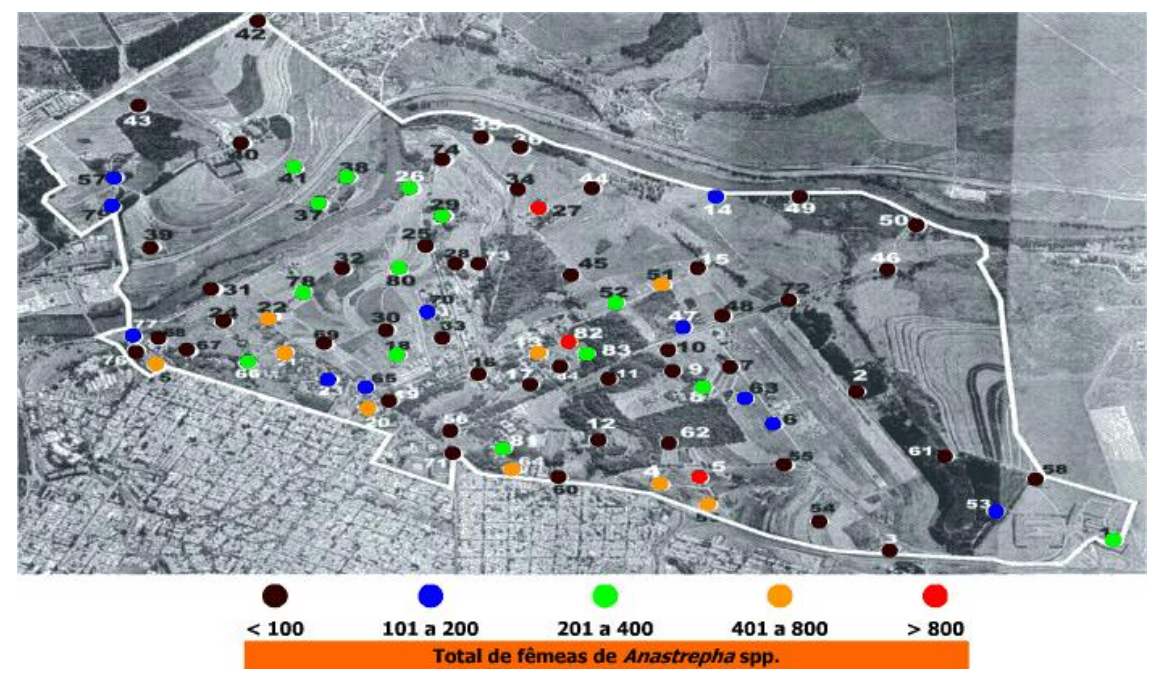

Figura 3 - Agrupamento das armadilhas de acordo com o número de fêmeas de Anastrepha capturadas no campus Luiz de Queiroz/USP, Piracicaba, SP, no período de julho/1998 a junho/1999.

As armadilhas dos grupos 2, 3 e 4 estavam instaladas em áreas com diversas espécies de árvores frutíferas ou próximas daquelas em que as capturas foram relativamente altas, provavelmente, influindo nas capturas das armadilhas adjacentes pela alta abundância de moscas nestes locais.

Os índices faunísticos para as 84 armadilhas tomadas em conjunto estão resumidos na tabela 4. As armadilhas com menores capturas (menos de 42 fêmeas) foram, na maioria, aquelas estabelecidas em locais com vegetação formada por mata ciliar, pastagens ou plantas nativas provavelmente inadequadas como hospedeiras de moscas-das-frutas. Em algumas estações de coleta não se verificou a relação da diversidade de hospedeiros com a riqueza de espécies de Anastrepha, como a armadilha 19, que apresentou valores relativamente baixos com relação ao número de fêmeas capturadas (86) e diversidade de espécies (3), embora a diversidade de árvores frutíferas cultivadas no local fosse grande. Cuidados culturais são sistematicamente aplicados naquele local deixando a área limpa e livre de frutos caídos no solo, eliminando os sítios de oviposição para as moscas-das-frutas e diminuindo assim sua população. É possível 
que estes cuidados culturais tenham contribuído para os baixos valores de captura e de diversidade específica. A armadilha 51 apresentou a maior riqueza de espécies (13) e número relativamente alto (637) de fêmeas capturadas, apesar da baixa diversidade de frutíferas cultivadas e do local ser circundado em grande proporção por mata ciliar e plantas nativas. As armadilhas 32 e 43, instaladas em uma plantação de seringueiras e em mata ciliar, respectivamente, capturaram número baixo de fêmeas, entretanto apresentaram valores relativamente altos de riqueza específica.

Tabela 4. Análise faunística das espécies de Anastrepha capturadas no campus Luiz de Queiroz, Piracicaba, SP, julho/1998 junho/1999.

\begin{tabular}{lr}
\hline Parâmetros & \\
\hline Riqueza (S) & 18 \\
Índice de Simpson & 0,660 \\
Índice de Shannon & 0,7521 \\
Índice de Hill modificado (eqüitatividade) & 0,459 \\
& \\
Número de espécies: & \\
Dominantes & 2 \\
Não-dominantes & 16 \\
& \\
Número de espécies: & \\
Constantes & 6 \\
Acessórias & 4 \\
Acidentais & 8 \\
\hline
\end{tabular}

A análise por armadilha das relações entre a dinâmica populacional das espécies de Anastrepha e as características dos locais carece de dados conclusivos. Uma análise holística da área seria mais consistente, uma vez que, levando-se em consideração a pequena distância entre as armadilhas, no máximo $=1.460 \mathrm{~m}$, qualquer característica local poderia influir não apenas nas coletas em uma armadilha mas também em armadilhas adjacentes, apesar de estarem instaladas em microhabitáts diversos. Portanto, em geral, a distribuição agregada das espécies de Anastrepha no campus parece ter 
ocorrido em função da presença de plantas hospedeiras em determinados locais. Segundo Vargas et al. (1990), o número de adultos de tefritídeos capturados em uma armadilha também é influenciado pelo tipo de vegetação em que a armadilha está instalada.

Dentre as 18 espécies detectadas no campus, apenas A. fraterculus e A. obliqua foram espécies dominantes (Tabela 5).

Tabela 5. Freqüência, dominância e constância das espécies de Anastrepha capturadas em armadilhas tipo McPhail no campus Luiz de Queiroz, Piracicaba, SP, julho/1998 - junho/1999 (número de amostras: 51).

\begin{tabular}{|c|c|c|c|c|c|}
\hline Espécies de Anastrepha & $\mathrm{N}$ & Freqüuência (\%) & Dominância* & \multicolumn{2}{|c|}{ Constância\# } \\
\hline A. amita & 77 & 0,33 & $\mathrm{n}$ & 64,71 & $\mathrm{w}$ \\
\hline A. barbiellinii & 141 & 0,61 & $\mathrm{n}$ & 64,71 & w \\
\hline A. bistrigata & 491 & 2,11 & $\mathrm{n}$ & 94,12 & $\mathrm{w}$ \\
\hline A. daciformis & 10 & 0,04 & $\mathrm{n}$ & 11,76 & $\mathrm{z}$ \\
\hline A. dissimilis & 15 & 0,06 & $\mathrm{n}$ & 19,61 & $\mathrm{z}$ \\
\hline A. distincta & 22 & 0,09 & $\mathrm{n}$ & 17,65 & $\mathrm{z}$ \\
\hline A. fraterculus & 18.648 & 80,16 & $\mathrm{~d}$ & 98,04 & $\mathrm{w}$ \\
\hline A. grandis & 34 & 0,15 & $\mathrm{n}$ & 39,22 & $\mathrm{y}$ \\
\hline A. leptozona & 5 & 0,02 & $\mathrm{n}$ & 7,84 & $\mathrm{z}$ \\
\hline A. manihoti & 27 & 0,12 & $\mathrm{n}$ & 35,29 & $\mathrm{y}$ \\
\hline A. montei & 21 & 0,09 & $\mathrm{n}$ & 23,53 & $\mathrm{z}$ \\
\hline A. obliqua & 2.925 & 12,57 & $\mathrm{~d}$ & 96,08 & $\mathrm{w}$ \\
\hline A. pickeli & 22 & 0,09 & $\mathrm{n}$ & 27,45 & $\mathrm{y}$ \\
\hline A. pseudoparallela & 715 & 3,07 & $\mathrm{n}$ & 96,08 & w \\
\hline A. punctata & 3 & 0,01 & $\mathrm{n}$ & 3,92 & $\mathrm{z}$ \\
\hline A. serpentina & 35 & 0,15 & $\mathrm{n}$ & 21,57 & $\mathrm{z}$ \\
\hline A. sororcula & 71 & 0,31 & $\mathrm{n}$ & 41,18 & $\mathrm{y}$ \\
\hline A. zenildae & 1 & 0,004 & $\mathrm{n}$ & 0,00 & $\mathrm{z}$ \\
\hline
\end{tabular}

A. fraterculus foi mais freqüente no campus representando $80,2 \%$ do total de fêmeas capturadas. Em ordem decrescente de freqüência, seguiram-se A. obliqua $(12,6 \%)$, A. pseudoparallela $(3,1 \%)$ e A. bistrigata $(2,1 \%)$. As demais espécies apresentaram freqüência menor que 1\% (Figura 4 e Tabela 5). Embora diversas espécies 
de Anastrepha estejam presentes num pomar, apenas uma ou duas representam mais de 90\% de todas as moscas coletadas em armadilhas (Aluja et a1., 1996). A. fraterculus e A. obliqua foram as duas espécies mais freqüentes no campus representando $92,8 \%$ do total de fêmeas capturadas. A alta dominância de apenas uma ou duas espécies também foi verificada em estudos similares conduzidos no Brasil (Nascimento \& Zucchi, 1981; Nascimento et al., 1983; Kovaleski, 1997; Veloso, 1997; Canal et al., 1998; Garcia \& Corseuil, 1998), na Costa Rica (Soto-Manitiú \& Jirón, 1989) e no México (Malo et al. 1987; Aluja et al., 1990; Celedonio-Hurtado et al., 1995).

Os maiores valores de constância (>90\%) nas amostras analisadas foram de $A$. fraterculus, A. obliqua, A. pseudoparallela e A. bistrigata. Além destas espécies, A. amita e A. barbiellinii foram constantes. As espécies acessórias foram A. grandis, A. manihoti, A. pickeli e A. sororcula e 8 espécies foram acidentais (A. daciformis, A. dissimilis, A. distincta, A. leptozona, A. montei, A. punctata, A. serpentina e A. zenildae) (Tabela 5).

Dentre as espécies acidentais, A. leptozona, A. punctata e A. zenildae foram aquelas que apresentaram os menores valores de constância revelando a ocorrência esporádica destas espécies no campus.

A. zenildae foi representada por apenas um exemplar, evidenciando o baixo nível populacional desta espécie no campus. É possível que este fato decorra da competição com A. fraterculus pelos hospedeiros comuns que exploram ou de A. zenildae não estar bem adaptada aos fatores abióticos da região, já que sua ocorrência tem sido rara nos levantamentos realizados no Estado de São Paulo.

Em estudo conduzido em Piracicaba, SP, Arrigoni (1984) concluiu que $A$. fraterculus foi mais freqüente, entretanto, com relação à constância foi espécie acessória. 

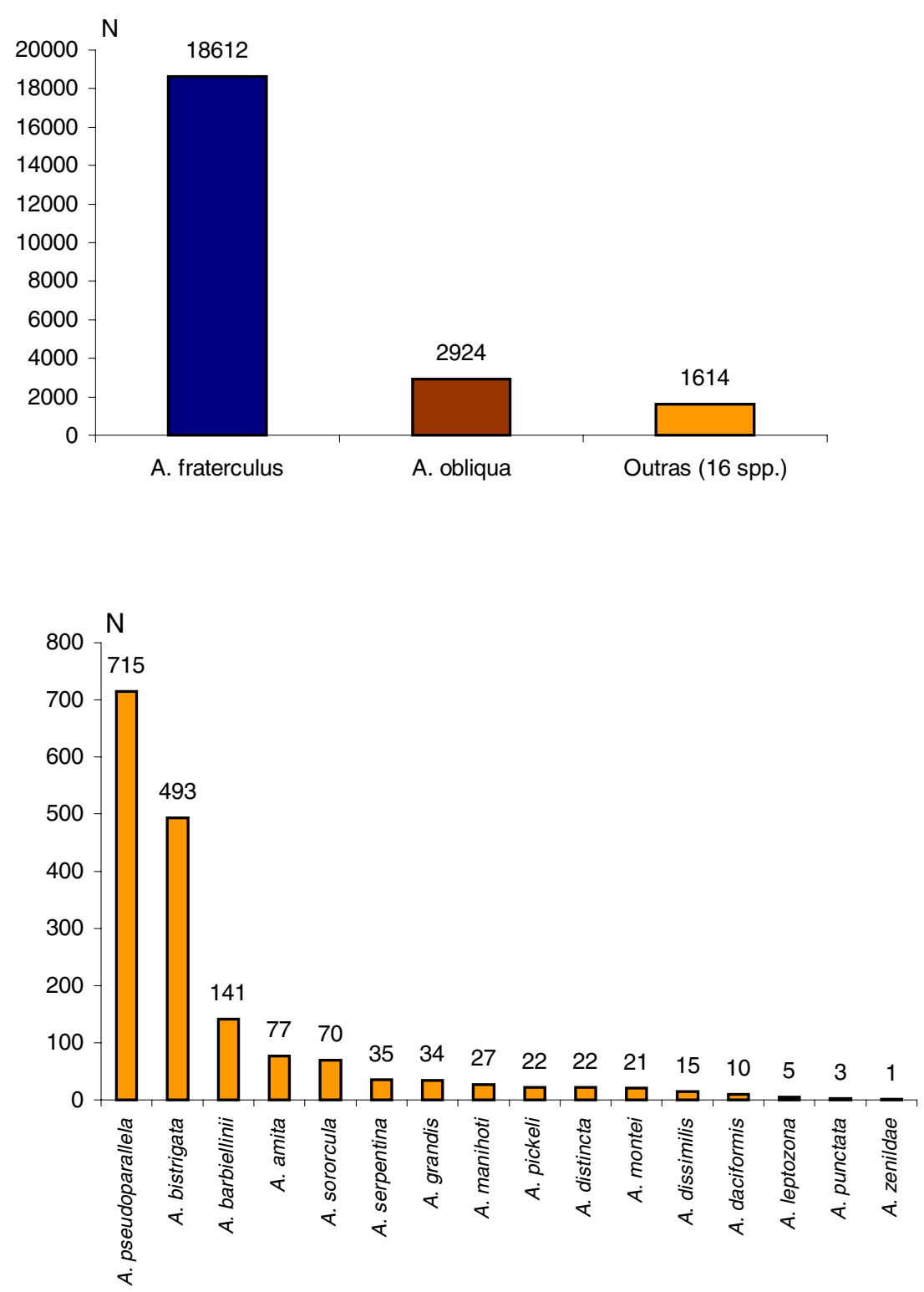

Figura 4 - Total de fêmeas de A. fraterculus, A. obliqua e outras 16 espécies capturadas em armadilhas tipo McPhail no campus Luiz de Queiroz/USP, Piracicaba, SP, no período de julho/1998 a junho/1999.

O número de espécies $(\mathrm{S}=18)$ registrado no campus foi relativamente alto quando comparado às riquezas específicas obtidas em outros levantamentos conduzidos em São Paulo (Arrigoni, 1984; Calza et al., 1988; Raga et al., 1996). Esse resultado pode ser 
atribuído à grande diversidade de espécies de plantas cultivadas na área. Aluja et al. (1996) verificaram que a diversidade de espécies variou nos 5 pomares de manga estudados no México. O pomar localizado em área com maior diversidade botânica apresentou a maior riqueza de espécies de Anastrepha.

O valor elevado do índice de Simpson $(0,66)$ e os valores baixos do índice de Shannon $(0,7521)$ e de eqüitatividade $(0,459)$ resultaram da alta freqüência de $A$. fraterculus, revelando a existência de uma espécie dominante. A contribuição proporcional de A. obliqua, minimizou o efeito dominante de A. fraterculus no resultado geral, ou seja, se A. obliqua fosse excluída da comunidade o valor do índice de Simpson seria muito mais elevado e os valores de Shannon e de eqüitatividade muito mais baixos, considerando-se que as freqüências das demais espécies (16) totalizaram apenas 7,2\%. O índice de Simpson reflete a probabilidade de que dois indivíduos escolhidos ao acaso numa comunidade pertençam a mesma espécie. $O$ índice de Shannon mede o grau de incerteza em prever a que espécie pertencerá um indivíduo escolhido, ao acaso, de uma amostra. Eqüitatividade refere-se `a distribuição da abundância das espécies. Portanto, quanto maior o valor de Simpson menor o valor de Shannon e a equiitatividade tenderá a zero.

Kovaleski (1997) também obteve valores elevados do índice de Simpson (entre 0,67 e 0,99 ) em dois pomares de maçãs em Vacaria, RS, em conseqüência da alta frequiência de A. fraterculus. Em levantamentos realizados em 6 municípios do Estado do Amazonas, Ronchi-Teles (2000) observou dominância mais baixa com valores que variaram entre 0 e 0,568 e valores altos do índice de diversidade (Shannon-Weaver) entre 1,3 e 2,47 .

Os resultados por armadilha são apresentados na tabela 6. Os índices faunísticos foram calculados apenas para aquelas que capturaram mais de 50 fêmeas, uma vez que o tamanho da amostra influi significativamente nos resultados (Ludwig \& Reynolds, 1988), podendo-se incorrer em erros na interpretação dos dados obtidos.

Os locais com maior riqueza específica (S) foram: armadilha 51 (13 espécies), armadilha 29 (12 espécies), armadilha 27 (11 espécies), armadilhas 37, 47 e 82 (10 espécies cada uma). É interessante notar que os locais não correspondem, 
necessariamente, àqueles pontos de amostragem com maior abundância de moscas-dasfrutas: a armadilha 51, por exemplo, capturou apenas 637 fêmeas (2,75\% do total) e a 29 , apenas $343(1,48 \%)$. Em ambos os locais, a oferta e diversidade de plantas hospedeiras foi elevada.

O índice de Simpson variou de 0,318 (armadilha 43) a 0,989 (armadilha 5). A armadilha 5 apresentou o menor valor do índice de Shannon $(0,043)$ e os menores valores de eqüitatividade $(0,253)$. Esses índices refletem a forte dominância por $A$. fraterculus $(99,3 \%)$ e a baixa riqueza específica. Por outro lado, a armadilha 43 apresentou o maior índice de Shannon $(1,556)$ e valores relativamente altos de eqüitatividade $(0,590)$, revelando a distribuição eqüitativa das abundâncias entre as espécies. As demais armadilhas apresentaram valores de Simpson e de Shannon intermediários.

A análise dos índices faunísticos por armadilha revelou, como esperado, que nas armadilhas onde o índice de Simpson foi elevado os valores dos índices de Shannon e eqüitatividade foram baixos e, ao contrário, nas armadilhas com baixos valores de Simpson, os valores de Shannon e eqüitatividade foram altos (Tabela 6).

A. fraterculus foi a única espécie coletada em todas as armadilhas com pelo menos um exemplar de Anastrepha, mostrando que está disseminada por toda a área de estudo. A. obliqua e A. pseudoparallela foram capturadas em $80 \%$ dos pontos de coleta, sendo que a primeira em números muito superiores, refletindo diferenças de estratégia de ciclo de vida. A. daciformis, A. leptozona, A. punctata e A. zenildae foram espécies raras, ocorrendo em menos de $10 \%$ dos locais de coleta. 
Tabela 6. Captura de 18 espécies de Anastrepha e índices faunísticos para 84 armadilhas tipo McPhail instaladas no campus Luiz de Queiroz/USP, Piracicaba, SP, julho/1998 - junho/1999.

\begin{tabular}{|c|c|c|c|c|c|c|c|c|c|c|c|c|c|c|c|c|c|c|c|c|c|c|c|}
\hline Arm & ami & bar & bis & dac & dis & dit & fra & gra & lep & man & mon & obl & pse & pic & pun & ser & sor & zen & $\mathrm{p}_{\mathrm{i}}$ & $\mathrm{S}$ & $\lambda$ & $\mathrm{H}^{\prime}$ & $\mathrm{E}$ \\
\hline 1 & & & 13 & & & 1 & 201 & 2 & & & & 6 & 1 & & & & 1 & & 0,97 & 7 & 0,802 & 0,476 & 0,405 \\
\hline 2 & 1 & 1 & 1 & & & & 5 & & & & & 1 & 6 & & & & & & 0,06 & 6 & & & \\
\hline 3 & & & 1 & & & & 41 & & & 1 & & 19 & & & & 1 & & & 0,27 & 5 & 0,515 & 0,838 & 0,718 \\
\hline 4 & & & 12 & & & & 599 & & & 1 & & 12 & 2 & & & & 1 & & 2,69 & 6 & 0,913 & 0,234 & 0,361 \\
\hline 5 & & 2 & 2 & & & & 6.981 & & & & & 14 & 8 & 1 & & & 13 & & 30,18 & 7 & 0,989 & 0,043 & 0,253 \\
\hline 6 & & 2 & & & & & 155 & & & & & 7 & 3 & & & & & & 0,72 & 4 & 0,864 & 0,327 & 0,407 \\
\hline 7 & 1 & & & & & 1 & 15 & & & & & 9 & 4 & & & & & & 0,13 & 5 & & & \\
\hline 8 & 2 & 5 & 1 & & & & 63 & & & & 1 & 112 & 18 & & & 1 & & & 0,91 & 8 & 0,422 & 1,098 & 0,685 \\
\hline 9 & 1 & 3 & & & & & 25 & 1 & & & & 14 & 7 & & & & 1 & & 0,22 & 7 & 0,326 & 1,368 & 0,706 \\
\hline 10 & & & 3 & & & & 40 & 1 & & & & 13 & 10 & & & & & & 0,29 & 5 & 0,419 & 1,112 & 0,680 \\
\hline 11 & & 3 & 1 & & & & 10 & & & & & 2 & 3 & & & & & & 0,08 & 5 & & & \\
\hline 12 & 2 & 1 & 2 & & 1 & & 77 & & & & & 6 & 1 & & & & & & 0,39 & 7 & 0,738 & 0,633 & 0,402 \\
\hline 13 & & & 2 & & & & 443 & & & & & 36 & 3 & & & 1 & & & 2,08 & 5 & 0,840 & 0,343 & 0,465 \\
\hline 14 & 3 & 4 & 6 & & & 1 & 93 & & & & & 2 & 7 & & & & 1 & & 0,50 & 8 & 0,640 & 0,864 & 0,410 \\
\hline 15 & 8 & 1 & 3 & & & & 58 & & 1 & & & 7 & 6 & & & & & & 0,36 & 7 & 0,499 & 1,099 & 0,501 \\
\hline 16 & & 3 & 3 & & & & 75 & 1 & & & & 4 & 3 & & & & & & 0,38 & 6 & 0,716 & 0,677 & 0,410 \\
\hline 17 & & 3 & 1 & & & & 10 & & & & & 2 & 3 & & & & & & 0,08 & 5 & & & \\
\hline 18 & & 21 & & & & & 127 & 1 & & & & 53 & 50 & & & & & & 1,08 & 5 & 0,345 & 1,223 & 0,792 \\
\hline 19 & & & 2 & & & & 6 & & & & & 78 & & & & & & & 0,37 & 3 & 0,828 & 0,362 & 0,476 \\
\hline 20 & & & 25 & & & 2 & 504 & 1 & & & & 135 & 3 & & & & & & 2,88 & 6 & 0,608 & 0,711 & 0,622 \\
\hline 21 & & 2 & 22 & 1 & & 1 & 584 & & & & & 123 & 3 & 1 & & & 4 & & 3,10 & 9 & 0,637 & 0,696 & 0,567 \\
\hline 22 & & 1 & 37 & & & & 399 & & & & & 269 & 2 & & & & 3 & & 3,06 & 6 & 0,461 & 0,895 & 0,808 \\
\hline 23 & & & & & & 1 & 109 & & & & & 13 & 2 & & & & 1 & & 0,54 & 5 & 0,759 & 0,500 & 0,489 \\
\hline 24 & & & 2 & & & & 28 & & & 1 & & 10 & & & 1 & & & & 0,18 & 5 & & & \\
\hline 25 & & & & & & & 7 & & & & & & 1 & & & & & & 0,03 & 2 & & & \\
\hline 26 & 9 & & 8 & & & & 311 & & & & & 1 & & & & & 1 & & 1,42 & 5 & 0,890 & 0,275 & 0,390 \\
\hline 27 & 16 & 2 & 16 & 1 & 2 & 2 & 824 & & 1 & & & 41 & 10 & & & & 4 & & 3,95 & 11 & 0,807 & 0,505 & 0,364 \\
\hline 28 & & & 1 & & & & 77 & & & & & 2 & 1 & & & & & & 0,35 & 4 & 0,905 & 0,248 & 0,373 \\
\hline 29 & 4 & 1 & 5 & 1 & & 1 & 299 & 6 & & 1 & & 13 & 9 & 1 & & & 2 & & 1,47 & 12 & 0,763 & 0,639 & 0,347 \\
\hline 30 & & & 13 & & & 1 & 39 & & & & & 6 & 4 & & & & & & 0,27 & 5 & 0,439 & 1,087 & 0,650 \\
\hline
\end{tabular}


Tabela 6. Captura de 18 espécies de Anastrepha e índices faunísticos para 84 armadilhas tipo McPhail instaladas no campus Luiz de Queiroz/USP, Piracicaba, SP, julho/1998 - junho/1999.

\begin{tabular}{|c|c|c|c|c|c|c|c|c|c|c|c|c|c|c|c|c|c|c|c|c|c|c|c|}
\hline Arm & ami & bar & bis & dac & dis & dit & fra & gra & lep & man & mon & obl & pse & pic & pun & ser & sor & zen & $\mathrm{p}_{\mathrm{i}}$ & $\mathrm{S}$ & $\lambda$ & $\mathrm{H}^{\prime}$ & $\mathrm{E}$ \\
\hline 31 & & & & & & & 1 & & & & & & 1 & & & & & & 0,01 & 2 & & & \\
\hline 32 & 4 & 2 & 4 & & & & 66 & & & & & 4 & 2 & & & & 2 & & 0,36 & 7 & 0,626 & 0,891 & 0,416 \\
\hline 33 & & & & & & & 7 & & & 1 & & 4 & & & & & & & 0,05 & 3 & & & \\
\hline 34 & 1 & & & & & & 2 & & & & & & 2 & & & & & & 0,02 & 3 & & & \\
\hline 35 & & & & & 1 & & 1 & & & & & & 1 & & & & & & 0,01 & 3 & & & \\
\hline 36 & & 3 & & & & & 4 & & & & & & 3 & & & & 1 & & 0,05 & 4 & & & \\
\hline 37 & & & 6 & & & & 155 & & & 11 & 2 & 202 & 1 & 3 & 1 & 1 & 1 & & 1,65 & 10 & 0,443 & 0,998 & 0,734 \\
\hline 38 & & & & & & & 31 & & & & & 267 & 1 & & & & & & 1,28 & 3 & 0,808 & 0,355 & 0,557 \\
\hline 39 & 1 & & 1 & 1 & & & 30 & & & 1 & & 19 & 3 & 4 & & & & & 0,26 & 8 & 0,358 & 1,314 & 0,659 \\
\hline 40 & & & 1 & & & & 64 & & & 1 & & 28 & 3 & & & & & & 0,42 & 5 & 0,520 & 0,835 & 0,707 \\
\hline 41 & & 5 & & & & 1 & 315 & & & 1 & 2 & 11 & 19 & 1 & & & & & 1,53 & 8 & 0,791 & 0,509 & 0,398 \\
\hline 42 & 1 & 1 & 4 & & & & 79 & & & & & 9 & & & & & & & 0,40 & 5 & 0,718 & 0,602 & 0,476 \\
\hline 43 & & 22 & 4 & 4 & & & 46 & & & 3 & 2 & 5 & 4 & 3 & & & & & 0,39 & 9 & 0,318 & 1,538 & 0,587 \\
\hline 44 & & & & & & & 18 & & & & 1 & & 1 & & & & & & 0,09 & 3 & & & \\
\hline 45 & & 18 & & & 4 & & 13 & & & & & & 49 & & & & & & 0,36 & 4 & 0,412 & 1,078 & 0,736 \\
\hline 46 & 2 & & 1 & & & & 5 & & & & & & 26 & 1 & & & & & 0,15 & 5 & & & \\
\hline 47 & 1 & 5 & 33 & 2 & & & 92 & & & & 1 & 23 & 3 & 1 & & & 2 & & 0,70 & 10 & 0,381 & 1,305 & 0,604 \\
\hline 48 & & & & & & & 2 & & & & & & 1 & & & & & & 0,01 & 2 & & & \\
\hline 49 & & & & & & & 1 & & & & & & 3 & & & & & & 0,02 & 2 & & & \\
\hline 50 & 1 & & 3 & & & & 10 & 1 & & & & 1 & 16 & & & & & & 0,14 & 6 & & & \\
\hline 51 & 1 & 12 & 5 & & 2 & & 512 & 3 & & 1 & 2 & 55 & 41 & & & 1 & 1 & 1 & 2,74 & 13 & 0,658 & 0,789 & 0,433 \\
\hline 52 & & 1 & 2 & & 1 & & 256 & & & & 2 & 13 & 14 & 1 & & & 1 & & 1,25 & 9 & 0,778 & 0,544 & 0,395 \\
\hline 53 & & 8 & & & & & 110 & & & & & 1 & 4 & 1 & & & & & 0,53 & 5 & 0,792 & 0,472 & 0,435 \\
\hline 54 & 1 & & & & & & 6 & & & & 1 & & & & & & & & 0,03 & 3 & & & \\
\hline 55 & & & & & & & 48 & & & & & 1 & 2 & & & & & & 0,22 & 3 & 0,888 & 0,261 & 0,423 \\
\hline 56 & & & 2 & & & 1 & 31 & & & & & 1 & 1 & & & & & & 0,16 & 5 & & & \\
\hline 57 & & 2 & 3 & & & & 39 & & & & & 1 & 90 & & & & & & 0,58 & 5 & 0,529 & 0,812 & 0,711 \\
\hline 58 & 1 & & 1 & & & & 5 & & & & & & 1 & & & & & & 0,03 & 4 & & & \\
\hline 59 & & & 3 & & & & 518 & & & & & 5 & & & & & 1 & & 2,26 & 4 & 0,970 & 0,089 & 0,021 \\
\hline 60 & & & 5 & & & & 18 & & & & & & 5 & & & & & & 0,12 & 3 & & & \\
\hline
\end{tabular}


Tabela 6. Captura de 18 espécies de Anastrepha e índices faunísticos para 84 armadilhas tipo McPhail instaladas no campus Luiz de Queiroz/USP, Piracicaba, SP, julho/1998 - junho/1999.

\begin{tabular}{|c|c|c|c|c|c|c|c|c|c|c|c|c|c|c|c|c|c|c|c|c|c|c|c|}
\hline Arm & ami & bar & bis & dac & dis & dit & fra & gra & lep & man & mon & obl & pse & pic & pun & ser & sor & zen & $\mathrm{p}_{\mathrm{i}}$ & $\mathrm{S}$ & $\lambda$ & $\mathrm{H}^{\prime}$ & $\mathrm{E}$ \\
\hline 61 & 2 & 3 & & & & & 58 & & & & & & 34 & & & & 1 & & 0,42 & 5 & 0,472 & 0,911 & 0,752 \\
\hline 62 & 1 & 1 & & & & & 20 & & & & & & 9 & & & & & & 0,13 & 4 & & & \\
\hline 63 & & 4 & 1 & & & & 51 & & & & 1 & 112 & 3 & 1 & & & & & 0,74 & 7 & 0,507 & 0,888 & 0,680 \\
\hline 64 & & & 80 & & & 6 & 142 & & 1 & & & 178 & & 17 & & & 1 & & 1,83 & 7 & 0,324 & 1,263 & 0,823 \\
\hline 65 & & 1 & 2 & & & & 79 & & & & & 15 & 3 & & & & 1 & & 0,43 & 6 & 0,635 & 0,749 & 0,515 \\
\hline 66 & & 3 & 10 & & & & 338 & & & & & 18 & & & & 1 & 1 & & 1,59 & 6 & 0,833 & 0,399 & 0,408 \\
\hline 67 & & & 10 & & 1 & 1 & 64 & & & & & 5 & & & & & & & 0,35 & 5 & 0,644 & 0,725 & 0,519 \\
\hline 68 & & & & & & & 22 & & & & & 3 & & & & & & & 0,11 & 2 & & & \\
\hline 69 & & & 5 & & & & 39 & & & & & 19 & 3 & 1 & & & & & 0,29 & 5 & 0,427 & 1,068 & 0,703 \\
\hline 70 & & & 7 & & 1 & & 143 & & & 2 & & 4 & 3 & 1 & & & & & 0,69 & 7 & 0,792 & 0,525 & 0,380 \\
\hline 71 & & & 2 & & & & 5 & & 1 & & & 2 & & & & & 1 & & 0,05 & 5 & & & \\
\hline 72 & & & & & & & 2 & & & & & & & & & & & & 0,01 & 1 & & & \\
\hline 73 & & 1 & & & & & 10 & & & 2 & 2 & 1 & 9 & & & & & & 0,11 & 6 & & & \\
\hline 74 & & 3 & 1 & & & & 14 & & & & & & 3 & & & & & & 0,09 & 4 & & & \\
\hline 75 & & 1 & 19 & & & & 513 & & & & & 126 & 2 & & & & 5 & & 2,86 & 6 & 0,630 & 0,681 & 0,602 \\
\hline 76 & & & 1 & & & & 15 & & & & & 53 & & & & & & & 0,30 & 3 & 0,637 & 0,596 & 0,670 \\
\hline 77 & 1 & 2 & 5 & & & & 142 & & & & & 11 & 3 & 1 & & & & & 0,71 & 7 & 0,747 & 0,604 & 0,408 \\
\hline 78 & 4 & 3 & 9 & & & 1 & 198 & & & & & 7 & 8 & & & & & & 0,99 & 7 & 0,745 & 0,629 & 0,390 \\
\hline 79 & & & 2 & & & & 100 & & & & & 9 & 69 & & & & & & 0,77 & 4 & 0,458 & 0,894 & 0,819 \\
\hline 80 & & 2 & 2 & & & & 188 & 1 & & & & 5 & 10 & & & & 1 & & 0,90 & 7 & 0,812 & 0,470 & 0,386 \\
\hline 81 & & 2 & 14 & & & 1 & 192 & & & & & 22 & 8 & & 1 & & & & 1,03 & 7 & 0,653 & 0,762 & 0,465 \\
\hline 82 & & 4 & 40 & & 1 & & 1.467 & 9 & & & 1 & 629 & 34 & & & 24 & 18 & & 9,57 & 10 & 0,514 & 0,896 & 0,652 \\
\hline 83 & 4 & & & & 1 & & 174 & 7 & & & 1 & 28 & 30 & & & 4 & 1 & & 1,07 & 9 & 0,513 & 1,051 & 0,510 \\
\hline 84 & & & & & & & 4 & & & & & 2 & & & & & & & 0,03 & 2 & & & \\
\hline
\end{tabular}

Espécies de Anastrepha: ami: A. amita, bar: A. barbiellinii, bis: A. bistrigata, dac: A. daciformis, dis: A. dissimilis, dit: A. distincta, fra: A. fraterculus, gra: A. grandis, lep: A. leptozona, man: A. manihoti, mon: A. montei, obl: A. obliqua, pse: A.pseudoparallela, pic: A. pickeli, pun: A. punctata, ser: A. serpentina, sor: A. sorocula, zen: A. zenildae. Índices: $\mathrm{p}_{\mathrm{i}}$ : Freqüência; $\mathrm{S}$ : Riqueza específica, $\lambda$ : Índice de Simpson, H': Índice de Shannon, E: Equitatividade (Hill modificado). 


\subsection{Flutuação populacional das espécies mais abundantes}

Foram capturadas 23.263 fêmeas de Anastrepha em armadilhas tipo McPhail em 12 meses. Na figura 5 observa-se a flutuação populacional de Anastrepha spp. durante o período de coleta. Os níveis populacionais mantiveram-se relativamente altos no período de agosto a novembro, atingindo um pico máximo em setembro, quando foram capturadas aproximadamente $40 \%$ do total das fêmeas. $\mathrm{O}$ aumento da população de $A$. fraterculus nesse período contribuiu significativamente para esse resultado geral, como se nota na figura 6. Um outro aumento populacional, embora menor, foi observado nos meses de fevereiro e março, refletindo o aumento no nível populacional de A. obliqua, uma vez que nesse período o tamanho da população de A. fraterculus manteve-se relativamente menor. O período em que os níveis populacionais foram menores correspondeu aos meses de maio e junho.

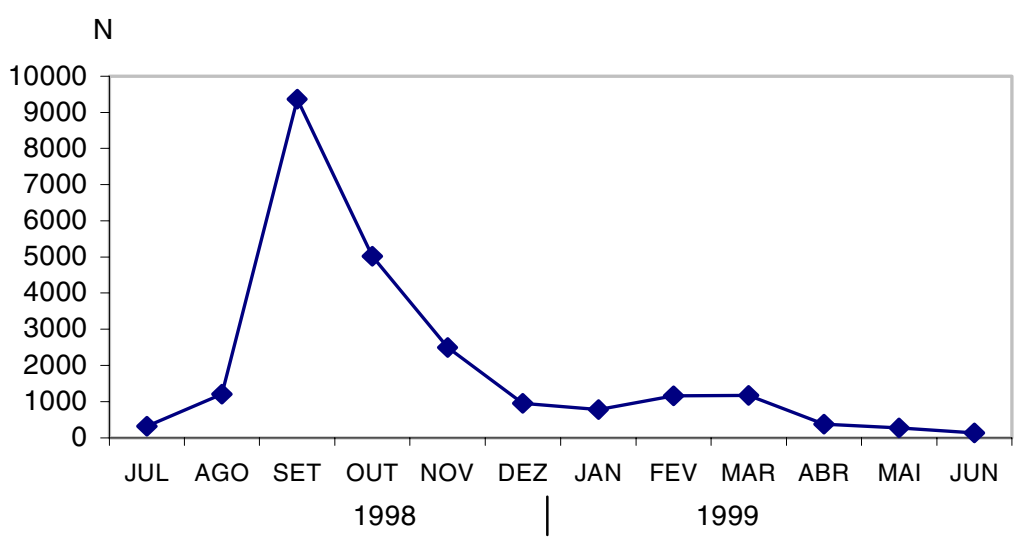

Figura 5 - Flutuação populacional de adultos de Anastrepha spp. capturados em armadilhas tipo McPhail no campus Luiz de Queiroz, Piracicaba, SP, julho/1998 - junho/1999.

A flutuação populacional de A. fraterculus apresentou o mesmo padrão observado para o total de fêmeas capturadas, em consequiência de sua significativa contribuição proporcional. Ocorreu aumento dos níveis populacionais nos meses de 
agosto a novembro, com uma explosão populacional em setembro e níveis mais baixos nos demais meses do ano (Figura 6). Um aumento significativo nas capturas de $A$. fraterculus em setembro na armadilha 5, estabelecida em um pomar de jabuticabeiras, sugere que a oferta de jabuticabas determinou o pico populacional.

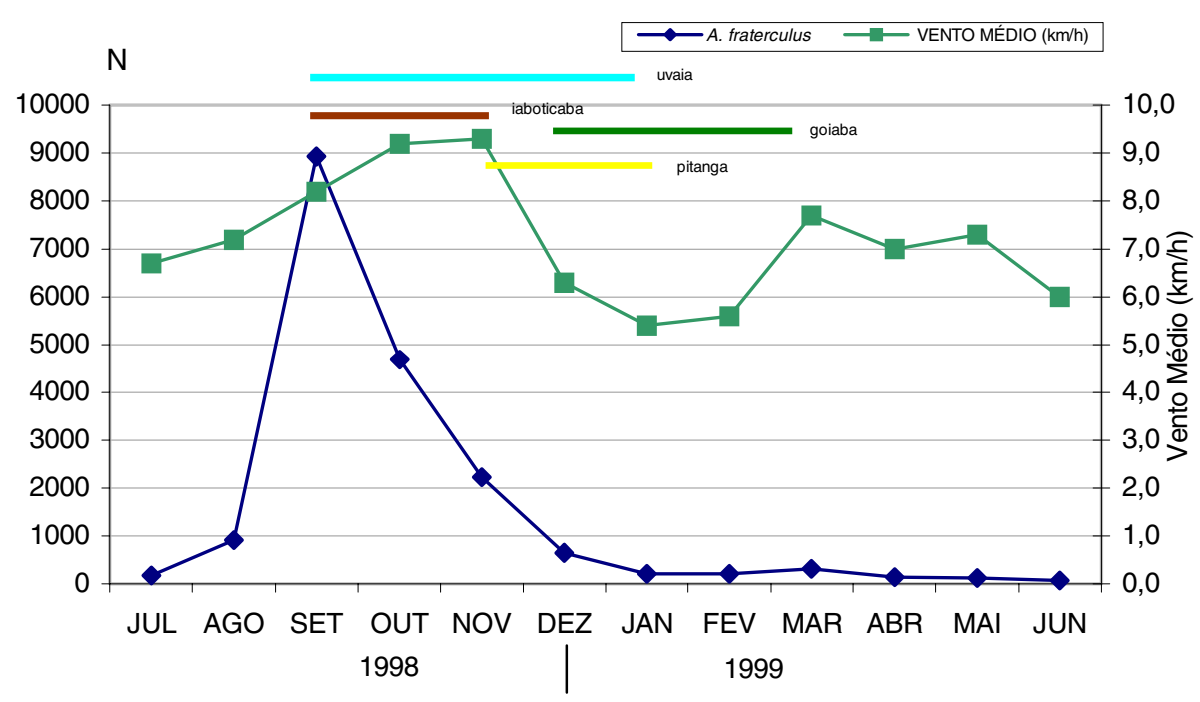

Figura 6 - Flutuação populacional de adultos de A. fraterculus capturados em armadilhas tipo McPhail, velocidade média do vento e período de frutificação de hospedeiros no campus Luiz de Queiroz, Piracicaba, SP, julho/1998 junho/1999.

Na flutuação populacional de A. fraterculus capturadas nas armadilhas 5, 27 e 82 (Figura 7), nota-se que o período de maiores capturas (setembro) coincide com a época de frutificação de jabuticabeiras (setembro a novembro). Considerando-se a vasta gama de hospedeiros utilizada por A. fraterculus, as outras espécies de hospedeiros devem ter contribuído para a manutenção de sua população nos outros meses do ano, como a goiaba, a uvaia e a pitanga, cujos períodos de frutificação correspondem aos meses de dezembro a março, setembro a janeiro e novembro a janeiro, respectivamente. Em pomares diversificados as flutuações são provavelmente minimizadas pela presença de plantas hospedeiras alternativas Aluja (1994). 

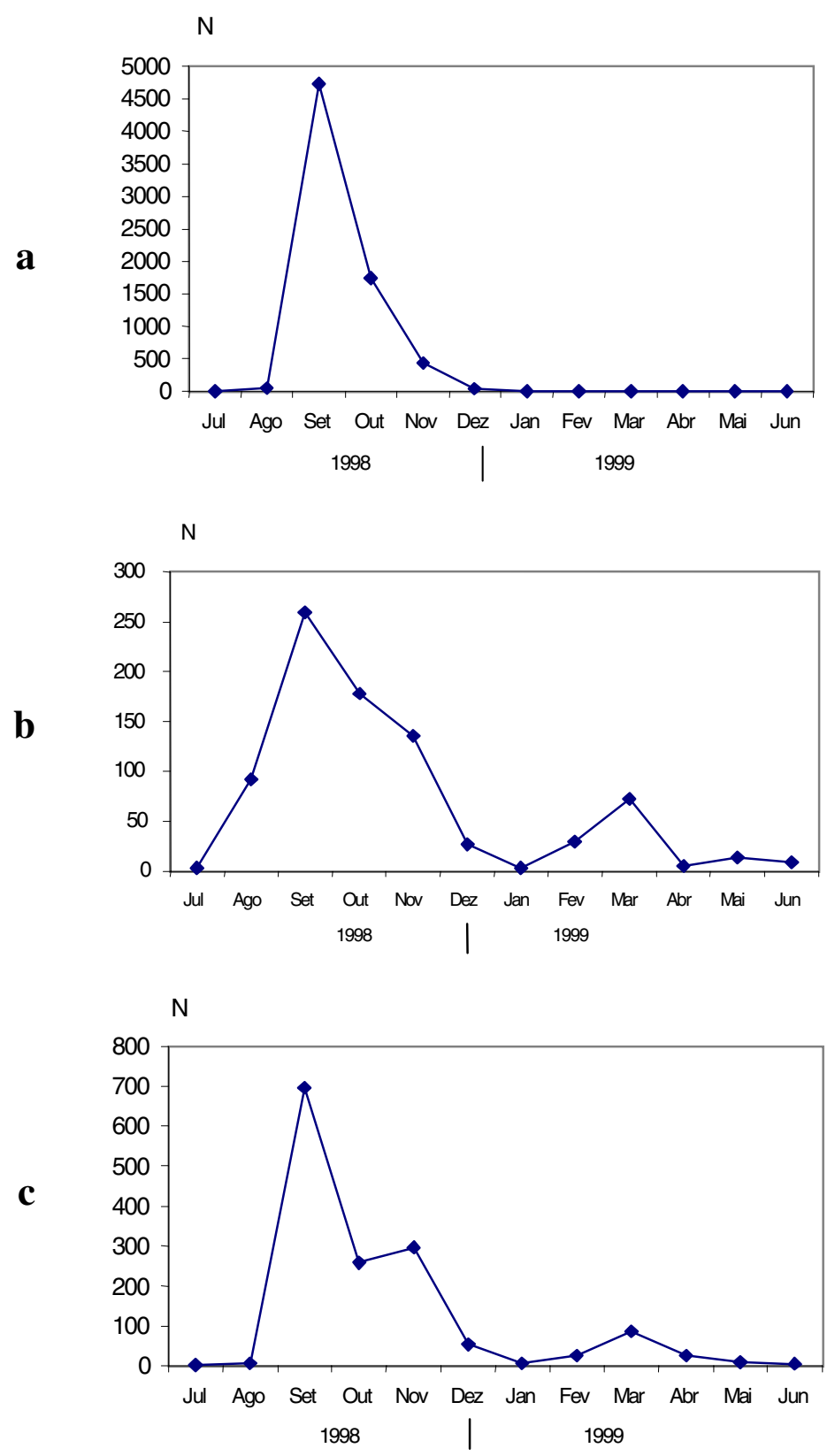

Figura 7 - Flutuação populacional de de adultos de A. fraterculus capturados nas armadilhas 5 (a), 27 (b) e 82 (c) no campus Luiz de Queiroz, Piracicaba, SP, julho/1998 - junho/1999. 
A população de A. obliqua manteve-se menor do que a de A. fraterculus ao longo de todo o ano, com exceção nos meses de janeiro a março, principalmente em fevereiro, quando ocorreu um pico populacional de A. obliqua. A disponibilidade de frutos considerados hospedeiros preferenciais A. obliqua como, manga, serigüela, carambola e cajá-manga, sobretudo das duas primeiras, nesta época do ano provavelmente determinou o aumento no tamanho da população de A. obliqua (Figura $8)$.

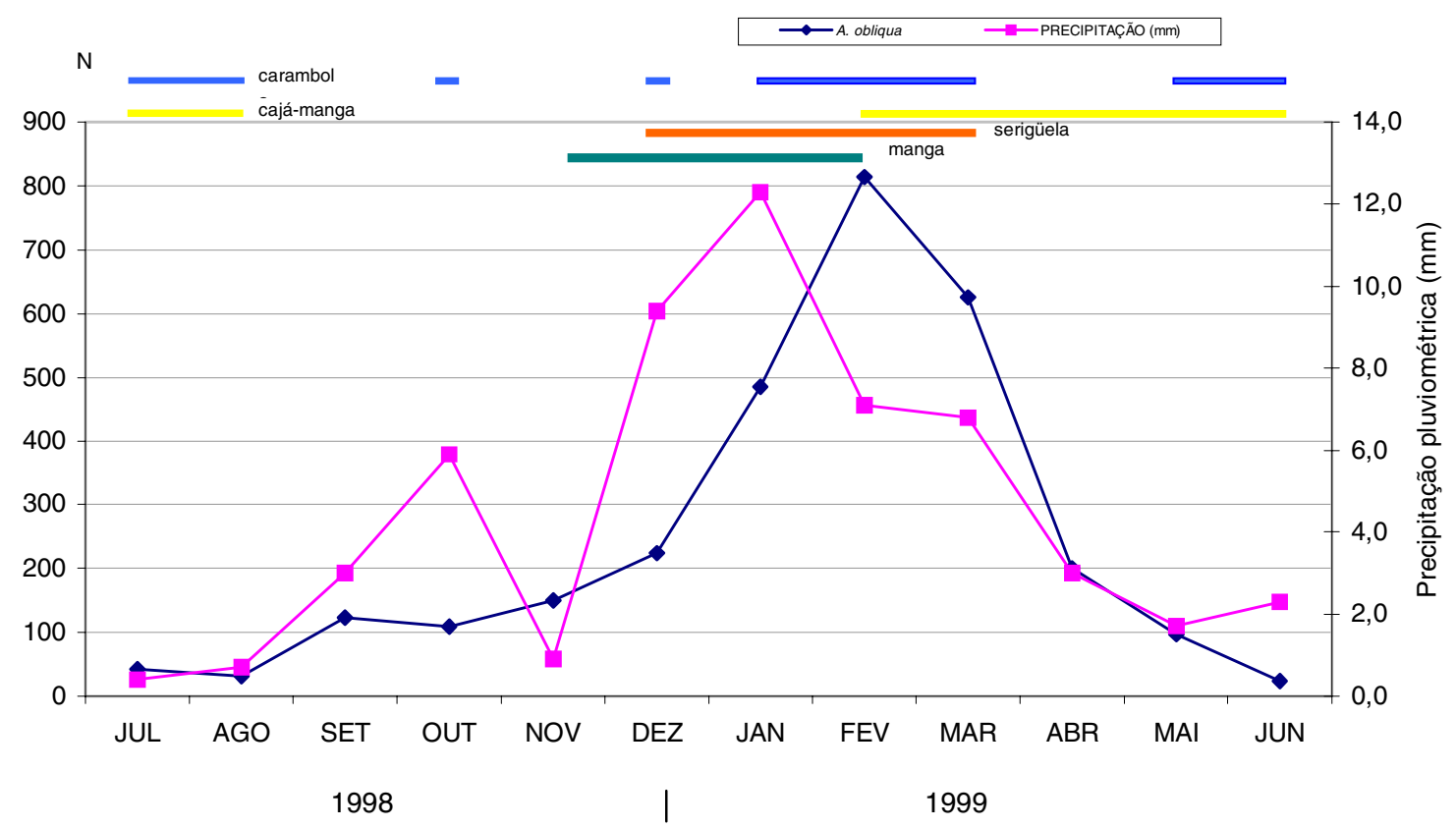

Figura 8 - Flutuação populacional de adultos de A. obliqua capturados em armadilhas tipo McPhail e precipitação pluviométrica e período de frutificação de hospedeiros no campus Luiz de Queiroz, Piracicaba, SP, julho/1998 junho/1999.

Houve um aumento populacional gradativo de A. bistrigata de julho a outubro e outro entre fevereiro e maio, com um pico em março (Figura 9). Duas quedas acentuadas na captura desta espécie ocorreram em janeiro e junho. Possivelmente, A. bistrigata infestou goiaba de fevereiro a maio, quando ocorre a frutificação desta mirtácea. 


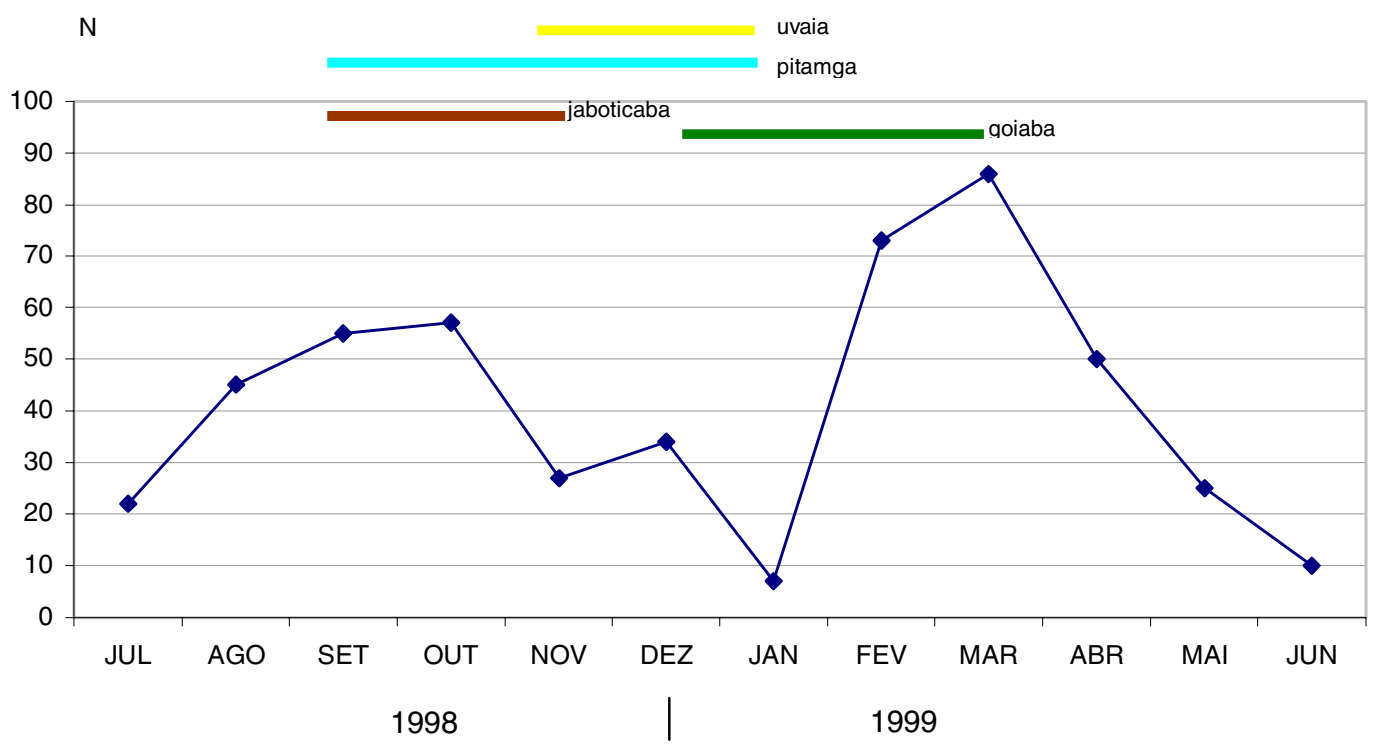

Figura 9 - Flutuação populacional de adultos de A. bistrigata capturados em armadilhas McPhail e período de frutificação de hospedeiros no campus Luiz de Queiroz, Piracicaba, SP, julho/1998 - junho/1999.

A. pseudoparallela foi a terceira espécie mais abundante no campus e a sua flutuação populacional caracterizou-se por um aumento na captura em agosto e setembro declinando até dezembro, quando atingiu o menor valor. Verificou-se uma discreta elevação no nível populacional em janeiro e em abril, mantendo-se em níveis baixos nos demais meses. Nas coletas de frutos, A. pseudoparallela esteve associada apenas às espécies de Passiflora, que frutificam praticamente o ano todo. Não se observou relação definida entre a flutuação populacional desta espécie e a frutificação de seu hospedeiro primário, portanto, outros fatores como ação de parasitóides ou predadores podem estar relacionados às variações no nível da população de $A$. pseudoparallela (Figura 10). 


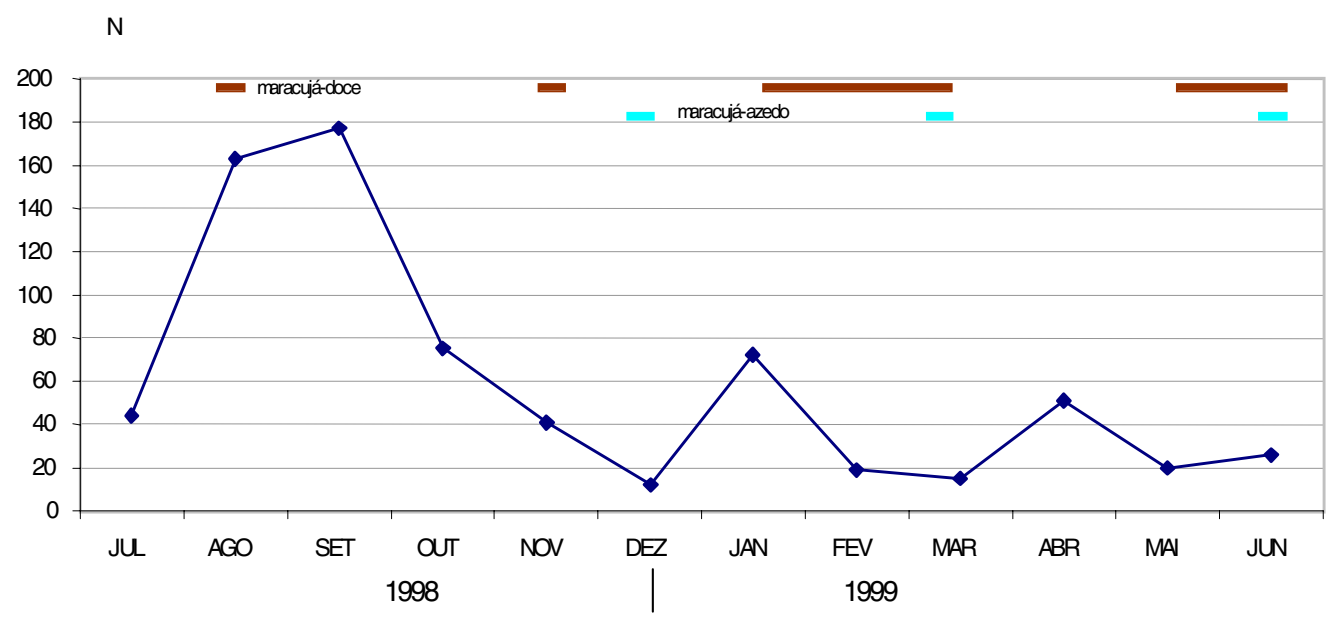

Figura 10 - Flutuação populacional de adultos de A. pseudoparallela capturados em armadilhas tipo McPhail e período de frutificação de hospedeiros no campus Luiz de Queiroz, Piracicaba, SP, julho/1998 - junho/1999.

A relação entre as variáveis climáticas e a flutuação populacional das espécies de Anastrepha foi analisada utilizando-se o modelo linear simples (coeficiente de correlação de Pearson), ao nível de significância de $\mathrm{p}<0,05$. A análise das relações entre as variáveis climáticas e a flutuação populacional de Anastrepha e das espécies mais freqüentes encontra-se na tabela 7.

Os resultados mostraram que nenhuma das variáveis analisadas correlacionou com as capturas do conjunto das espécies de Anastrepha. A análise individual das espécies mais abundantes mostrou que A. pseudoparallela e A. bistrigata também não apresentaram correlação com os dados meteorológicos. Entretanto, a flutuação populacional de A. fraterculus correlacionou positivamente com a velocidade média do vento. Esta correlação poderia ser resultante do movimento de adultos, causado pelo vento, de um loca1, onde o nível populacional de A. fraterculus era elevado, para outros, resultando em maiores capturas nas armadilhas de um modo global. Segundo Aluja (1994), estudos de liberação-recaptura de A. obliqua e A. ludens em pomar mostraram que o vento afeta seus movimentos, orientando as moscas na mesma direção do vento. 
Arrigoni (1984) verificou que a velocidade do vento foi a única variável climática correlacionada às capturas de Anastrepha spp., em Piracicaba. Contudo, para melhor interpretação deste resultado há necessidade de estudos mais aprofundados.

Tabela 7. Análise das relações entre os parâmetros climáticos e a flutuação populacional das espécies mais freqüentes de Anastrepha no campus Luiz de Queiroz, Piracicaba, SP, julho/1998 - junho/1999.

\begin{tabular}{lcccccc}
\hline & $\begin{array}{c}\text { Precipitação } \\
\text { pluviométrica } \\
(\mathrm{mm})\end{array}$ & $\begin{array}{c}\text { Umidade } \\
\text { relativa } \\
(\%)\end{array}$ & $\begin{array}{c}\text { Tpt } \\
\text { máxima } \\
\left({ }^{\circ} \mathrm{C}\right)\end{array}$ & $\begin{array}{c}\mathrm{Tpt} \\
\text { mínima } \\
\left({ }^{\circ} \mathrm{C}\right)\end{array}$ & $\begin{array}{c}\text { Tpt } \\
\text { média } \\
\left({ }^{\circ} \mathrm{C}\right)\end{array}$ & $\begin{array}{c}\text { Velocidade } \\
\text { do vento } \\
(\mathrm{km} / \mathrm{h})\end{array}$ \\
\hline Anastrepha spp. & $-0,06$ & $-0,33$ & 0,01 & 0,10 & 0,06 & 0,57 \\
A. fraterculus & $-0,12$ & $-0,39$ & $-0,07$ & 0,02 & $-0,02$ & $0,59^{*}$ \\
A. obliqua & $0,65^{*}$ & $0,67^{*}$ & $0,77 *$ & $0,77^{*}$ & $0,79 *$ & $-0,38$ \\
A. pseudoparallela & $-0,24$ & $-0,44$ & $-0,14$ & $-0,10$ & $-0,12$ & 0,27 \\
A. bistrigata & 0,10 & 0,02 & 0,47 & 0,42 & 0,45 & 0,29 \\
\hline *correlação segundo o modelo linear simples (coeficiente de Pearson) ao nível de significância de $\mathrm{p}<0,05$.
\end{tabular}

A flutuação populacional de A. obliqua apresentou correlação positiva com precipitação pluviométrica, umidade relativa e temperaturas máxima, mínima e média. As variações populacionais de A. obliqua e os dados de precipitação pluviométrica, umidade relativa e temperatura média, máxima e mínima ao longo do tempo estão nas figuras 8, 11 e 12. Segundo Bateman (1972), a umidade do ambiente e a temperatura podem ser determinantes na abundância de tefritídeos. A temperatura pode influir direta ou indiretamente por meio de efeitos sobre as taxas de desenvolvimento, mortalidade e fecundidade. 


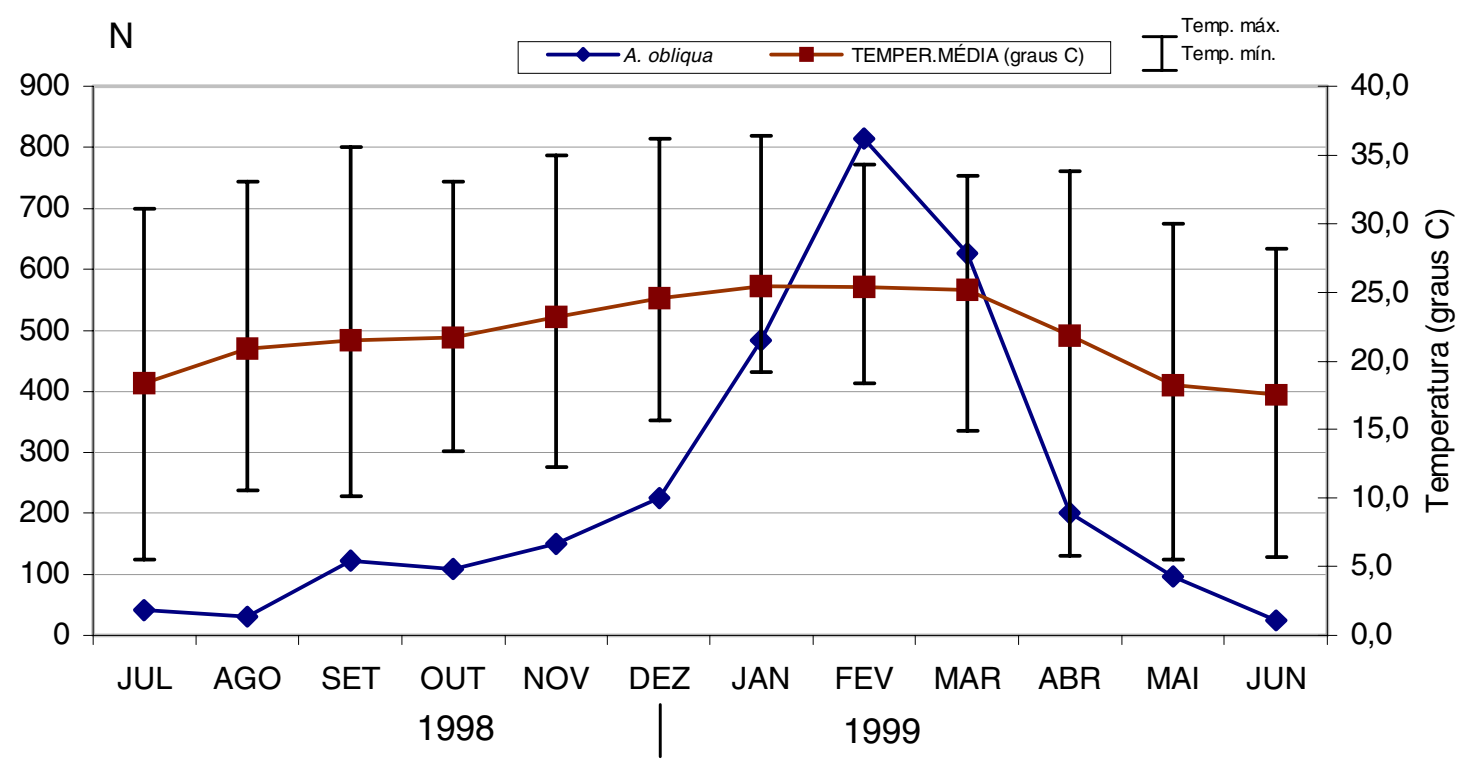

Figura 11 - Flutuação populacional de adultos de A. obliqua capturados em armadilhas McPhail e temperatura média, máxima e mínima no campus Luiz de Queiroz,

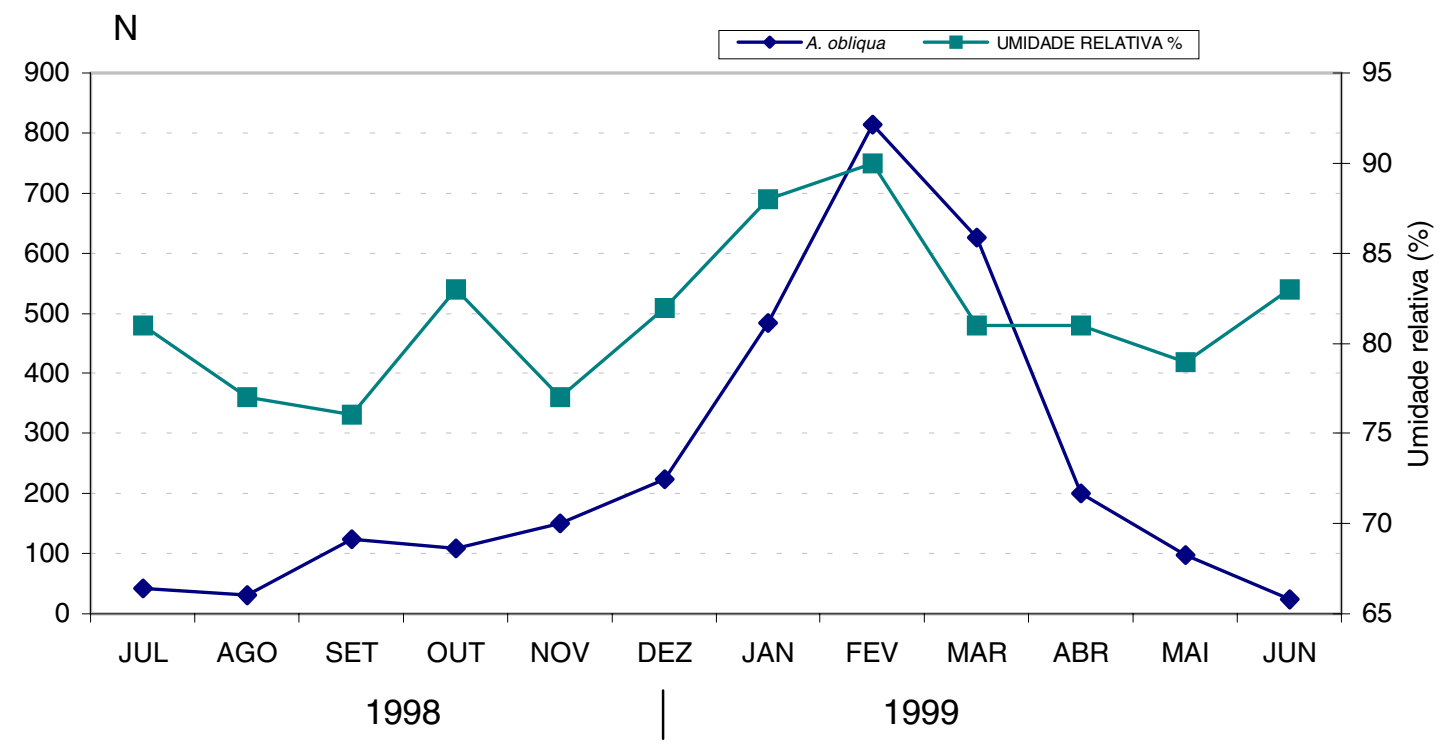

Figura 12 - Flutuação populacional de adultos de A. obliqua capturados em armadilhas tipo McPhail e umidade relativa no campus Luiz de Queiroz, Piracicaba, SP, julho/1998 - junho/1999. 
A abundância de moscas-das-frutas pode ser influenciada por vários fatores tanto bióticos como abióticos (Bateman, 1972). Estudos em pomares comerciais têm revelado que as flutuações populacionais de adultos estão relacionadas a dois complexos de variáveis: disponibilidade de plantas hospedeiras e condições climáticas (Aluja, 1994).

A importância específica das variáveis climáticas nas populações das espécies de moscas-das-frutas é difícil de ser determinada, considerando-se que elas também correlacionam entre si (Tabela 8). Além disso, as variáveis climáticas podem influir indiretamente na disponibilidade de hospedeiros, como observado na Malásia por Tan e Serit (1994), onde os maiores picos populacionais de B. dorsalis ocorreram na estação úmida, em decorrência da pluviosidade ter influenciado a produção e a disponibilidade de frutos hospedeiros, aumentando o número de adultos desta espécie. Embora a flutuação populacional de A. obliqua esteja correlacionado às variáveis climáticas, verificou-se também relação com a época de frutificação de seus hospedeiros primários. É possível que as condições meteorológicas tenham favorecido a produção de frutos adequados para A. obliqua. De modo geral, a disponibilidade de frutos hospedeiros parece ter sido mais importante que as variáveis climáticas para o aumento no nível populacional das espécies de Anastrepha no campus, como verificado por vários autores no Brasil (Puzzi \& Orlando, 1965; Malavasi \& Morgante, 1981; Fehn, 1982; Rossi et al., 1988; Zahler, 1991; Arrigoni, 1984; Aguiar-Menezes \& Menezes, 1996; Canal et al., 1998; Veloso, 1997; Ronchi-Teles, 2000) e em outros países (Celedonio-Hurtado et al., 1995; Aluja et al., 1996; Soto-Manitiu \& Jirón, 1989; Tan \& Serit, 1994). 
Tabela 8. Análise das relações entre os parâmetros climáticos no campus Luiz de Queiroz, Piracicaba, SP, julho/1998 - junho/1999.

\begin{tabular}{lcccccc}
\hline & $\begin{array}{c}\text { Precipitação } \\
\text { pluviométrica } \\
(\mathrm{mm})\end{array}$ & $\begin{array}{c}\text { Umidade } \\
\text { relativa } \\
(\%)\end{array}$ & $\begin{array}{c}\text { Tpt } \\
\text { máxima } \\
\left({ }^{\circ} \mathrm{C}\right)\end{array}$ & $\begin{array}{c}\mathrm{Tpt} \\
\text { mínima } \\
\left({ }^{\circ} \mathrm{C}\right)\end{array}$ & $\begin{array}{c}\text { Tpt } \\
\text { média } \\
\left({ }^{\circ} \mathrm{C}\right)\end{array}$ & $\begin{array}{c}\text { Velocidade do } \\
\text { vento }(\mathrm{km} / \mathrm{h})\end{array}$ \\
\hline $\begin{array}{l}\text { Precipitação } \\
\text { pluviométrica }\end{array}$ & 1,00 & $0,71^{*}$ & $0,63^{*}$ & $0,82^{*}$ & $0,76^{*}$ & $-0,44$ \\
$\begin{array}{l}\text { Umidade } \\
\text { relativa }\end{array}$ & $0,71^{*}$ & 1,00 & 0,29 & 0,50 & 0,42 & $-0,66^{*}$ \\
$\begin{array}{l}\text { Temperatura } \\
\text { máxima }\end{array}$ & $0,63^{*}$ & 0,29 & 1,00 & $0,93^{*}$ & $0,97^{*}$ & $-0,05$ \\
$\begin{array}{l}\text { Temperatura } \\
\text { média }\end{array}$ & $0,82^{*}$ & 0,50 & $0,93^{*}$ & 1,00 & $0,99^{*}$ & $-0,15$ \\
$\begin{array}{l}\text { Velocidade do } \\
\text { vento }\end{array}$ & $0,76^{*}$ & 0,42 & $0,97^{*}$ & $0,99^{*}$ & 1,00 & $-0,11$ \\
$\begin{array}{l}\text { Velocidade do } \\
\text { vento }\end{array}$ & $-0,44$ & $-0,66^{*}$ & $-0,05$ & $-0,15$ & $-0,11$ & 1,00 \\
\hline *correlação segundo o modelo linear simples (coeficiente de Pearson) ao nível de significância de $\mathrm{p}<0,05$.
\end{tabular}

A população de adultos de Anastrepha exibe grandes flutuações de ano para ano e não obedece a um padrão determinado (Aluja, 1994). O tamanho das populações e a época do aumento populacional variaram de ano para ano nos pomares de maçãs em Vacaria , RS (Kovaleski, 1997). Como a flutuação populacional de Anastrepha observada neste trabalho refere-se ao período de coletas de apenas um ano, as oscilações populacionais ao longo do ano não podem ser consideradas como padrão definitivo para este local.

\subsection{Coleta e relações com plantas hospedeiras}

Foram coletadas 565 amostras de frutos pertencentes a 11 famílias e, a pelo menos 25 espécies botânicas (as espécies cítricas foram agrupadas em Citrus spp.), em 47 estações de captura dentre as 84 estações estabelecidas no campus. Foram identificadas 10.290 fêmeas. Das 18 espécies de Anastrepha capturadas em armadilhas, somente 6 emergiram das amostras de frutos: A. bistrigata, A. fraterculus, A. obliqua, A. 
pseudoparallela, A. serpentina e A. sororcula. A maioria das espécies de moscas-dasfrutas presentes no campus não foi obtida a partir de frutos, embora diferentes espécies de frutos tenham sido coletadas, possivelmente por utilizar uma pequena gama de hospedeiros que não tenham sido coletados. Portanto, é desejável a continuidade deste tipo de investigação para o maior conhecimento da relação trófica deste grupo de insetos.

A Tabela 9 mostra as espécies de Anastrepha associadas às espécies de frutíferas coletadas no campus. A. fraterculus foi obtida de 22 espécies botânicas, sendo a espécie que infestou a maior diversidade de frutos. Adultos de A. obliqua emergiram de 9 espécies botânicas, principalmente de Anacardiaceae, revelando sua preferência por esta família. A. bistrigata foi obtida de Spondias dulcis (Anacardiaceae) e de Psidium guajava (Myrtaceae) e A. sororcula de Eugenia uniflora e Psidium guajava (Myrtaceae). A. pseudoparallela infestou exclusivamente Passifloraceae e A. serpentina esteve restrita às espécies de Sapotaceae. Há especificidade entre certas espécies e plantas hospedeiras como o grupo pseudoparallela associado quase exclusivamente ao gênero Passiflora (Passifloraceae) e o grupo serpentina à família Sapotaceae (Norrbom, 1985).

Levantamentos de moscas-das-frutas em frutos hospedeiros no Brasil revelaram que A. fraterculus é a mais polífaga do gênero Anastrepha por infestar frutos de diversas espécies e famílias (Malavasi et al., 1980, Zucchi,1988; Aguiar \& Menezes, 1996, Kovaleski, 1997; Veloso, 1997; Souza Filho, 1999). Zucchi (2000b) compilou os dados de hospedeiros das espécies de Anastrepha e reportou 67 espécies de hospedeiros para A. fraterculus no Brasil. Filho et al. (2000) relataram a primeira ocorrência da infestação de A. fraterculus em morango (Fragaria x anamassa). As espécies das famílias Myrtaceae e Rosaceae são consideradas os hospedeiros mais importantes de $A$. fraterculus (Malavasi et al., 1980; Aluja et al., 1987). Souza Filho (1999) obteve A. fraterculus de 12 famílias e verificou sua constância em todas as espécies das famílias Myrtaceae, Rosaceae e Rutaceae. No presente estudo esta espécie foi associada às 11 famílias amostradas, infestando inclusive espécies da família Sapotaceae (Manilkara zapota e Pouteria caimito) e Passifloraceae (Passiflora edulis). 
Tabela 9. Espécies de Anastrepha associadas às espécies frutíferas coletadas no campus Luiz de Queiroz, Piracicaba, SP, janeiro - dezembro/1999.

\begin{tabular}{|c|c|c|c|c|c|c|c|}
\hline \multirow[t]{2}{*}{$\begin{array}{c}\text { Plantas hospedeiras } \\
\end{array}$} & \multirow[b]{2}{*}{$\begin{array}{c}\text { Nomes comuns } \\
\text { dos frutos }\end{array}$} & \multicolumn{6}{|c|}{ Espécies de Anastrepha } \\
\hline & & 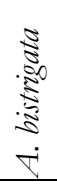 & है & $\begin{array}{l}3 \\
\frac{3}{5} \\
\frac{3}{0} \\
\stackrel{+}{+}\end{array}$ & 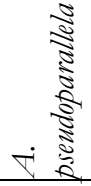 & 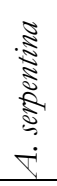 & 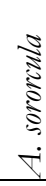 \\
\hline \multicolumn{8}{|l|}{ Anacardiaceae } \\
\hline Mangifera indica $\mathrm{L}$. & Manga & & $\bullet$ & $\bullet$ & & & \\
\hline Spondias dulcis Forst. f. & Cajá-manga & $\bullet$ & $\bullet$ & $\bullet$ & & & \\
\hline Spondias purpurea L. & Serigüela & & & $\bullet$ & & & \\
\hline \multicolumn{8}{|l|}{ Lauraceae } \\
\hline Persea americana Mill. & & & $\bullet$ & & & & \\
\hline \multicolumn{8}{|l|}{ Malpighiaceae } \\
\hline Malpighia glabra L. & Acerola & & $\bullet$ & & & & \\
\hline \multicolumn{8}{|l|}{ Myrtaceae } \\
\hline Eugenia involucrata DC. & Cereja & & $\bullet$ & & & & \\
\hline Eugenia pyriformis Cambess. & Uvaia & & $\bullet$ & $\bullet$ & & & \\
\hline Eugenia uniflora L. & Pitanga & & $\bullet$ & $\bullet$ & & & $\bullet$ \\
\hline Myrciaria cauliflora (Mart.) O. Berg. & Jabuticaba & & $\bullet$ & & & & \\
\hline Plinia glomerata (Berg.) Amsh. & Cabeludinha & & $\bullet$ & & & & \\
\hline Psidium guajava L. & Goiaba & $\bullet$ & $\bullet$ & $\bullet$ & & & $\bullet$ \\
\hline Syzygium jambos (L.) Alston & Jambo & & $\bullet$ & & & & \\
\hline \multicolumn{8}{|l|}{ Oxalidaceae } \\
\hline Averrhoa carambola $\mathrm{L}$. & Carambola & & $\bullet$ & $\bullet$ & & & \\
\hline \multicolumn{8}{|l|}{ Palmae } \\
\hline Syagrus romanzoffiana (Cham.) Glassman & Coquinho & & $\bullet 1$ & & & & \\
\hline \multicolumn{8}{|l|}{ Passifloraceae } \\
\hline Passiflora alata Dryander & Maracujá-doce & & & & $\bullet$ & & \\
\hline Passiflora edulis Sims & Maracujá-azedo & & $\bullet$ & & $\bullet$ & & \\
\hline \multicolumn{8}{|l|}{ Rosaceae } \\
\hline Eriobotrya japonica Lindl. & Nêspera & & $\bullet$ & & & & \\
\hline Prunus persica (L.) Batsch & Pêssego & & $\bullet$ & & & & \\
\hline Rubus sp. & Amora & & $\bullet$ & & & & \\
\hline \multicolumn{8}{|l|}{ Rubiaceae } \\
\hline Coffea arabica L. & Café & & $\bullet$ & $\bullet$ & & & \\
\hline \multicolumn{8}{|l|}{ Rutaceae } \\
\hline Citrus reticulata Blanco & Tangerina-cravo & & $\bullet$ & & & & \\
\hline Citrus spp. & citros & & $\bullet$ & $\bullet$ & & & \\
\hline \multicolumn{8}{|l|}{ Sapotaceae } \\
\hline Chrysophyllum cainito L. & Caimito & & & & & $\bullet$ & \\
\hline Manilkeara rapota L. & Sapoti & & $\bullet^{2}$ & & & $\bullet$ & \\
\hline Pouteria caimito (Ruiz \& Pav.) Radlk. & Abiu & & $\bullet$ & & & & \\
\hline
\end{tabular}


Uma nova associação A. fraterculus em Syagrus romanzoffiana (coquinho) foi constatada. É reportado neste trabalho o primeiro registro da associação de $A$. fraterculus em Manilkara zapota (sapoti) no Brasil.

As relações entre plantas hospedeiras e espécies de Anastrepha estão apresentadas na figura 13. A goiaba (Psidium guajava) associou-se a maior diversidade de espécies, sendo infestada por A. bistrigata (24\%), A. fraterculus (55\%), A. obliqua (20\%) e A. sororcula (1\%) (Figura 13a). Em levantamento de tefritídeos associados às plantas hospedeiras no Estado de São Paulo, Souza Filho (1999) obteve em goiaba 7 espécies de Anastrepha, representando o hospedeiro com maior diversidade de espécies. Em levantamentos realizados em outras regiões do Brasil, a goiaba foi associada aos maiores valores de diversidade de espécies (Malavasi et al., 1980; Silva et al., 1996; Canal, 1997; Veloso, 1997).

Da pitanga (Eugenia uniflora) emergiram A. fraterculus (97,3\%), A. obliqua $(2,6 \%)$ e A. sororcula ( $0,1 \%)$ (Figura 13b). A uvaia (E. pyriformis) foi infestada por $A$. fraterculus (71\%) e A. obliqua (29\%) (Figura 13c).

Com relação às espécies de Anacardiaceae, cajá-manga (Spondias dulcis) foi infestada por A. bistrigata $(0,1 \%)$, A. fraterculus $(0,3 \%)$ e A. obliqua $(99,6 \%)$ (Figura13d), manga (Mangifera indica) por A. fraterculus (5\%) e A. obliqua (95\%) (Figura 13e) e serigüela (S. purpurea) exclusivamente por A. obliqua (Figura 13f).

A carambola (Averrhoa carambola) foi infestada predominantemente por $A$. obliqua $(99,6 \%)$ e em pequena proporção por A. fraterculus $(0,4 \%)$ (Figura 13g). A preferência de A. obliqua por carambola, espécie da família Oxalidaceae, também foi verificada por Souza Filho (1999).

Em maracujá-azedo (Passiflora edulis), observou-se $11 \%$ de A. fraterculus e $89 \%$ de A. pseudoparallela (Figura 13h), enquanto em maracujá-doce (P. alata) obtevese $100 \%$ de A. pseudoparallela (Figura 13i). Zucchi et al. (1996) e Souza Filho (1999) haviam verificado a infestação em maracujá-azedo por A. fraterculus.

As espécies de Rosaceae estiveram associadas exclusivamente à A. fraterculus. A família Rutaceae associou-se à $A$. fraterculus, com exceção de duas amostras, das quais emergiram três exemplares de A. obliqua. De modo semelhante, a única espécie de 
Rubiaceae amostrada, Coffea arabica, foi infestada predominantemente por $A$. fraterculus e por apenas um exemplar de A. obliqua. Estas associações com A. obliqua poderiam ser classificadas como acidentais, considerando-se sua baixa proporção em relação ao total de indivíduos que emergiram. Souza Filho (1999) e Veloso (1997) também obtiveram resultados similares.

a
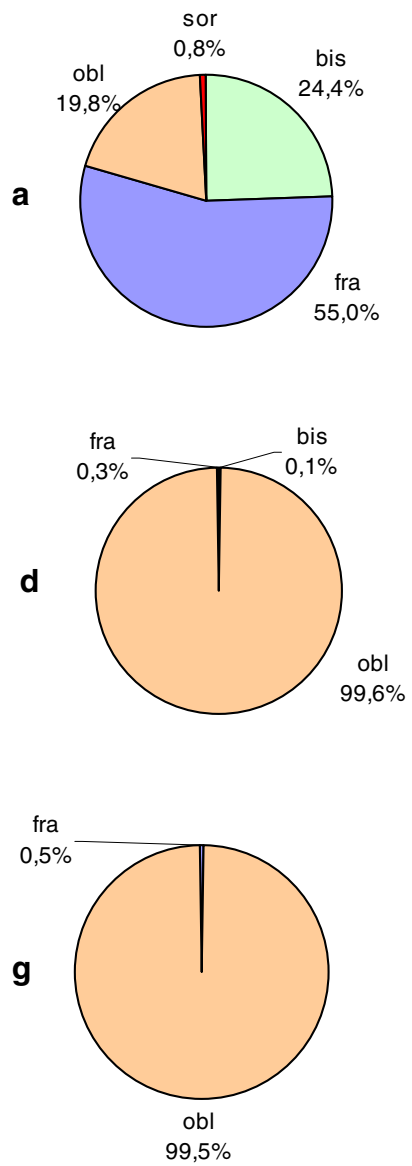


h

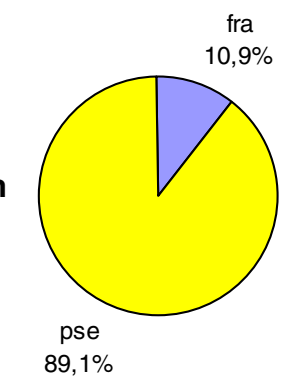

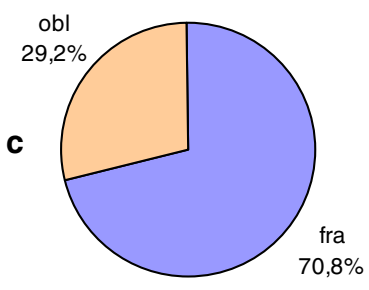
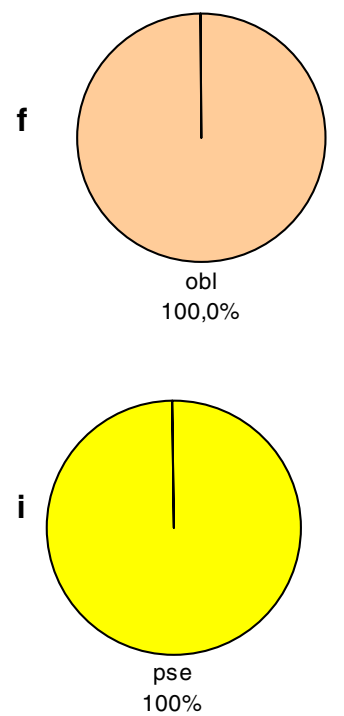

Figura 13 - Associação de espécies de Anastrepha às plantas hospedeiras coletadas no campus Luiz de Queiroz, Piracicaba, SP, janeiro-dezembro/1999. a- goiaba $(\mathrm{n}=1472)$; b- pitanga $(\mathrm{n}=856)$; c- uvaia $(\mathrm{n}=722)$; d- cajá-manga $(\mathrm{n}=671)$; e- manga $(\mathrm{n}=474)$; f- serigüela $(\mathrm{n}=4210)$; g- carambola $(\mathrm{n}=1295)$; $\mathrm{h}$ maracujá-azedo ( $\mathrm{n}=46)$; i- maracujá-doce ( $\mathrm{n}=115)$; n: número de fêmeas de Anastrepha, bis: A. bistrigata, fra: A. fraterculus, obl: A. obliqua, pse: A.pseudoparallela, sor: A. sorocula 
Tabela 10 - Número de fêmeas de Anastrepha obtido de frutos no campus Luiz de Queiroz, Piracicaba, SP, janeiro - dezembro/1999.

\begin{tabular}{|c|c|c|c|c|c|c|c|c|c|c|c|c|}
\hline \multirow{3}{*}{$\frac{\text { Plantas hospedeiras }}{\text { Famílias/espécies (nomes comuns) }}$} & \multicolumn{12}{|c|}{ Meses } \\
\hline & Jan & Fev & Mar & Abr & Mai & Jun & Jul & Ago & Set & Out & Nov & Dez \\
\hline & \multicolumn{12}{|c|}{ Total de fêmeas } \\
\hline \multicolumn{13}{|l|}{ Anacardiaceae } \\
\hline Mangifera indica (manga) & 194 & 106 & & & & & & & 3 & & 99 & 72 \\
\hline Spondias dulcis (cajá-manga) & & 189 & 277 & 82 & 97 & 6 & 1 & 5 & 14 & & & \\
\hline Spondias purpurea (serigüela) & 86 & 2444 & 1680 & & & & & & & & & \\
\hline Lauraceae & & & & & & & & & & & & \\
\hline $\begin{array}{l}\text { Persea americana (abacate) } \\
\text { Malpighiaceae }\end{array}$ & & 1 & & & & & & & & & & \\
\hline $\begin{array}{l}\text { Malpighia glabra (acerola) } \\
\text { Myrtaceae }\end{array}$ & & 2 & & & & & & & & & 11 & 8 \\
\hline Eugenia involucrata (cereja) & & & & & & & & & 66 & & & \\
\hline Eugenia pyriformis (uvaia) & & & & & & & & & 401 & 277 & 44 & \\
\hline Eugenia uniflora (pitanga) & 1 & & & & & & & & 687 & 143 & 25 & \\
\hline Myrciaria cauliflora (jabuticaba) & & & & & & & & & & 10 & & \\
\hline Plinia glomerata (cabeludinha) & & & & & & & & & & & 1 & \\
\hline Psidium guajava (goiaba) & 99 & 846 & 170 & 12 & 3 & 1 & & & 25 & 13 & 27 & 276 \\
\hline $\begin{array}{l}\text { Sysygium jambos (jambo) } \\
\text { Oxalidaceae }\end{array}$ & & & & & & & & & & & & 51 \\
\hline Averrhoa carambola (carambola) & 144 & 505 & 36 & 39 & 126 & 135 & 205 & 92 & 3 & & & 8 \\
\hline Palmae & & & & & & & & & & & & \\
\hline $\begin{array}{l}\text { Syagrus romanzoffiana (coquinho) } \\
\text { Passifloraceae }\end{array}$ & & 1 & & & & & & & & & & \\
\hline Passiflora alata (maracujá-doce ) & & & & & & & 114 & & & & & \\
\hline $\begin{array}{l}\text { Passiflora edulis (maracujá-azedo) } \\
\text { Rosaceae }\end{array}$ & & 5 & & & & & 41 & & & & & \\
\hline Eriobotrya japonica (nêspera) & & & & & & & & & 27 & 9 & & \\
\hline Prunus persica (pêssego) & & & & & & & & & 2 & 8 & 4 & \\
\hline Rubus sp. (amora) & & & & & & & & & 1 & & & \\
\hline Rubiaceae & & & & & & & & & & & & \\
\hline Coffea arabica (café) & & & 11 & 24 & 17 & 2 & & & & & 1 & \\
\hline Rutaceae & & & & & & & & & & & & \\
\hline Citrus reticulata (tangerina) & & & & & & & & & 1 & 17 & 5 & \\
\hline Citrus spp. (citros) & & 4 & 21 & 11 & 2 & 11 & 11 & 10 & 10 & 8 & 12 & 4 \\
\hline Sapotaceae & & & & & & & & & & & & \\
\hline Chrysophyllum cainito (caimito) & & & & & & & & & & & & 2 \\
\hline Manilkara zapota (sapoti) & & & & & & & & & & & 5 & 2 \\
\hline Pouteria caimito (abiu) & & & & 5 & 2 & & & & & & & \\
\hline
\end{tabular}


Na Tabela 10 observa-se os períodos de coletas de frutíferas infestadas com os respectivos totais de fêmeas de Anastrepha obtidos das amostras. Verificou-se que as épocas de coleta das amostras de diferentes espécies frutíferas, coincidiram com aquelas apresentadas no cronograma da infestação de espécies de Anastrepha no Estado de São Paulo elaborado por Souza Filho (1999).

Os adultos de moscas-das-frutas emergiram de amostras de goiaba coletadas no período de setembro a junho e verificou-se um aumento da infestação nas coletas de dezembro a março. As amostras de pitanga e uvaia infestadas foram coletadas de setembro a novembro e de jambo apenas no mês de dezembro. Embora a infestação em citros tenha sido baixa, obteve-se amostras destes frutos infestados ao longo de todo o ano. Este quadro indica a ocorrência de uma sucessão de hospedeiros associados principalmente à A. fraterculus, sugerindo que estes hospedeiros poderiam ser responsáveis pela manutenção da população desta espécie no campus ao longo do ano (Figura 6). Nugyen et al. (1992) verificaram que populações de A. suspensa na Flórida mantiveram-se ao longo do ano pela sucessão de seus hospedeiros preferenciais presentes na área e as variedades de citros foram atacadas apenas na época em que o índice de infestação nos hospedeiros primários foi alto ou no período de escassez destes hospedeiros.

Um cenário semelhante ocorre com os hospedeiros preferenciais de A. obliqua, com a seguinte sucessão de hospedeiros: manga (novembro a fevereiro), cajá-manga (fevereiro a setembro, com maiores infestações em fevereiro e março), serigüela (janeiro a março) e carambola (dezembro a setembro) (Figura 8). 


\section{CONCLUSÕES}

Os resultados obtidos no estudo conduzido no campus Luiz de Queiroz/USP, Piracicaba, SP, nos períodos de julho de 1998 a junho de 1999 (coletas com armadilhas) e de janeiro a dezembro de 1999 (em frutos), permitem concluir que:

- Um total de 18 espécies de Anastrepha ocorre na área estudada.

- Anastrepha fraterculus e A. obliqua são espécies dominantes.

- A distribuição das fêmeas de Anastrepha por armadilha é fortemente agregada, com 5 armadilhas, dentre as 84 distribuídas pelo campus, capturando $50 \%$ do total de fêmeas.

- Anastrepha fraterculus é a mais freqüente, representando $80,2 \%$ do total de fêmeas e também a mais constante ocorrendo em 98,04\% das amostras analisadas.

- Um aumento populacional das espécies de Anastrepha ocorre de agosto a novembro com um pico máximo em setembro.

- O valor elevado do índice de Simpson e os valores baixos dos índices de Shannon e de Hill modificado (equiitatividade) refletem a dominância de $A$. fraterculus no campus. 
- A disponibilidade de frutos hospedeiros é mais importante na determinação do tamanho das populações das espécies mais abundantes de Anastrepha que as variáveis meteorológicas.

- Anastrepha fraterculus é a espécie que infesta maior diversidade de frutos.

- Os hospedeiros preferidos de A. obliqua pertencem à família Anacardiaceae.

- Anastrepha pseudoparallela e A. serpentina infestam somente Passifloraceae e Sapotaceae, respectivamente.

- Um novo registro de Anastrepha fraterculus em Syagrus romanzoffiana (coquinho) é obtido.

- É reportado o primeiro registro da associação de A. fraterculus com Manilkara zapota (sapoti) no Brasil. 


\section{REFERÊNCIAS BIBLIOGRÁFICAS}

AGUIAR-MENEZES, E.L.; MENEZES, E.B. Flutuação populacional das moscas-dasfrutas e sua relação com a disponibilidade hospedeira em Itaguaí, RJ. Anais da Sociedade Entomológica do Brasil, v.25, n.2, p.223-232, 1996.

AGUIAR-MENEZES, E.L.; MENEZES, E.B. Rio de Janeiro. In: MALAVASI, A.; ZUCCHI, R.A. (Ed.) Moscas-das-frutas de importância econômica no Brasil: conhecimento básico e aplicado. Ribeirão Preto: Holos, 2000. cap.38, p.259-263.

ALUJA, M. Bionomics and management of Anastrepha. Annual Review of Entomology, v.39, p.155-178, 1994.

ALUJA, M.; CABRERA, M.; RIOS, E.; GUILLÉN, J.; CELEDONIO-HURTADO, H.; HENDRICHS, J.; LIEDO, P. A survey of the economically important fruit flies (Diptera: Tephritidae) present in Chiapas and a few other fruit growing regions in Mexico. Florida Entomologist, v.70, p.320-329, 1987.

ALUJA, M.; CELEDONIO-HURTADO, H.; LIEDO, P.; CABRERA, M.; CASTILLO, F.; GUILLÉN, J.; RIOS, E. Seasonal population fluctuations and ecological implications for management of Anastrepha fruit flies (Diptera: Tephritidae) in commercial mango orchards in Southern Mexico. Journal of Economic Entomology, v.89, p.654-667, 1996. 
ALVARENGA, C.D.; CANAL, N.A.; ZUCCHI, R.A. Minas Gerais. In: MALAVASI, A.; ZUCCHI, R.A. (Ed.) Moscas-das-frutas de importância econômica no Brasil: conhecimento básico e aplicado. Ribeirão Preto: Holos, 2000. cap.39, p.265-270.

ARAUJO, E.L. Estudo morfométrico no acúleo de cinco espécies de Anastrepha Schiner, 1868 (Diptera: Tephritidae) do grupo fraterculus. Piracicaba, 1997. 91p. Dissertação (Mestrado) - Escola Superior de Agricultura "Luiz de Queiroz", Universidade de São Paulo.

ARAUJO, E.L.; BATISTA, J.L.; ZUCCHI, R.A. Paraíba. In: MALAVASI, A.; ZUCCHI, R.A. (Ed.) Moscas-das-frutas de importância econômica no Brasil: conhecimento básico e aplicado. Ribeirão Preto: Holos, 2000a. cap.32, p.227-228.

ARAUJO, E.L.; LIMA, F.A.M.; ZUCCHI, R.A. Rio Grande do Norte. In: MALAVASI, A.; ZUCCHI, R.A. (Ed.) Moscas-das-frutas de importância econômica no Brasil: conhecimento básico e aplicado. Ribeirão Preto: Holos, 2000b. cap.31, p.223-226.

ARAUJO, E.L.; ZUCCHI, R.A.; CANAL D., N.A. Caracterização e ocorrência de Anastrepha zenildae Zucchi (Diptera: Tephritidae) e seus parasitóides (Hymenoptera: Braconidae) numa nova planta hospedeira, no Rio Grande do Norte. Anais da Sociedade Entomológica do Brasil, v.25, n.1, p.147-150, 1996.

ARRIGONI, E.B. Dinâmica populacional de moscas-das-frutas (Diptera - Tephritidae) em três regiões do Estado de São Paulo. Piracicaba, 1984. 165p. Tese (Doutorado) Escola Superior de Agricultura "Luiz de Queiroz", Universidade de São Paulo.

AUTUORI, M. Uma nova espécie do gênero Anastrepha Schin. (Dipt. Trypetidae). Revista de Entomologia, v.6, n.2, p.194-196, 1936. 
AZEVEDO FILHO, J.A.; SOUZA FILHO, M.F.; RAGA, A. Anastrepha fraterculus (Dip.: Tephritidae) infestation in strawberries in the State of São Paulo, Brazil. In: INTERNATIONAL CONGRESS OF ENTOMOLOGY, 21., Foz do Iguassu, 2000. Resumos. Londrina: Embrapa Soja, 2000. p.998.

BAtEman, M.A. The ecology of fruit flies. Annual Review of Entomology, v.17, p.493- 581, 1972.

BEZZI, M. Le specie dei generi Ceratitis, Anastrepha e Dacus. Bolletino de Laboratorio di Zoologia Generale e Agraria della Facoltà Agraria in Portici, v.3, p.273-313, 1909.

BEZZI, M. Una nuova specie brasiliana del genere Anastrepha (Dipt.). Bolletino de Laboratorio di Zoologia Generale e Agraria della Facoltà Agraria in Portici, v.13, p.3-14, 1919.

BLANCHARD, E.E. Especies argentinas del género Anastrepha Schiner (Diptera: Tephritidae). Revista de Investigación Agrícola, v.15, p.281-342, 1961.

CALZA, R.; SUPLICY FILHO, N.; RAGA, A.; RAMOS, M.R.K. Levantamento de Moscas-das-frutas do gênero Anastrepha em vários municípios de São Paulo. Arquivos do Instituto Biológico, v.55, n.1/4, p.55-60, 1988.

CANAL, N.A. Levantamento, flutuação populacional e análise faunística das espécies das moscas-das-frutas (Dip.: Tephritidae) em quatro municípios do norte do Estado de Minas Gerais. Piracicaba, 1997. 113p. Tese (Doutorado) - Escola Superior de Agricultura "Luiz de Queiroz", Universidade de São Paulo. 
CANAL D., N.; ALVARENGA, C.D.; ZUCCHI, R.A. Análise faunística de espécies de moscas-das-frutas (Dip., Tephritidae) em Minas Gerais. Scientia Agricola, v.55, n.1, p.15-24, 1998.

CANAL D., N.; KOVALESKI, A.; ZUCCHI, R.A. Levantamento de moscas-da: frutas (Diptera, Tephritidae) em pomares de maçã em Vacaria, RS. In: CONGRESSO BRASILEIRO DE ENTOMOLOGIA, 14., Piracicaba, 1993. Resumos. Piracicaba: SEB; FEALQ, 1993. p.24.

CARABALLO, J. Las moscas de frutas del género Anastrepha Schiner, 1868 (Diptera: Tephritidae) de Venezuela. Maracay, 1981. 210 p. Tese (Doutorado) - Universidad Central de Venezuela.

CARREJO, N.S.; GONZÁLEZ O., R. Una nueva especie de Anastrepha Schiner, 1868 (Diptera: Tephritidae) de Colombia. Boletin del Museo de Entomologia del la Universidad del Valle, v.1, p.47-53, 1993.

CELEDONIO, H.; ALUJA, M.; LIEDO, P. Adult population fluctuation Anastrepha species (Diptera: Tephritidae) in tropical orchard habitat in Chiapas, Mexico. Environmental Entomology, v.24, p.861-869, 1995.

COSTA LIMA, A. da. Moscas-das-frutas do gênero Anastrepha Schiner, 1868. Memórias do Instituto Oswaldo Cruz, v.28, n 4, p 487-575, 1934.

COSTA LIMA, A. da. Novas moscas de frutas do genero "Anastrepha" (Diptera: Trypetidae). O Campo, v.9, p.61-64, 1938. 
COSTA, G.M.M.; MACEDO, F.P.; LIMA, F.A.M.; MEDEIROS, M.A.A.; SOUZA, J.M.G.A.; MAIA, S.C.A.; MALAVASI, A. Ocorrência da "mosca-da-fruta" Ceratitis capitata (Diptera, Tephritidae) em Natal-RN. In: CONGRESSO BRASILEIRO DE ENTOMOLOGIA, 14., Piracicaba, 1993. Resumos. Piracicaba: SEB; FEALQ, 1993. p.177.

COUTURIER, G.; ZUCCHI, R.A.; SARAIVA, G.; SILVA, N.M. da. New records of fruit flies of the genus Anastrepha (Diptera: Tephritidae) and their host plants, in the Amazon region. Annales de la Société Entomologique de France, v.29, n.2, p.223-224, 1993.

CUCULIZA T.M.; TORRES, V.E. "Moscas de la fruta" en las principales plantas hospederas del valle de Huanuco. Revista Peruana de Entomologia, v.18, n.1, p.76-79, 1975.

DREW, R.A.I. The tropical fruit flies (Diptera: Tephritidae: Dacinae) of the Australasian and Ocean regions. Memoirs of the Queensland Museum, v.26, p.1-521, 1989.

ESCOLA SUPERIOR DE AGRICULTURA LUIZ DE QUEIROZ. DEPARTAMENTO DE CIÊNCIAS EXATAS. Base de dados do posto agrometeorológico. http: / / ce.esalq.usp.br/dce/posto.htm. (15 maio 2001.)

ESKAFI, F.M.; CUNNINGHAM, R.T. Host plant of fruit flies (Diptera: Tephritidae) of economic importance in Guatemala. Florida Entomologist, v.70, n.1, p.116-123, 1987.

FEHN, L.M. Coleta e reconhecimento de moscas das frutas em região metropolitana de Curitiba e Irati, Paraná, Brasil. Anais da Sociedade Entomológica do Brasil, v.10, n.2, p.209-238, 1981. 
FEHN, L.M. Influência dos fatores meteorológicos na flutuação e dinâmica de população de Anastrepha spp. Pesquisa Agropecuária Brasileira, v.17, n.4, p.533544, 1982.

FERNANDES, O.A. Estudos bioecológicos e avaliação de danos causados por moscasdas-frutas (Diptera: Tephritidae) em Citrus sinensis Osbeck var. Pera. Ribeirão Preto, 1987. 79p. Dissertação (Mestrado) - Faculadade de Filosofia, Ciências e Letras, Universidade de São Paulo.

FERNANDES, O.A.; BUSOLI, A.C.; ZUCCHI, R.A. Dinâmica populacional de moscas das frutas do gênero Anastrepha (Diptera: Tephritidae) em pomar cítrico em Jaboticabal. In: CONGRESSO BRASILEIRO DE ENTOMOLOGIA, 9., Londrina, 1984. Resumos. Londrina: SEB, 1984. p.96.

FERNANDEZ, A.M.; RODRIGUEZ, D.; HERNANDEZ-ORTIZ, V. Notas sobre el genero Anastrepha Schiner en Cuba con descripcion de una nueva especie (Diptera: Tephritidae). Folia Entomologica Mexicana, v.99, p.29-36, 1997.

FISCHER, C.R. Nota sobre Anastrepha punctata Hend. (Dipt. Trypetidae) e uma espécie nova de Cyrtonotum (Dipt. Drosophilidae). Revista de Entomologia, v.3, n.1, p.83-92, 1933.

FONSECA, J.P. da. Relação das principais pragas observadas nos anos de 1931, 1932 e 1933, nas principais plantas de maior cultivo no Estado de São Paulo. Arquivos do Instituto Biológico, v.5, p.263-289, 1934.

GARCIA, F.R.M.; CORSEUIL, E. Flutuação populacional de Anastrepha fraterculus (Wiedemann) e Ceratitis capitata (Wiedemann) (Diptera, Tephritidae) em pomares de pessegueiro em Porto Alegre, Rio Grande do Sul. Revista Brasileira de Zoologia, v.15, n.1, p.153-158, 1998. 
GÓNZALEZ, I.M.; LEZAMA, H.J.; JIRÓN, L.F. Anastrepha fruit flies in Costa Rica: three new records. Revista de Biologia Tropical, v.36, p.334-335, 1988.

HAJI, F.N.P.; MIRANDA, I.G. Pernambuco. In: MALAVASI, A; ZUCCHI, R.A. (Ed.) Moscas-das-frutas de importância econômica no Brasil: conhecimento básico e aplicado. Ribeirão Preto: Holos, 2000. cap.33, p.229-233.

HEMPEL, A. Notas sobre as moscas das fructas. Boletim de Agricultura, v.2, n.3, p.162-167, 1901.

HEMPEL, A. O bicho dos frutos e seus parasitas. Boletim de Agricultura, v.7, n.5, p.206-214, 1906.

HERNÁNDEZ-ORTIZ, V. El genero Anastrepha Schiner en Mexico (Diptera: Tephritidae): taxonomia, distribucion y sus plantas huespedes. Xalapa: Sociedade Mexicana de Entomologia, 1992. 162 p.

HERNÁNDEZ-ORTIZ, V. Nueva especie de Anastrepha Schiner del grupo spatulata en Mexico (Diptera: Tephritidae). Folia Entomologica Mexicana, v.104, p.121-127, 1998.

HERNÁNDEZ-ORTIZ, V.; ALUJA, M. Listado de especies del género neotropical Anastrepha (Diptera: Tephritidae) con notas sobre su distribución y plantas hospederas. Folia Entomologica Mexicana, v.88, p.89-105, 1993.

INSTITUTO BRASILEIRO DE FRUTAS. Estrutura da produção brasileira. ibraf@uol.com.br. (20 maio 2001a.) 
INSTITUTO BRASILEIRO DE FRUTAS. Exportação de frutas frescas. ibraf@uol.com.br. (20 maio 2001b.)

IHERING, H. Laranjas bichadas. Revista Agrícola, v.6, n.70, p.179-181, 1901.

JIRÓN, I.F.; SOTO-MANITIU, J.; NORRBOM, A.L. A preliminary list of the fruit flies of the genus Anastrepha (Diptera: Tephritidae) in Costa Rica. Florida Entomologist, v.71, p.130-137, 1988.

KORYTKOWSKI, C.; OJEDA, D. Especies del género Anastrepha Schiner, 1868 en el noroeste peruano. Revista Peruana de Entomologia, v.11, p.32-70, 1968.

KORYTKOWSKI, C.; OJEDA, D. Distribución ecológica de especies del género Anastrepha Schiner, 1868 en el noroeste peruano. Revista Peruana de Entomologia, v.77, p.285-287, 1969.

KOVALESKI, A. Processos adaptativos na colonização da maçã (Malus domestica L.) por Anastrepha fraterculus (Wied.) (Diptera: Tephritidae) na região de Vacaria, RS. São Paulo, 1997. 122p. Tese (Doutorado) - Instituto de Biociências, Universidade de São Paulo.

KOVALESKI, A.; URAMOTO, K.; SUGAYAMA, R.L.; CANAL, N.A.; MALAVASI, A. A survey of Anastrepha Schiner (Diptera: Tephritidae) species in the apple growing area of the state of Rio Grande do Sul, Brazil. Revista Brasileira de Entomologia, v.43, n.3/4, p.229-234, 1999.

KOVALESKI, A.; SUGAYAMA, R.L.; URAMOTO, K.; MALAVASI, A. Rio Grande do Sul. In: MALAVASI, A.; ZUCCHI, R.A. (Ed.) Moscas-das-frutas de importância econômica no Brasil: conhecimento básico e aplicado. Ribeirão Preto: Holos, 2000. cap. 42, p.285-290. 
KREBS, C.J. Ecology: the experimental analysis of distribution and abundance. 2.ed. New York: Harper \& Row, 1978. 678p.

LEYVA, J.L.; REYES, T.A. New record for Anastrepha montei (Diptera: Tephritidae) from northeastern Mexico. Florida Entomologist, v.72, n.4, p.699-700, 1989.

LORENZI, H. Árvores brasileiras: manual de identificação e cultivo de plantas arbóreas nativas do Brasil. Nova Odessa: Plantarum, 1992. 367p.

LUDWIG, J.A.; REYNOLDS, J.F. Statistical ecology: a primer on methods and computing. New York: John Wiley, 1988. 337p.

MALAVASI, A. Áreas-livres ou de baixa prevalência. In: MALAVASI, A.; ZUCCHI, R.A. (Ed.) Moscas-das-frutas de importância econômica no Brasil: conhecimento básico e aplicado. Ribeirão Preto: Holos, 2000. cap.23, p.175-181.

MALAVASI, A.; MORGANTE, J.S. Biologia de "moscas-das-frutas" (Diptera: Tephritidae). II. Índices de infestação em diferentes hospedeiros e localidades. Revista Brasileira de Biologia, v.40, n.1, p.17-24, 1980.

MALAVASI, A.; MORGANTE, J.S. Adult and larval population flutuaction of Anastrepha fraterculus and its relationship to host availability. Environmental Entomology, v.10, p.275-278, 1981.

MALAVASI, A.; MORGANTE, J.S.; ZUCCHI, R.A. Biologia de "moscas-das-frutas" (Diptera: Tephritidae). I. Lista de hospedeiros e ocorrência. Revista Brasileira de Biologia, v.40, n.1, p.9-16, 1980. 
MALAVASI, A.; ZUCCHI, R.A.; SUGAYAMA, R.L. Biogeografia. In: MALAVASI, A.; ZUCCHI, R.A. (Ed.) Moscas-das-frutas de importância econômica no Brasil: conhecimento básico e aplicado. Ribeirão Preto: Holos, 2000. cap. 10, p. 93-98.

MALO, E.; BAKER, P.S.; VALENZUELA, J. The abundance of species of Anastrepha (Diptera: Tephritidae) in the coffee producing area of coastal Chiapas, Southern Mexico. Folia Entomologica Mexicana, v.73, p.125-140, 1987.

MARTINS, D.S.; URAMOTO, K.; MALAVASI, A. Occurrence and distribution of fruit flies in three papaya commercial orchards in the state of Espirito Santo, Brazil. MEETING OF THE WORKING GROUP ON FRUIT FLIES OF THE WESTERN HEMISPHERE, 2., Viña del Mar, 1996. Viña del Mar: Working Group on Fruit Flies of the Western Hemisphere, 1996. p.31.

MARTINS, D.S.; URAMOTO, K.; MALAVASI, A. Espírito Santo. In: MALAVASI, A.; ZUCCHI, R.A. (Ed.) Moscas-das-frutas de importância econômica no Brasil: conhecimento básico e aplicado. Ribeirão Preto: Holos, 2000. cap. 37, p.253-258.

McALPINE, J.F. Phylogeny and classification of the Muscomorpha. In: McALPINE, J.F. (Ed.) Manual of neartic diptera. Ottawa: Biosystema Research Centre, 1989. p.1397-1518.

MENEZES, R.V.S. de; NUNES, E.M.; BRANCO, R.S.C.; ZUCCHI, R.A. Piauí. In: MALAVASI, A.; ZUCCHI, R.A. (Ed.) Moscas-das-frutas de importância econômica no Brasil: conhecimento básico e aplicado. Ribeirão Preto: Holos, 2000. cap. 29, p.213-215. 
MIRANDA-SALCEDO, M.A.; LEYVA, J.L. New records of Anastrepha sagittata and A. montei (Diptera: Tephritidae) from western Mexico. Florida Entomologist, v.79, n.2, p.264-265, 1996.

MORGANTE, J.S.; MALAVASI, A.; L. BUSH. Biochemical systematics and evolutionary relationships of Neotropical Anastrepha. Annals of the Entomological Society of America, v.73, p.622-630, 1980.

NASCIMENTO, A.S.; CARVALHO, R.S. Bahia. In: MALAVASI, A.; ZUCCHI, R.A. (Ed.) Moscas-das-frutas de importância econômica no Brasi: conhecimento básico e aplicado. Ribeirão Preto: Holos, 2000. cap. 34, p.235-239.

NASCIMENTO, A.S.; ZUCCHI, R.A. Dinâmica populacional das moscas-das-frutas do gênero Anastrepha (Dip., Tephritidae) no recôncavo baiano. I. Levantamento das espécies. Revista Agropecuária Brasileira, v.16, n.6, p.763-767, 1981.

NASCIMENTO, A.S.; ZUCCHI, R.A.; SILVEIRA NETO, S. Dinâmica populacional de moscas-das-frutas do gênero Anastrepha (Dip., Tephritidae) no Recôncavo Baiano. III. Análise Faunística. Pesquisa Agropecuária Brasileira, v.18, n.4, p.319-328, 1983.

NASCIMENTO, A.S.; MORGANTE, J.S.; MALAVASI, A.; URAMOTO, K. Occurrence and distribution of Anastrepha in melon production areas in Brazil. In: ALUJA, M.; LIEDO, P. (Ed.) Fruit flies - biology and management. New York: Springer-Verlag, 1993. p.39-42.

NASCIMENTO, A.S.; ZUCCHI, R.A.; MORGANTE, J.S. ; MALAVASI, A. Dinâmica populacional de moscas-das-frutas do gênero Anastrepha (Dip., Tephritidae) no Recôncavo Baiano. II. Flutuação populacional. Pesquisa Agropecuária Brasileira, v.17, n.7, p.969-980, 1982. 
NORA, I.; HICKEL, E.R.; PRANDO, H.F. Santa Catarina. In: MALAVASI, A.; ZUCCHI, R.A. (Ed.) Moscas-das-frutas de importância econômica no Brasil: conhecimento básico e aplicado. Ribeirão Preto: Holos, 2000. cap. 40, p.271-275.

NORRBOM, A.L. Phylogenetic analysis and taxonomy of the cryptostrepha, daciformis, robusta and schausi species groups of Anastrepha Schiner (Diptera: Tephritidae). Pennsylvania, 1985. 355p. Thesis (Ph. D.) - Pennsylvania State University.

NORRBOM, A.L. The species of Anastrepha (Diptera: Tephritidae) with a grandis type wing pattern. Proceedings of the Entomological Society of Washington, v.93, n. , p.101-124, 1991.

NORRBOM, A.L. Two new species of Anastrepha (Diptera: Tephritidae) with atypical wing patterns. Proceedings of the Entomological Society of Washington, v.95, n.1, p.52-58, 1993.

NORRBOM, A.L. Revision of the Anastrepha benjamini species group and the ${ }^{a}$ pallidipennis complex (Diptera: Tephritidae). Insecta Mundi, v.11, p.141-157, 1997.

NORRBOM, A.L. A revision of the Anastrepha daciformis species group (Diptera: Tephritidae). Proceedings of the Entomological Society of Washington, v.100, n.1, p.160-192, 1998.

NORRBOM, A.L. Fruit fly (Diptera: Tephritidae) classification and diversity. http://www.sel.barc.usda.gov/diptera/tephriti/Tephclas.htm. (27 junho 2001a.) 
N O R R B O M, A. L. Te phritida e class ification table http://www.sel.barc.usda.gov/diptera/tephriti/Tephclas.htm. (27 junho 2001b.)

NORRBOM, A.L.; KIM, K.C. Revision of the schausi group of Anastrepha Schiner (Diptera: Tephritidae), with a discussion of the terminology of the female terminalia in the Tephritoidea. Annals of the Entomological Society of America, v.81, n.2, p.164-173, 1988a.

NORRBOM. A.L.; KIM, K.C. A list of the recorded host plants of the species of Anastrepha (Diptera: Tephritidae). Washington: USDA; APHIS, 1988b. 114p.

NORRBOM, A.L.; CARROLL, L.E.; FREIDBERG, A. Status of knowledge. In: THOMPSON, F.C. (Ed.) Fruit fly expert identification system and systematic information database. Leiden: North American Dipterists' Society/Backhuys, 1998. p.9-47.

NORRBOM, A.L.; ZUCCHI, R.A.; HERNÁNDEZ-ORTIZ, V. Phylogeny of the genera Anastrepha and Toxotrypana (Trypetinae: Toxotripanini) based on morphology. In: NORRBOM, A.L.; ALUJA, M. (Ed.) Fruit flies (Tephritidae): phylogeny and evolution of behavior. Boca Raton: CRC Press, 1999. cap. 12, p.299-342.

NGUYEN, R.; POUCHER, C.; BRAZZEL, J.R. Seasonal occurrence of Anastrepha suspensa (Diptera: Tephritidae) in Indian River County, Florida. Journal of Economic Entomology, v.85, p.813-820, 1992.

NUÑEZ-BUENO, L. Contribucion a1 reconocimiento de las moscas de las frutas (Diptera: Tephritidae) en Colombia. Revista ICA, v.16, n.4, p.173-179, 1981.

NUÑEZ-BUENO, L. Las moscas de las frutas (Diptera: Tephritidae). Revista ICA, v.29, p.121-134, 1994. 
O'DOHERTY, R.; LINK, J.E. Fruit flies in Belize, Central America. In: ALUJA, M.; LIEDO, P. (Ed.) Fruit flies - biology and management. New York: SpringerVerlag, 1993. p.35-37.

OHASHI, O.S.; DOHARA, R.; ZUCCHI, R.A.; CANAL, N.A. Ocorrência de Anastrepha obliqua (Macquart) (Diptera: Tephritidae) em acerola Malpighia punicifolia L. no Estado do Pará. Anais da Sociedade Entomológica do Brasil, v.26, n.2, p.389-390, 1997.

OLIVEIRA, F.L.; ARAUJO, E.L.; CHAGAS, E.F.; ZUCCHI, R.A. Maranhão. In: MALAVASI, A.; ZUCCHI, R.A. (Ed.) Moscas-das-frutas de importância econômica no Brasil: conhecimento básico e aplicado. Ribeirão Preto: Holos, 2000. cap. 28, p.211-212.

PAPADOPOULOS, N.T.; KATSOYANNOS, B.I.; CAREY, J.R.; KOULOUSSIS, N.A. Seasonal and annual occurrence of the mediterranean fruit fly (Diptera: Tephritidae) in northern Greece. Annals of the Entomological Society of America, v.94, n.1, p.41-50, 2001.

PARRA, J.R.P.; ZUCCHI, R.A.; SILVEIRA NETO, S. Flutuação populacional e atividade diária de vôo da mosca-do-mediterrâneo em cafeeiros 'Mundo Novo'. Pesquisa Agropecuária Brasileira, v.17, n.7, p.985-992, 1982.

PUZZI, D.; ORLANDO, A. Estudos sobre a ecologia das "moscas das frutas" (Trypetidae) no Estado de São Paulo, visando o controle racional da praga. Arquivos do Instituto Biológico, v.32, n.1, p.7-20, 1965.

RAGA, A.; SOUZA FILHO, M.F. de; ARTHUR, V.; MARTINS, A.L.M. Avaliação da infestação de moscas-das-frutas em variedades de café (Coffea spp). Arquivos do Instituto Biológico, v. 63, n.2, p.59-63, 1996 a. 
RAGA, A.; SOUZA FILHO, M.F. de; SATO, M.E. CERÁVOLO, L.C. Dinâmica populacional de adultos de moscas-das-frutas (Diptera: Tephritidae) em pomar de citros de Presidente Prudente, SP. Arquivos do Instituto Biológico, v.63, n.2, p.2328, $1996 b$.

RAGA, A.; SOUZA FILHO, M.F. de; ARTHUR, V.; SATO, M.E.; MACHADO, L.A.; BATISTA FILHO, A. Observações sobre a incidência de moscas-das-frutas (Diptera: Tephritidae) em frutos de laranja (Citrus sinensis). Arquivos do Instituto Biológico, v. 64, n.2, p.125-129, 1997.

RODRIGUES, R.R. (Coord.). Trilhas do parque da Esalq: árvores frutíferas. Piracicaba: Escola Superior de Agricultura "Luiz de Queiroz", Departamento de Botânica, 1996. 28p.

RODRIGUEZ G., G.; DELVALLE MARK, P.; SILVA-ACUÑA, R. Fluctuación poblacional y aplicación del análisis de sendero a la época del incremento de Anastrepha striata Schiner (Diptera: Tephritidae) afectando a Psidium guajava L. en el estado Monagas, Venezuela. Boletin de Entomologia Venezolana, v.14, n.1, p.63-76, 1999.

RONCHI-TELES, B. Ocorrência e flutuação populacional de espécies de moscas-dasfrutas e parasitóides com ênfase para o gênero Anastrepha (Diptera: Tephritidae) na Amazônia brasileira. Manaus, 2000. 156p. Tese (Doutorado) - Instituto Nacional de Pesquisas da Amazônia, Fundação Universidade do Amazonas.

RONCHI-TELES, B.; SILVA, N.M. Primeiro registro de ocorrência da mosca-domediterrâneo, Ceratitis capitata (Wied. 1824) (Diptera: Tephritidae), na Amazônia Brasileira. Anais da Sociedade Entomológica do Brasil, v.25, n.3, p.569-570, 1996. 
RONCHI-TELES, B.; ZUCCHI, R.A.; SILVA, N.M. Novos registros de espécies de Anastrepha (Dip.; Tephritidae) e seus hospedeiros no Estado de Roraima. In: CONGRESSO BRASILEIRO DE ENTOMOLOGIA, 15., Caxambu, 1995. Resumos. Caxambu: SEB, 1995. p.239.

ROSSI, M.M.; MATIOLI, J.C.; BUENO, V .H.P .Principais espécies de moscas-dasfrutas (Diptera: Tephritidae) e sua dinâmica populacional em pessegueiros na região de Caldas, sul de Minas Gerais. Revista de Agricultura, v.63, n.3, p.329-342, 1988.

SALES, F.J.M. de; GONÇALVES, N.G.G. Ceará. In: MALAVASI, A.; ZUCCHI, R.A. (Ed.) Moscas-das-frutas de importância econômica no Brasil: conhecimento básico e aplicado. Ribeirão Preto: Holos, 2000. cap. 30, p.217-222.

SAUERS-MULLER, A. van. An overview of the carambola fruit fly Bactrocera species (Diptera: Tephritidae), found recently in Suriname. Florida Entomologist, v.74, n.3, p 432-440, 1991.

SENTELHAS, P.C. Tipo de clima em Piracicaba. pcsentel@ carpa.ciagri.usp.br (5 setembro 2001.)

SELIVON, D. Estudo sobre a diferenciação populacional em Anastrepha fraterculus (Wiedemann) (Diptera: Tephritidae). São Paulo, 1996. 137p. Tese (Doutorado) Instituto de Biociências, Universidade de São Paulo.

SILVA, J.G. Estudos Moleculares. In: MALAVASI, A.; ZUCCHI, R.A. (Ed.) Moscasdas-frutas de importância econômica no Brasil: conhecimento básico e aplicado. Ribeirão Preto: Holos, 2000. cap. 3, p.29-39. 
SILVA, J.G.; URAMOTO, K.; MALAVASI, A. First report of Ceratitis capitata (Diptera: Tephritidae) in the eastern Amazon, Pará, Brazil. Florida Entomologist, v.81, n.4, p.574-577, 1998.

SILVA, N.M. da. Levantamento e análise faunística de moscas-das-frutas (Diptera: Tephritidae) em quatro locais da Estado do Amazonas. Piracicaba, 1993. 152p. Tese (Doutorado) - Escola Superior de Agricultura "Luiz de Queiroz", Universidade de São Paulo.

SILVA, N.M. da; RONCHI-TELES; B. Amapá, Amazonas, Pará, Rondônia e Roraima. In: MALAVASI, A.; ZUCCHI, R.A. (Ed.) Moscas-das-frutas de importância econômica no Brasil: conhecimento básico e aplicado. Ribeirão Preto: Holos, 2000. cap.27, p.203-209.

SILVA, N.M. da; SILVEIRA NETO, S.; ZUCCHI, R.A. The natural host plants of Anastrepha in the State of Amazonas, Brazil. In: McPHERON, B.A.; STECK, G.J. (Ed.). Fruit fly pests: a world assessment of their biology and management. Delray Beach: St. Lucie Press, 1996. p.353-357.

SILVEIRA NETO, S.; NAKANO, O.; BARBIN, D.; VILA NOVA, N.A. Manual de ecologia dos insetos. São Paulo: Agronômica Ceres, 1976. 420p.

SOTO-MANITIU, J.; JIRÓN, L.F. Studies on the population dynamics of the fruit flies, Anastrepha (Diptera: Tephritidae), associated with mango (Mangifera indica L.) in Costa Rica. Tropical Pest Management, v.35, p.425-427, 1989.

SOUZA FILHO, M.F. de. Biodiversidade de moscas-das-frutas (Diptera: Tephritidae) e seus parasitóides (Hymenoptera) em plantas hospedeiras no Estado de São Paulo. Piracicaba, 1999. 173 p. Dissertação (Mestrado) - Escola Superior de Agricultura "Luiz de Queiroz", Universidade de São Paulo. 
SOUZA FILHO, M.F. de; RAGA, A.; ZUCCHI, R.A. São Paulo. In: MALAVASI, A.; ZUCCHI, R.A. (Ed.) Moscas-das-frutas de importância econômica no Brasil: conhecimento básico e aplicado. Ribeirão Preto: Holos, 2000. cap. 41, p.277-283.

STECK, G.J. Biochemical systematics and population genetic structure of Anastrepha fraterculus and related species (Diptera: Tephritidae). Annals of the Entomological Society of America, v.84, p.10-29, 1991.

STECK, G.J. Taxonomic status of Anastrepha fraterculus. In: WORKSHOP ON THE SOUTH AMERICAN FRUIT FLY ANASTREPHA FRATERCULUS (WIED.): ADVANCES IN ARTIFICIAL REARING, TAXONOMIC STATUS AND BIOLOGICAL STUDIES; Viña del Mar, 1996. Proceedings. Viena: FAO;IAEA, 1998. p.13-20.

STEYSKAL, G. Pictorial key to species of the genus Anastrepha (Dip., Tephritidae). Washington: Entomological Society of Washington, 1977, 35p.

STONE, A. A revision of the genus Pseudodacus Hendel (Dip., Trypetidae). Revista de Entomologia, v.10, p.282-289, 1939.

STONE, A. The fruit flies of the genus Anastrepha. Washington: USDA, 1942. 112p. (USDA. Micellaneous Publication, 439).

TAN, K.H.; SERIT, M. Adult population dynamics of Bactrocera dorsalis (Diptera: Tephritidae) in relation to host phenology and weather in two villages of Penang Island, Malaysia. Environmental Entomology, v.23, p.267-275, 1994.

TAVARES, J.S. Anastrepha serpentina Wied., nova praga dos frutos no Brasil. Brotéria, v.13, n.1, p.52-54, 1915. 
THOMPSON, F.C. Introduction. In: THOMPSON, F.C. (Ed.) Fruit fly expert identification system and systematic information database. Leiden: North American Dipterists' Society;Backhuys, 1998. p.5-6.

UCHÔA F., M.A. Biodiversidade de moscas frugívoras (Diptera, Tephritoidea), seus frutos hospedeiros e parasitóides (Hymenoptera) em áreas de cerrado do Estado de Mato Grosso do Sul. Piracicaba, 1999. 104p. Tese (Doutorado) - Escola Superior de Agricultura "Luiz de Queiroz", Universidade de São Paulo.

UCHÔA F., M.A.; ZUCCHI, R.A. Mato Grosso e Mato Grosso do Sul. In: MALAVASI, A.; ZUCCHI, R.A. (Ed.) Moscas-das-frutas de importância econômica no Brasil: conhecimento básico e aplicado. Ribeirão Preto: Holos, 2000. cap. 35, p.241-245.

VARGAS, R.I.; HARRIS, E.J.; NISHIDA, T. Distribution and seasonal occurrence of Ceratitis capitata (Wiedemann) (Diptera: Tephritidae) on the island of Kauai in the Hawaiian Island. Environmental Entomology, v.12, p.303-310, 1983.

VARGAS, R.I.; STARK, J.D.; NISHIDA, T. Population dynamics, habitat preference, and seasonal distribution patterns of Oriental fruit fly and melon fly (Diptera: Tephritidae) in an agricultural area. Environmental Entomology, v.19, p.1820$1828,1990$.

VELOSO, V.R.S. Dinâmica populacional de Anastrepha spp. e Ceratitis capitata (Wied., 1824) (Diptera: Tephritidae) nos cerrados de Goiás, Goiânia, GO. Goiânia, 1997. 115p. Tese (Doutorado) - Escola de Agronomia, Universidade Federal de Goiás. 
VELOSO, V.R.S.; FERNANDES, P.M.; ZUCCHI, R.A. Goiás. In: MALAVASI, A.; ZUCCHI, R.A. (Ed.) Moscas-das-frutas de importância econômica no Brasil: conhecimento básico e aplicado. Ribeirão Preto: Holos, 2000. cap. 36, p.247-252.

WALDER, J.M.M. Técnica do macho estéril - Controle genético. In: MALAVASI, A.; ZUCCHI, R.A. (Ed.) Moscas-das-frutas de importância econômica no Brasil: conhecimento básico e aplicado. Ribeirão Preto: Holos, 2000. cap. 19, p.151-158.

YEPES R., F.C. Nuevos registros de especies de moscas de las frutas en Colombia. Revista de la Facultad Nacional de Agronomia de Medellin, v.52, n.1, p.549$562,1999$.

ZAHLER, P.M. Moscas-das-frutas em três pomares do Distrito Federal: levantamento de espécies e flutuação populacional. Ciência e Cultura, v.42, n.2, p.177-182, 1990.

ZAHLER, P.M. Moscas-das-frutas (Diptera, Tephritidae) em dois pomares de manga (Mangifera indica) do Distrito Federal: levantamento de espécies e flutuação populacional. Revista Ceres, v.38, n.217, p.206-216, 1991.

ZUCCHI, R.A. Taxonomia das espécies de Anastrepha Schiner, 1868 (Dip. Tephritidae) assinaladas no Brasil. Piracicaba, 1978. 105p. Tese (Doutorado) - Escola Superior de Agricultura "Luiz de Queiroz", Universidade de São Paulo.

ZUCCHI, R.A. Moscas-das-frutas (Dip., Tephritidae) no Brasil: taxonomia, distribuição geográfica e hospedeiros. In: ENCONTRO SOBRE MOSCAS-DAS-FRUTAS, 1., Campinas, 1987. Anais. Campinas: Fundação Cargill, 1988. p.1-10. 
ZUCCHI, R.A. Redescoberta de Anastrepha fumipennis Lima, 1937 e constatação de A. pallidipennis Greene, 1934 (Dipt., Tephritidae) no Brasil. In: CONGRESSO BRASILEIRO DE ENTOMOLOGIA, 12., Belo Horizonte, 1989. Resumos. Belo Horizonte: SEB, 1989. p.509.

ZUCCHI, R.A. Taxonomia. In: MALAVASI, A.; ZUCCHI, R.A. (Ed.) Moscas-dasfrutas de importância econômica no Brasil: conhecimento básico e aplicado. Ribeirão Preto: Holos, 2000a. cap. 1, p. 13-24.

ZUCCHI, R.A. Espécies de Anastrepha, sinonímias, plantas hospedeiras e parasitóides. In: MALAVASI, A.; ZUCCHI, R.A. (Ed.) Moscas-das-frutas de importância econômica no Brasil: conhecimento básico e aplicado. Ribeirão Preto: Holos, 2000b. cap. 4, p.41-48.

ZUCCHI, R.A. Mosca-do-mediterrâneo, Ceratitis capitata (Diptera: Tephritidae). In: VILELA, E.F.; ZUCCHI, R.A.; CANTOR F. (Ed.) Histórico e impacto das pragas introduzidas no Brasil. Ribeirão Preto, Holos, 2001. cap.1, p.15-22.

ZUCCHI, R.A.; SILVA, N.M. da; SILVEIRA NETO, S. Anastrepha species from the Brazilian Amazon: distribution, hosts, and lectotype designations. In: McPHHERON, B.A.; STECK, G.J. (Ed.). Fruit fly pests: a world assessment of their biology and management. Delray Beach: St. Lucie Press, 1996. p.259-263.

ZUCCHI, R.A.; CANAL D., N.A.; PADUA, L.E.M.; SILVA, P.H.S. Primeiro registro de Anastrepha spp. (Dip., Tephritidae), seus hospedeiros e parasitóides (Hym., Braconidae) no Estado do Piauí. In: CONGRESSO BRASILEIRO DE ENTOMOLOGIA, 15., Caxambu, 1995. Resumos. Caxambu: SEB, 1995. p.231. 